ROSEMEIRE CARDOZO VIDAL

Algoritmo para estimar gravidade de DPOC através de sinais acústicos 
ROSEMEIRE CARDOZO VIDAL

Algoritmo para estimar gravidade de DPOC através de sinais acústicos

Dissertação de mestrado apresentada à Escola Politécnica da Universidade de São Paulo para obtenção do título de Mestre em Ciências

São Paulo 
ROSEMEIRE CARDOZO VIDAL

\section{Algoritmo para estimar gravidade de DPOC através de sinais acústicos}

Dissertação de mestrado apresentada à Escola Politécnica da Universidade de São Paulo para obtenção do título de Mestre em Ciências

Área de concentração: Engenharia Mecânica Automação e Controle

Orientador: Prof. Dr. Raul Gonzalez Lima

São Paulo 
Este exemplar foi revisado e corrigido em relação à versão original, sob responsabilidade única do autor e com a anuência de seu orientador.

São Paulo, de de

Assinatura do autor:

Assinatura do orientador:

Catalogação-na-publicação

Vidal, Rosemeire Cardozo

Algoritmo para estimar gravidade de DPOC através de sinais acústicos

/ R. C. Vidal -- versão corr. -- São Paulo, 2017.

$60 \mathrm{p}$.

Dissertação (Mestrado) - Escola Politécnica da Universidade de São Paulo. Departamento de Engenharia Mecânica.

1.Transformada da Fourier de Tempo Curto 2.Espectrograma 3.Variância 4.Intensidade Sonora I.Universidade de São Paulo. Escola Politécnica.

Departamento de Engenharia Mecânica II.t. 
DEDICATÓRIA

Dedico este trabalho a Deus, à minha mãe Maria e minha mãe Helena, aos meus irmãos, ao meu filho Hugo e meu esposo Antonio. 


\section{AGRADECIMENTOS}

Ao professor Dr. Raul Gonzalez Lima, meu orientador, um exemplo de ser humano, professor e cientista, a quem serei eternamente grata pela dedicação, paciência, apoio, incentivo e confiança.

Agradeço à minha amiga, bibliotecária da Elétrica Profa Dra Ana Maria de Castro Badiali, que esteve comigo desde o ingresso na pós-graduação, pelo carinho e pelo exemplo de força.

Agradeço ao meu amigo Prof. Msc. José Alejandro Amaya Palácio, que esteve comigo em muitos momentos me ensinado, aconselhando e me mostrando que podemos vencer com alegria e determinação.

As minhas queridas amigas Profa. Me. Eliana Gregório Rodrigues e Profa Me. Eveline Cavalcante, pela ajuda e pelas palavras de incentivo e carinho.

Minha gratidão ao médico pneumologista Dr. Virgílio Alexandre Nunes de Aguiar pelo apoio e dedicação, e aos médicos do ambulatório do Hospital Estadual Guilherme Álvaro Dra Beatriz, Dra Fabiola e Dr. Jose Eduardo.

Aos meus colegas da "BatCaverna" com especial agradecimento à Thales, Mikiu, André, Luiz e Ana Isabel, pela paciência e pelas muitas vezes que dividiram comigo seus conhecimentos. 
"Tudo posso naquele que me fortalece" (Filipenses 4.13) 


\section{RESUMO}

O presente estudo tem como objetivo determinar se a gravidade da DPOC poderá ser estimada através da área do gráfico das intensidades sonoras dos sons respiratórios de pacientes com DPOC. O estudo realizado com 51 pacientes com DPOC leve, moderado, grave, muito grave e 7 indivíduos saudáveis não fumantes. Os sons respiratórios de cada participante, foram coletados através de estetoscópio adaptado com um mini microfone. O método compara as áreas das intensidades sonoras em função da frequência de pacientes de DPOC e indivíduos saudáveis. Neste contexto, para atender ao objetivo, um método foi proposto e testado baseado na combinação de técnicas de filtragem e TFTC, seguida de análise estatística, cálculo da média, desvio padrão e interpolação. Os resultados sugerem que a área do gráfico da variância da intensidade sonora em função da frequência diminui quando aumenta a gravidade da DPOC, exceto para os casos em que a bronquite crônica é predominante.

Palavras-chave: Doença Pulmonar Obstrutiva Crônica. Espectrograma. Variância. Intensidade sonora. Sons respiratórios. Transformada de Fourier. 


\begin{abstract}
The present study aims to determine if the severity of COPD can be estimated through the chart area of the sound intensities of respiratory sounds in patients with COPD. The study included 51 patients with mild, moderate, severe, very severe COPD and 7 healthy non-smokers. The breathing sounds of each participant were collected through a stethoscope adapted with a mini microphone. The method compares the areas of intensity sonic densities as a function of the frequency of COPD patients and healthy individuals. In this context, to meet the objective, a method was proposed and tested based on the combination of filtering techniques and TFTC, followed by statistical analysis, calculation of the mean, standard deviation and interpolation. The results suggest that the area of the graph of frequency-frequency sound intensity variance decreases as the severity of COPD increases, except for cases where chronic bronchitis is predominant.
\end{abstract}

Keywords: Chronic Obstructive Pulmonary Disease. Spectrogram. Variance. Sound intensity. Respiratory sounds. Fourier transform. 


\section{LISTA DE FIGURAS}

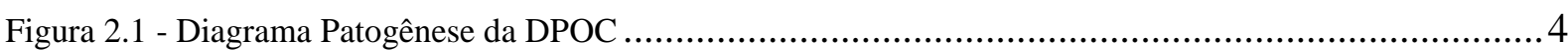

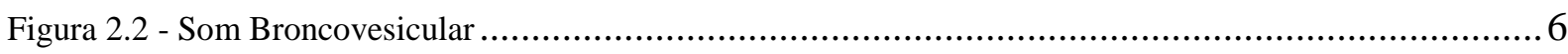

Figura 2.3 - Som Respiratório Anormal- Sibilos ............................................................................

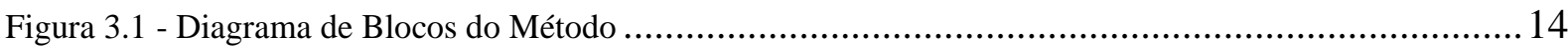

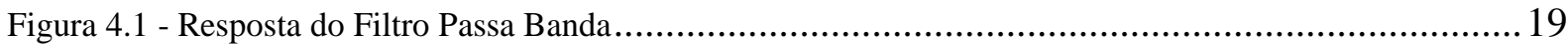

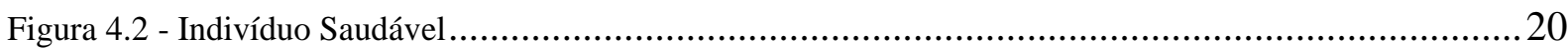

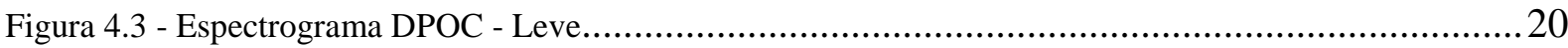

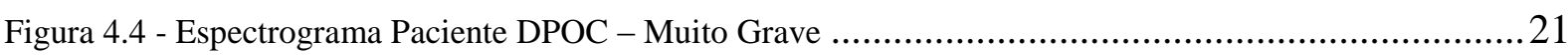

Figura 4.5 - Espectrograma Paciente DPOC - Grave ……............................................................. 21

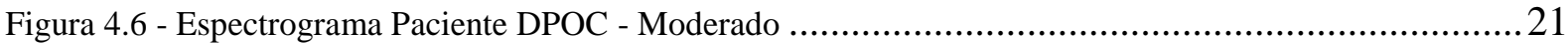

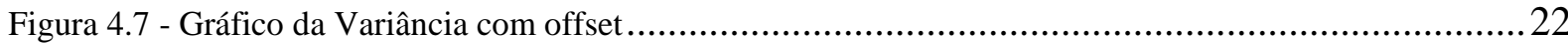

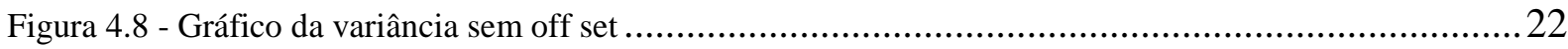

Figura 4.9 - Gráfico1 Áreas Indivíduos Saudáveis e Gravidade DPOC ...................................................26

Figura 4.10 - Gráfico2 Áreas Indivíduos Saudáveis e Gravidade DPOC ............................................... 26

Figura 4.11 - Gráfico3 Áreas Indivíduos Saudáveis e Gravidade DPOC ….............................................2

Figura 5.1 - Comparativo Saudável X DPOC Muito Grave ….............................................................29

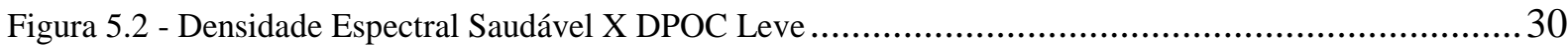

Figura 5.3 - Espectrograma DPOC Moderado com ruído …............................................................... 31

Figura 5.4 - Densidade Espectral Saudável X DPOC Moderado …...................................................... 31

Figura 5.5 - Espectrograma DPOC Leve com ruídos respiratórios ........................................................ 31

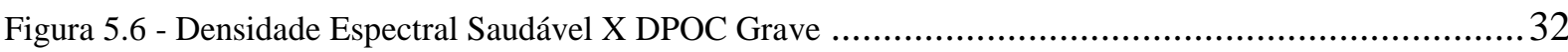

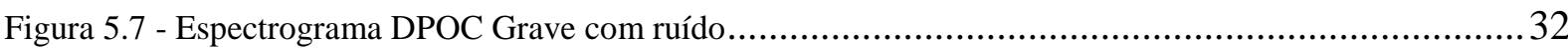

Figura 5.9 - Espectrograma Paciente DPOC Muito Grave …............................................................ 33

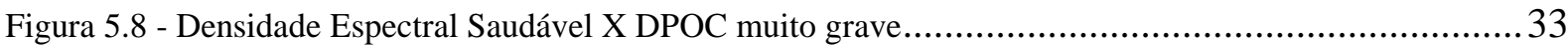




\section{LISTA DE TABELAS}

Tabela 1. Classificação da Gravidade Multidimensional: espirometria, exacerbações, hospitalização sintomas e falta de ar . .5

Tabela 2: Sons Respiratórios ..6

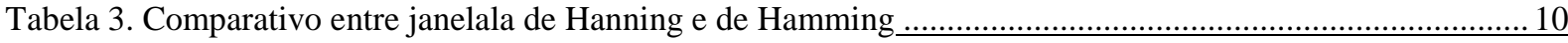

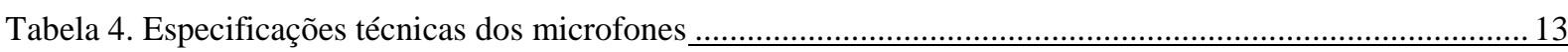

Tabela 5. Resultado Média do Desvio Padrão individuos saudáveis .................................................. 16

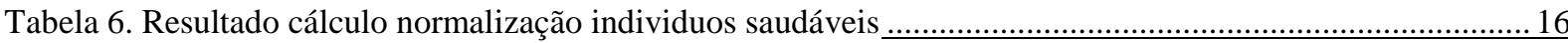

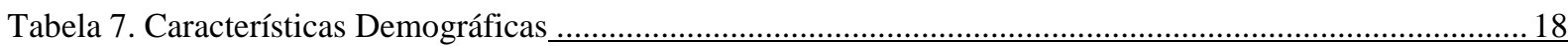

Tabela 8 - Áreas das variâncias das intensidades sonora de pacientes por grupo de gravidade _.......................23

Tabela 9 - Diferenças entre áreas de indivíduo normais e DPOC - filtro com frequência de corte $60-3 \mathrm{Kz} \ldots \ldots \ldots . . .24$

Tabela 10 - Diferenças entre áreas de indivíduo normais e DPOC - filtro com frequência de corte $60-2 \mathrm{Kz} \ldots \ldots . . .24$

Tabela 11 - Diferenças entre áreas de indivíduo normais e DPOC - filtro com frequência de corte $60-6 \mathrm{Kz} \ldots \ldots \ldots . . .25$

Tabela 12 - Percentuais de Acerto Método da Densidade Espectral ….......................................................26 


\section{SUMÁRIO}

INTRODUÇÃ

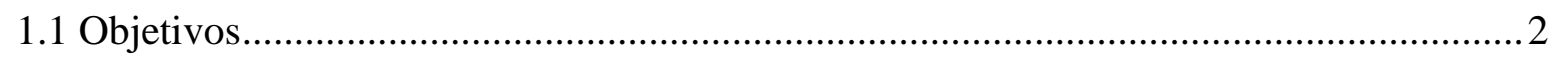

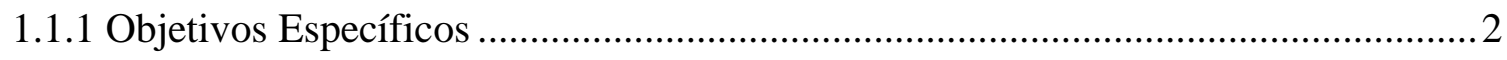

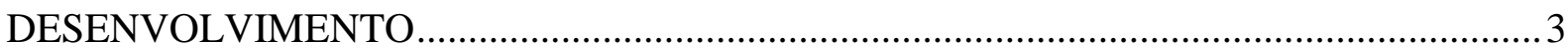

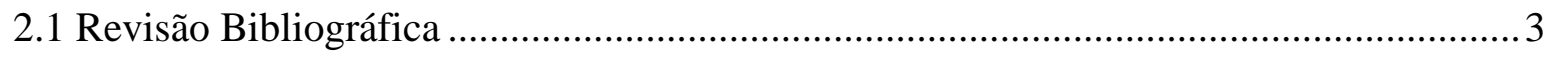

2.1.2 Doença Pulmonar Obstrutiva Crônica (DPOC).....................................................

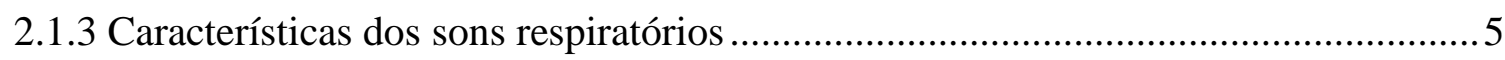

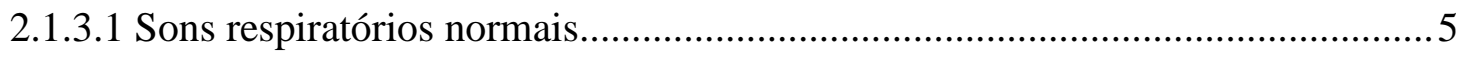

2.1.3.2 Sons Respiratórios Anormais ...................................................................

2.1.4 Ambiente e coleta dos sons respiratórios .................................................... 8

2.1.5 Aquisição e filtragem dos sons respiratórios ................................................... 8

2.1.6 Técnicas de Análise de Sons Respiratórios ........................................................

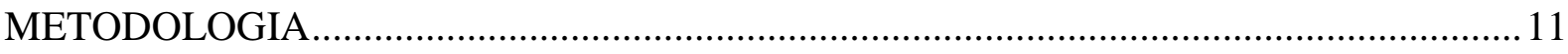

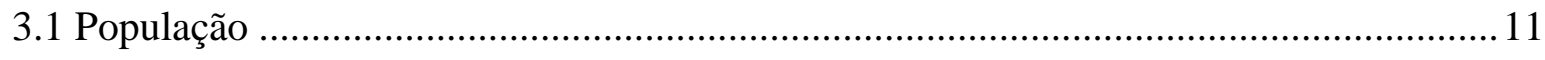

3.2 Procedimentos de coleta dos sons respiratórios .................................................... 11

3.3 Sistema para Aquisição dos Sons Respiratórios ........................................................ 12

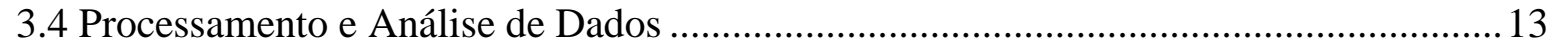

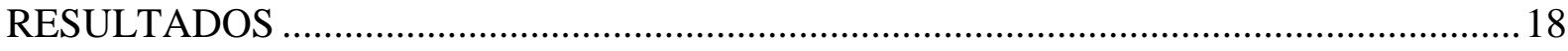

4.1 Características Demográficas da População.......................................................... 18

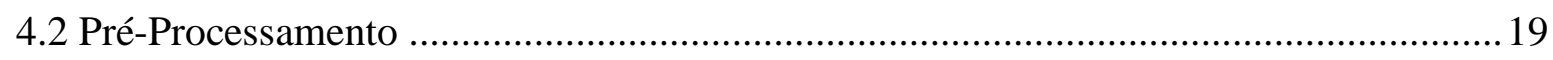

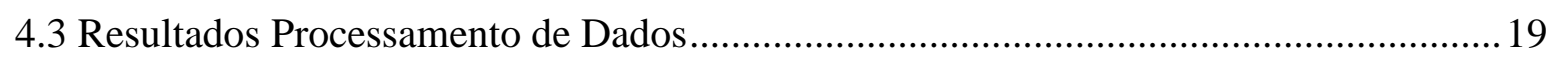

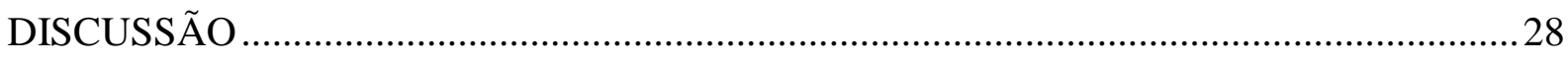

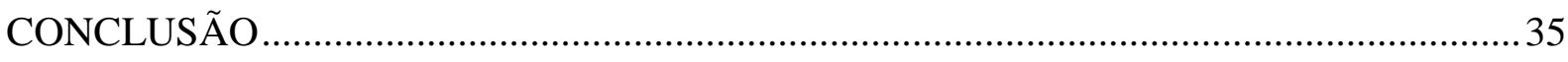

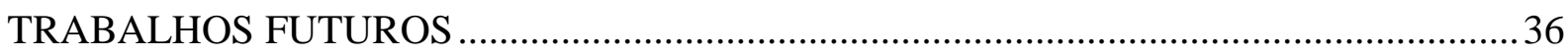

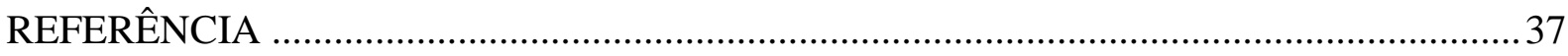

APÊNDICE A - ESPECTROGRAMAS DOS SINAIS ACÚSTICOS ..................................40 


\section{CAPÍTULO 1}

\section{INTRODUÇÃO}

A Doença Pulmonar Obstrutiva Crônica (DPOC) é uma doença frequente, prevenível e tratável, heterogênea em sua apresentação clínica e evolução, caracterizada por obstrução ao fluxo de ar, persistente e geralmente progressiva (TISIOLOGIA, 2016).

A avaliação da gravidade da DPOC é relativamente complexa, pois pode envolver a análise de muitos parâmetros, não somente as alterações espirométricas que são consideradas insuficientes para determinação da gravidade, mas também alterações fisiológicas, como das taxas de oxigênio e gás carbônico no sangue e da medida da difusão, das alterações na capacidade de exercício (como no teste da caminhada de 6 minutos), e ainda o número de exacerbações da doença no correr do tempo (GOLD, 2017).

As intensidades dos sons respiratórios estão relacionadas à passagem do fluxo de ar nas vias aéreas respiratórias. No enfisema os ruídos respiratórios se tornam diminuídos, principalmente nos graus mais avançados da doença, possivelmente pela retenção de ar nos pulmões, associadas à destruição dos tecidos alveolares (SOVIJARVI, 2000a). Os sons respiratórios também podem ser diminuídos quando a passagem de ar estiver quase que completamente comprometida, devido aumento da secreção contida nos brônquios (BOHADANA, 2014).

Estudos utilizando métodos computacionais, para avaliação e análise dos sons respiratórios, vêm sendo desenvolvidos e apresentados para identificação das características acústicas em patologias como a asma e a DPOC (JÁCOME, 2015) (JÁCOME e MARQUES, 2015) (MORILLO, JIMÉNEZ e MORENO, 2013) (MORILLO, 2013) (JÁCOME, 2015), com especial atenção a caracterização de sons respiratórios anormais (FIZ, 2002). 
O aperfeiçoamento desses métodos computacionais, de avaliação dos sons respiratórios, aliados aos métodos tradicionais de diagnóstico, poderá melhorar o processo de identificação da gravidade da DPOC.

\subsection{Objetivos}

O objetivo principal deste estudo é determinar se a gravidade da DPOC poderá ser estimada através da área do gráfico da variância das intensidades sonoras dos sons respiratórios de pacientes com DPOC, em função de suas frequências.

\subsubsection{Objetivos Específicos}

- Formar um banco de dados de sons respiratórios de pacientes com DPOC.

- Propor um critério quantitativo para estimar a gravidade da DPOC. 


\section{CAPÍTULO 2}

\section{DESENVOLVIMENTO}

\subsection{Revisão Bibliográfica}

Nesta seção apresentam-se a revisão bibliográfica dos seguintes assuntos: doença pulmonar obstrutiva crônica (DPOC), sons respiratórios normais e anormais, técnicas de aquisição, processamento e análise de sons respiratórios,

\subsubsection{Doença Pulmonar Obstrutiva Crônica (DPOC)}

A Doença Pulmonar Obstrutiva Crônica (DPOC) é uma doença frequente, prevenível e tratável, heterogênea em sua apresentação clínica e evolução, caracterizada por obstrução ao fluxo de ar, persistente e geralmente progressiva (ALAT, 2014). Atualmente, segundo a Global Initiative for Chronic Obstructive Lung Disease (GOLD), a DPOC é a quarta causa de morte mundial, com prospecção de ser a $3^{\text {a }}$ causa de morte até 2020. A Associação Latino Americana do Tórax (ALAT), publicou em 2014, o guia Latino Americano de EPOC (Enfermidades Pulmonares Obstrutivas Crônicas), baseado em evidências. O documento apresenta um levantamento epidemiológico da prevalência da DPOC na América Latina. Os resultados desta pesquisa realizada na cidade de São Paulo apontaram índice de 15,8\% de prevalência de DPOC no Brasil, perdendo apenas para o Chile (Santiago) com 15,9\% e Uruguai (Montevidéu)19,7\% (ALAT, 2014).

Os principais fatores de risco da DPOC são: tabagismo, exposição a materiais particulados devido à ocupação profissional e a combustão da biomassa. Na figura 2.1 é ilustrada a patogênese da DPOC. 
Figura 2.1 - Diagrama Patogênese da DPOC

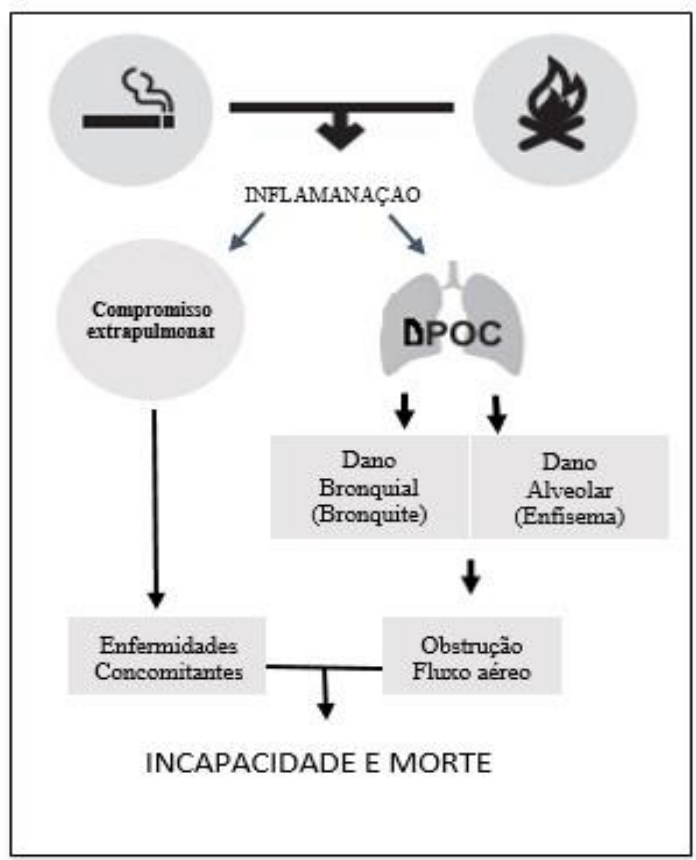

Fonte: Adaptado de (ALAT, 2014)

O diagnóstico da DPOC é inicialmente baseado nos sintomas que o paciente apresenta, como: tosse crônica, chiado no peito, expectoração e falta de ar ao esforço, que podem ser minimizados se identificados e tratados precocemente. Esses sintomas estão relacionados à bronquite crônica e ao enfisema, podendo ocorrer separadamente ou em associação (GOLD, 2016). Para confirmação do diagnóstico e determinação da gravidade da DPOC é imprescindível a realização da espirometria para confirmação da obstrução do fluxo de ar, porém, somente a análise das alterações espirométricas não são atualmente consideradas suficientes para classificar a gravidade e o prognóstico da DPOC. A variabilidade clínica e progressão da DPOC são consideradas aspectos críticos na determinação da classificação da gravidade. Para atender a essa necessidade o GOLD em seu relatório anual de práticas para diagnóstico, tratamento e prevenção da DPOC a partir de 2014 propõe uma abordagem multidimensional. Além dos resultados da espirometria, são consideradas também as alterações dos sintomas, as alterações na capacidade de exercício (como no teste da caminhada de 6 minutos), e ainda o número de exacerbações por ano. Na tabela 1 é apresentada a abordagem ABCD proposta pelo GOLD para classificação da gravidade da DPOC (GOLD, 2017). 
Tabela 1. Classificação da Gravidade Multidimensional: espirometria, exacerbações, hospitalização sintomas e falta de ar

\begin{tabular}{|c|c|c|c|c|c|}
\hline Gravidade & Espirometria & $\begin{array}{c}\mathrm{N}^{\mathrm{o}} \text { exacerbações } \\
(\text { ano })\end{array}$ & $\begin{array}{c}\mathrm{N}^{\circ} \text { de hospitalizações } \\
\text { (ano) }\end{array}$ & $\begin{array}{l}\text { Teste de Avaliação } \\
\text { da DPOC (CAT) }\end{array}$ & $\begin{array}{c}\text { Escala de Falta de ar } \\
\text { (MMRC) }\end{array}$ \\
\hline $\bar{A}$ & $\begin{array}{l}\mathrm{VEF}_{1} \geq 80 \% \\
\text { previsto }\end{array}$ & 0 ou 1 & 0 & $<10$ & $0-1$ \\
\hline$\overline{\mathbf{B}}$ & $\begin{array}{l}50 \% \leq \mathrm{VEF}_{1}< \\
80 \% \text { previsto }\end{array}$ & 0 ou 1 & 0 & $\geq 10$ & $\geq 2$ \\
\hline$\overline{\mathrm{C}}$ & $\begin{array}{l}30 \% \leq \mathrm{VEF}_{1}< \\
50 \% \text { previsto }\end{array}$ & $\geq 2$ & $\geq 1$ & $<10$ & $0-1$ \\
\hline $\bar{D}$ & $\begin{array}{l}\mathrm{VEF}_{1}<30 \% \\
\text { previsto }\end{array}$ & $\geq 2$ & $\geq 1$ & $\geq 10$ & $\geq 2$ \\
\hline
\end{tabular}

VEF1 Volume Expiratório Forçado no primeiro segundo CAT (COPD Assessment Test) mMRC (Modified Medical Research Counci)

Fonte: Adaptado de (GOLD, 2017)

\subsubsection{Características dos sons respiratórios}

O exame dos sons respiratórios é indispensável no processo de diagnóstico e tem um importante papel no monitoramento da progressão das doenças respiratórias. Os sons respiratórios são classificados como normais e anormais diferenciando se pela ausência ou a presença de ruídos sobrepostos a respiração.

\subsubsection{Sons respiratórios normais}

Sons respiratórios normais são sinais acústicos gerados nos pulmões e nas vias áreas saudáveis durante o ciclo respiratório. São caracterizados pelo baixo nível de ruído sendo mais audíveis na inspiração do que na expiração (BOHADANA, 2014). Os sons respiratórios normais são nomeados segundo o local onde são originados e suas características variam de acordo com o ciclo respiratório. A tabela 2 apresenta os tipos de sons respiratórios normais, e suas características: fase respiratória, intensidade, tonalidade e localização. Na figura 2.2 é apresentado o espectrograma de um sinal de som respiratório normal "broncovesicular", as fases inspiratórias e expiratórias são aproximadamente iguais e as frequências próximas de $500 \mathrm{~Hz}$. 
Tabela 2: Sons Respiratórios

\begin{tabular}{|c|c|c|c|c|}
\hline & Fase Respiratória & Intensidade & Tonalidade & $\begin{array}{c}\begin{array}{c}\text { Localização } \\
\text { (Ausculta) }\end{array} \\
\end{array}$ \\
\hline Vesicular & $\begin{array}{c}\text { Fase inspiratória é maior } \\
\text { que a expiratória. }\end{array}$ & Macia & $\begin{array}{l}\text { Baixas } \\
\text { frequências }\end{array}$ & $\begin{array}{c}\text { Todo campo pulmonar } \\
\text { exceto parte superior do } \\
\text { esterno e entre as } \\
\text { escápulas }\end{array}$ \\
\hline Broncovesicular & $\begin{array}{l}\text { Fases inspiratórias e } \\
\text { expiratórias são } \\
\text { aproximadamente } \\
\text { iguais. }\end{array}$ & Intermediária & $\begin{array}{l}\text { Médias } \\
\text { frequências }\end{array}$ & $\begin{array}{c}\text { Parte frontal no primeiro } \\
\text { e segundo espaços } \\
\text { intercostais e na parte } \\
\text { posterior entre as } \\
\text { escápulas }\end{array}$ \\
\hline Bronquial & $\begin{array}{c}\text { Fase expiratória é maior } \\
\text { que a inspiratória. }\end{array}$ & $\begin{array}{c}\text { Relativamente } \\
\text { alta } \\
\end{array}$ & $\begin{array}{c}\text { Altas } \\
\text { frequências }\end{array}$ & Sobre o manúbrio \\
\hline Traqueal & $\begin{array}{c}\text { Inspiratórios e } \\
\text { expiratórios são } \\
\text { aproximadamente } \\
\text { iguais. }\end{array}$ & $\begin{array}{l}\text { Relativamente } \\
\text { alta }\end{array}$ & $\begin{array}{l}\text { Altas } \\
\text { frequências }\end{array}$ & $\begin{array}{l}\text { Sobre a traqueia no } \\
\text { pescoço }\end{array}$ \\
\hline
\end{tabular}

Fonte: Adaptado de (SUDDARTH, 2009)

Figura 2.2 - Som Broncovesicular

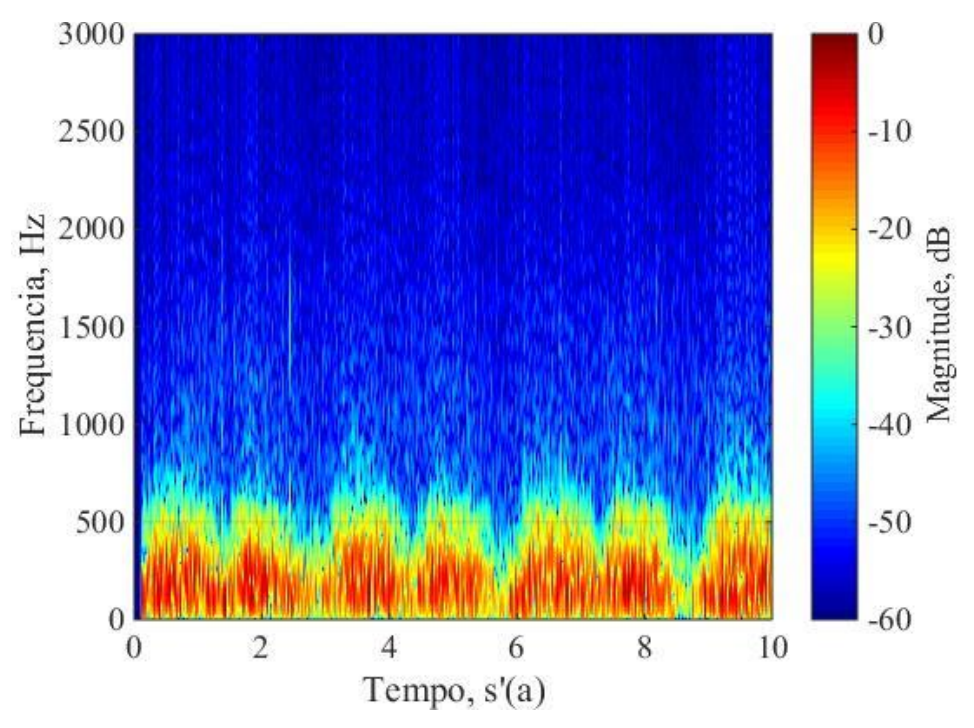

Fonte: Autor

Para Vannuccini (2000) os sons respiratórios normais resgistrados no tórax alcançam frequências entre $100-2 \mathrm{KHz}$ e quando registrado na traqueia valores entre 100-4KHz. Outros valores de frequências também foram reportados. Para Pasterkamp; Kraman e Wodicka (1997) sons normais atingem frequências entre $100-1 \mathrm{KHz}$ e quando registrados na traqueia compreendem valores entre 100-3KHz. Em Sovijärvi et al.(2000) frequências entre $50-2.5 \mathrm{KHz}$ para sons respiratórios normais registrados no tórax e para som traqueal frequências com alcance entre $850-1 \mathrm{KHz}$. 


\subsubsection{Sons Respiratórios Anormais}

Os sons respiratórios anormais são ruídos adicionais sobrepostos aos sons respiratórios normais, presentes em doenças pulmonares. Na DPOC sibilos, são sons respiratório anormais, que podem estar presentes tanto na inspiração quanto na expiração (GOLD, 2017).

\section{Sibilos}

Sibilos são sons de tonalidade musicais semelhantes a um assobio, resultado da passagem do fluxo de ar através das vias áreas obstruídas (POSTIAUX, 2004). Na figura 2.3 é apresentado o espectrograma de um som respiratório com sibilos (linhas horizontais) que ocorre em aproximadamente $0,5 \mathrm{~s}, 2 \mathrm{~s}, 4 \mathrm{~s}$ e $6 \mathrm{~s}$ sobrepostos ao som normal. Os sibilos podem ser encontrados na inspiração e na expiração (SUDDARTH, 2009), mas com maior prevalência na expiração (JÁCOME; MARQUES, 2014). Podem ser tanto de baixa frequência $100 \mathrm{~Hz}$ como de alta frequência $5 \mathrm{kHz}$, com duração > que 80ms (BOHADANA, 2014). Podem ser monofônicos ou polifônicos: monofônico quando o som é produzido pela obstrução de um único brônquio ou polifônico quando os sons são produzidos por diferentes brônquios. Sibilos polifônicos são normalmente encontrados na bronquite crônica (BOHADANA, 1989). A figura 2.3 é um exemplo de sibilos polifônicos, as linhas horizontais umas sobre as outras, em cada instante de tempo. Os sons respiratórios apresentam-se diminuídos, devido à passagem de ar comprometida. Em casos graves de obstrução das vias áreas, não há sibilos, pois é necessário que o haja fluxo de ar para que os sibilos ocorram (BOHADANA, 2014).

Figura 2.3 - Som Respiratório Anormal- Sibilos

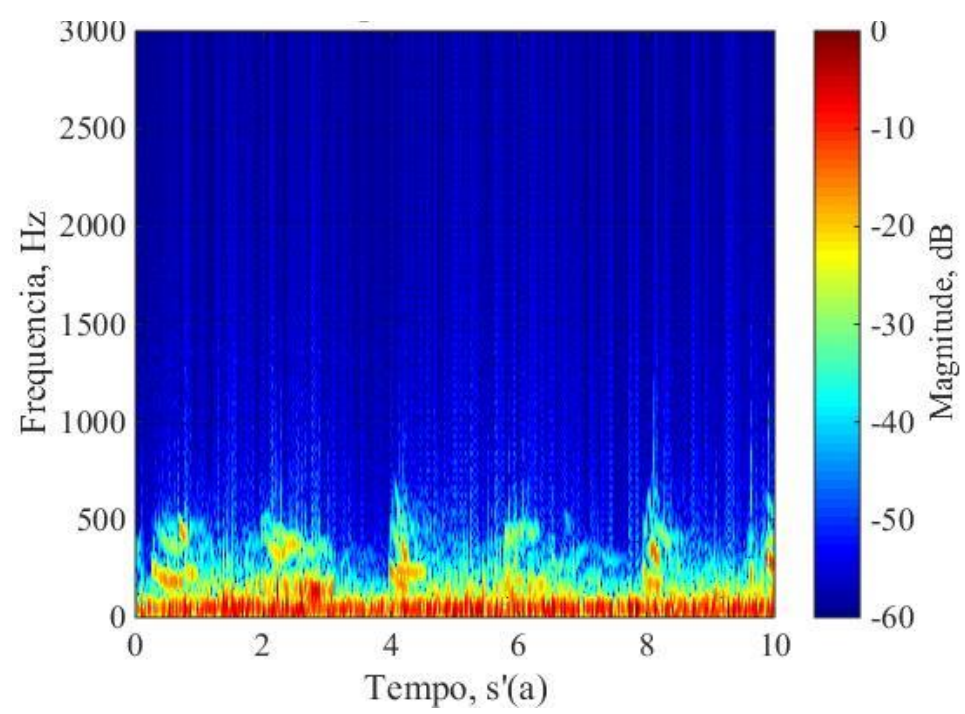

Fonte: Autor 


\subsubsection{Ambiente e coleta dos sons respiratórios}

A ausculta dos sons respiratórios é uma prática não invasiva, de baixo custo, realizada pelos profissionais de saúde, que consiste em ouvir os sons respiratórios. A ausculta requer alguns cuidados básicos, como controle do ambiente e posição do paciente, que devem ser atendidos durante a prática. Durante a gravação dos sons respiratórios, o ambiente deve ser avaliado e adequadamente preparado de forma a minimizar os possíveis ruídos que possam interferir na aquisição, se possível em sala separada (ROSSI et al., 2000).

O paciente deverá estar de preferência sentado com a boca entre aberta, respirando profundamente e pausadamente pela boca (POSTIAUX, 2004). A posição sentada resulta em respiração mais profunda consequentemente maior fluxo, maior intensidade de som respiratório. Para os casos de utilização de dispositivos sensores, como o microfone, o paciente deve estar sentado, com as mãos sobre as coxas, evitando o contato dos braços com as axilas, para impedir o aparecimento de interferências (ROSSI, 2000).

\subsubsection{Aquisição e filtragem dos sons respiratórios}

Os sons respiratórios atingem largura de banda, quando gravados no peito, de $60-100 \mathrm{~Hz}$ a $2 \mathrm{KHz}$ para sons normais, $60-100 \mathrm{~Hz}$ a $6 \mathrm{KHz}$ para sons anormais e quando gravados na traqueia atingem largura de banda de 100-60 a 4KHz (VANNUCCINI, 2000). O dispositivo sensor mais utilizado para aquisição de sons respiratórios são os microfones de eletreto. Em JÁCOME, (2015) um revisão é apresentado com trabalhos de sons respiratórios computadorizados em pacientes com DPOC. Dos sete trabalhos analisados, cinco usaram microfone de eletreto, sendo que um destes optou por acoplar o microfone a campânula de um estetoscópio. A vantagem dos microfones de eletreto é que além do baixo custo, tem ampla resposta em frequência que atualmente cobre um intervalo de $50 \mathrm{~Hz}-16 \mathrm{KHz}$, muito superior a banda de frequências exigida para captar os sons respiratórios compreendidos entre $60 \mathrm{~Hz}-6 \mathrm{KHz}$. Apesar da sensibilidade dos microfones atuais, as vibrações produzidas pela respiração na região do tórax, são muito sutis, necessitando que o microfone seja acoplado a uma câmara fechada (VANNUCCINI, 2000), como por exemplo, em uma campânula de estetoscópio, para que estas vibrações possam mover a membrana do microfone. Em Menon, Drishya e Nadarajan (2014), um microfone acoplado a campânula do estetoscópio e conectado a um computador, foi utilizado para capturar os sons respiratórios e compará-los com uma base de dados comercial (R.A.L.E). Da mesma forma em Yamashita, Matsunaga e Miyahara (2011) um microfone adapatado a um estetoscópio foi 
utilizado para distinguir um indivíduo saudável de um paciente com enfisema, utilizando análise de sons respiratórios. Uma desvantagem do uso do microfone incorporado ao estetoscópio são os ruídos capturados do ambiente, qualquer movimento no estetoscópio durante a gravação e o ruído poderá ser captado. Por outro lado a vantagem em usar esta combinação é que a membrana do estetoscópio funciona como um filtro de baixas frequências, atenuando os sons do batimento cardíaco e dos músculos que normalmente são capturados durante a aquisição (BOHADANA, 1989). A combinação de filtros passa altas e passa baixas, do tipo Butterworth de $4^{\mathrm{a}}$ ordem, são recomendados pelo CORSA, o primeiro para atenuar ruídos como dos batimentos cardiácos e o segundo para previnir aliasing (VANNUCCINI, 2000) (CHEETHAM, 2000). O aliasing pode ser evitado se a frequência de amostragem for maior que o dobro da frequência limite do sinal a ser amostrado (OPPENHEIM, 2010), filtros antialiasing podem ser implementados antes da amostragem (digitalização) quando o limite da maior frequência do sinal não for conhecido. Uma vez que os sons já estejam digitalizados a uma taxa de amostragem $44,1 \mathrm{KHz}$, e o máximo valor de frequência do sinal de interesse para sons respiratórios é de $6 \mathrm{kHz}$, uma taxa de amostragem superior $12 \mathrm{KHz}$ é suficiente para evitar alising. Filtros digitais também são utilizados quando se deseja limitar a banda de frequências de interesse. Em İÇER e GENGEÇ (2014), utilizou se filtro passa banda digital de resposta infinita ao impulso (RII) do tipo Butterwoth com frequências de corte 150-1,8KHz, para redução dos sons cardíacos e dos músculo.

\subsubsection{Técnicas de Análise de Sons Respiratórios}

Técnicas de processamento de sinais e análise estatística são utilizadas na caracterização e descrição dos sons respiratórios. Os sons respiratórios possuem características não estacionárias, ou seja, seu espectro de frequências muda no decorrer do tempo. Assim a análise das frequências utilizando as transformadas e as relações entre as amostras do sinal através da média e da variância são comumente utilizadas em pesquisas. A Transformada Rápida de Fourier (TRF) é uma ferramenta matemática de representação de sinais no domínio da frequência, utilizada na extração de características em análise de sons respiratórios. Entretanto para uma análise mais apropriada, devido às características não estacionárias dos sons respiratórios, a abordagem tempo frequência é mais indicada (CHARBONNEAU, 2000). Na Transformada de Fourier de Tempo Curto (TFTC) o sinal do som respiratório é particionado no tempo, método de janelamento, e em cada participação a TRF é aplicada, desta forma é possível representar o sinal no tempo-frequência. As janelas mais comumente utilizadas, apontadas pelo CORSA são as janelas de Hanning ou Hamming. Na tabela 3 é apresentado um 
comparativo dos parâmetros entre essas as duas janelas. Há de se considerar que a escolha do filtro de janelamento deve ser verificada quanto à distorção da resposta em frequência próxima à frequência de corte, se os valores forem muito elevados informações podem ser perdidas (NALON, 2009). A TFTC é amplamente aplicada na caracterização de sons respiratórios anormais com especial atenção na detecção de sibilos.

Em Morillo (2013) a análise das variações da densidade espectral no tempo, para diferenciar sons pulmonares pneumônicos e não pneumônicos em pacientes diagnosticados com DPOC é realizada utilizando como método de caracterização a TFTC com janela de Hamming e sobreposição de $25 \%$, e como método estatístico a média e a mediana. Em Homs-Corbera et al.(2004) a TFTC com janela de Hanning e sobreposição de 50\% foi utilizada na análise de sons respiratórios para detecção de sibilâncias, o método estatístico utilizado foi a média e desvio padrão. Em Taplidou e Hadjileontiadis (2007) propõe-se um método de análise para detectar picos de sibilâncias e eliminar a presença de ruídos, para tanto utilizou a TFTC com janela de Hanning e 50\% de sobreposição e como método estatístico a média e desvio padrão.

Tabela 3. Comparativo entre janelala de Hanning e de Hamming

\begin{tabular}{c|c|c|c|c}
\hline Janela & $\begin{array}{c}\text { Amplitude do pico } \\
\text { lateral }\end{array}$ & $\begin{array}{c}\text { Lóbulo } \\
\text { principal }\end{array}$ & $\begin{array}{c}\text { Faixa de } \\
\text { transição }\end{array}$ & $\begin{array}{c}\text { Atenuação } \\
\text { mínima }\end{array}$ \\
\hline Hanning & $-31 \mathrm{~dB}$ & $4 \pi / \mathrm{N}$ & $2,51 \pi / \mathrm{N}$ & $-44 \mathrm{~dB}$ \\
\hline Hamming & $-41 \mathrm{~dB}$ & $4 \pi / \mathrm{N}$ & $3,14 \pi / \mathrm{N}$ & $-53 \mathrm{~dB}$ \\
\hline
\end{tabular}

Fonte: Extraído de (NALON, 2009)

Em síntese podemos concluir que para estimar a gravidade da DPOC através área do gráfico das intensidades sonoras em função de suas frequências é necessário primeiramente coletar dados acústicos evitando interferência ambientais, para tanto o uso de microfone incorporado à campânula de um estetoscópio é indicado. Na digitalização a taxa de amostragem superior a $12 \mathrm{KHz}$ é suficiente, pois a banda de frequência máxima de interesse para sons respiratórios é de $6 \mathrm{KHz}$. Para análise das características e representação dos sons respiratórios, usar técnicas tempo-frequência como a TFTC e janela de Hamming com sobreposição de 50\% e como métodos estatísticos na análise da descrição das amostras usar media e desvio padrão. 


\section{CAPÍTULO 3}

\section{METODOLOGIA}

Neste capítulo apresenta-se a metodologia utilizada neste estudo, são detalhados a população e os procedimentos de coleta, o projeto do sistema para aquisição dos sons respiratórios e a descrição do método proposto.

As especificações para procedimentos de coleta, aquisição e processamento dos sons respiratórios, apresentadas neste estudo, foram baseadas nas recomendações técnicas do CORSA (Computerized Respiratory Sound Analysis), que integra um conjunto de artigos de boas práticas tecnológicas para aquisição, processamento e análise de sons respiratórios digitalizados (EARIS e CHEETHAM, 2000).

O presente estudo realizado entre os meses de julho e setembro de 2016, foi aprovado pelo Comitê de Ética em Pesquisa do Hospital Público Estadual Guilherme Álvaro (protocolo: 058810/2016) na cidade de Santos (SP). Todos os participantes da pesquisa assinaram o termo de consentimento livre e esclarecido e informaram sua idade, peso, altura e tabagismo.

\subsection{População}

Participaram do estudo 51 pacientes, ambulatoriais diagnosticados com DPOC, segundo os critérios do GOLD (GOLD, 2016) e 7 indivíduos saudáveis (3 homens e 4 mulheres). Os critérios de inclusão para os indivíduos saudáveis foram: ter 40 anos ou mais, ter IMC dentro da normalidade (entre 18,5 e $24,9 \mathrm{Kg} / \mathrm{m}^{2}$ ), não ter histórico de tabagismo nem de doenças pulmonares crônicas.

\subsection{Procedimentos de coleta dos sons respiratórios}

Os pacientes em consulta diagnosticados com DPOC foram convidados e encaminhados a pedido dos médicos do ambulatório, a uma sala de atendimento para coleta dos sons. A gravidade da DPOC foi informada pelo médico e dados pessoais como: idade, peso, altura, sexo 
e tabagismo foram levantados antes da coleta dos sons. Durante a coleta todos os pacientes foram colocados na posição sentado com leve inclinação para frente com as mãos apoiadas sobre os joelhos e orientados a respirar pausadamente com a boca semiaberta (ROSSI, 2000). A campânula do estetoscópio foi colocada sobre a pele do paciente para evitar interferências oriundas de vestimentas. As amostras com aproximadamente 12s, foram extraídas na região intercápulovertebral (lado direito e esquerdo) e traquéia de cada paciente. $\mathrm{O}$ mesmo procedimento foi realizado com os indivíduos saudáveis.

\subsection{Sistema para Aquisição dos Sons Respiratórios}

O sistema para aquisição dos sons respiratórios é constituído de um mini microfone de eletreto (modelo Lapela Mini-Mic, China), um estetoscópio (modelo MDF-777; MDF Instruments, Shanghai, China), software editor de áudio Audacity® (Versão 2.0.4; Free Software Foundation,Inc, Boston, United States) e o software de funções matemáticas MatLab® (R2014b, The MathWorks, Inc., Natick, Massachusetts, United States).

Para coletar os sons respiratórios foram testados dois minis microfones de eletreto do tipo lapela. Um microfone modelo ATR3350iS Audio-Technica de 3,5 mm e um Mini-Mic de 3,5 mm, as especificações técnicas são apresentadas na tabela 4. As recomendações do CORSA foram consideradas na escolha desses componentes (VANNUCCINI, 2000). Determinou-se um esquema de teste para comparar as respostas em frequência de cada microfone. Utilizou-se de um smartphone para gerar os sons de $250 \mathrm{~Hz}, 300 \mathrm{~Hz}, 440 \mathrm{~Hz}$ e $500 \mathrm{~Hz}$, com os microfones à distância de $5 \mathrm{~cm}$ da saída de áudio do aparelho. Testou-se também com os microfones acoplados a campânula do estetoscópio junto a saída de áudio do aparelho. Os testes também auxiliaram na identificação do nível de saturação de cada microfone, e, portanto, na determinação do volume que deveria ser utilizado durante a extração dos sons respiratórios. $\mathrm{O}$ microfone da marca Audio-Technica foi descartado após apresentar problemas com a bateria. 
Tabela 4. Especificações técnicas dos microfones

\begin{tabular}{c|c|c}
\hline \multirow{2}{*}{ Especificações } & ATR3350iS Audio-technica & Mini Mic \\
\hline Tipo de microfone & Eletrecto & Eletrecto \\
\hline Diretividade & Omnidirecional & Omnidirecional \\
\hline Relação sinal ruído & & $>60 \mathrm{~dB}$ \\
\hline Sensibilidade & $>60 \mathrm{~dB}$ & $-54 \mathrm{~dB}$ \\
\hline Resposta em frequência & & \\
\hline
\end{tabular}

Fonte: Autor

A campânula é a parte coletora do som, que quando utilizada na sua parte rasa e fechada por um diafragma, funciona como um atenuador de baixas frequências, permitindo que os sons respiratórios sejam mais facilmente auscultados. A campânula do estetoscópio foi separada do restante do instrumento, deixando apenas $4 \mathrm{~cm}$ da tubulação. O mini microfone foi fixado no restante da tubulação, preso à campânula, de forma comprimida, para que outras vibrações, senão as do movimento do diagrama fossem capturadas pelo microfone.

Utilizou-se na gravação e armazenamento dos sons respiratórios o software editor de áudio Audacity. Para favorecer melhor qualidade de áudio, os sons foram gravados a uma taxa de amostragem de $44.100 \mathrm{~Hz} / \mathrm{s}$ e quantização de 16 bits (CHEETHAM, 2000).

\subsection{Processamento e Análise de Dados}

Nesta seção descrevem-se o processamento e análise de dados realizado para o cálculo da área da variância das intensidades sonoras, utilizando o software MatLab.

O diagrama de blocos na figura 3.1, apresenta em detalhes todas as etapas do método que está subdivido em: pré-processamento, processamento e análise de dados. 
Figura 3.1 - Diagrama de Blocos do Método

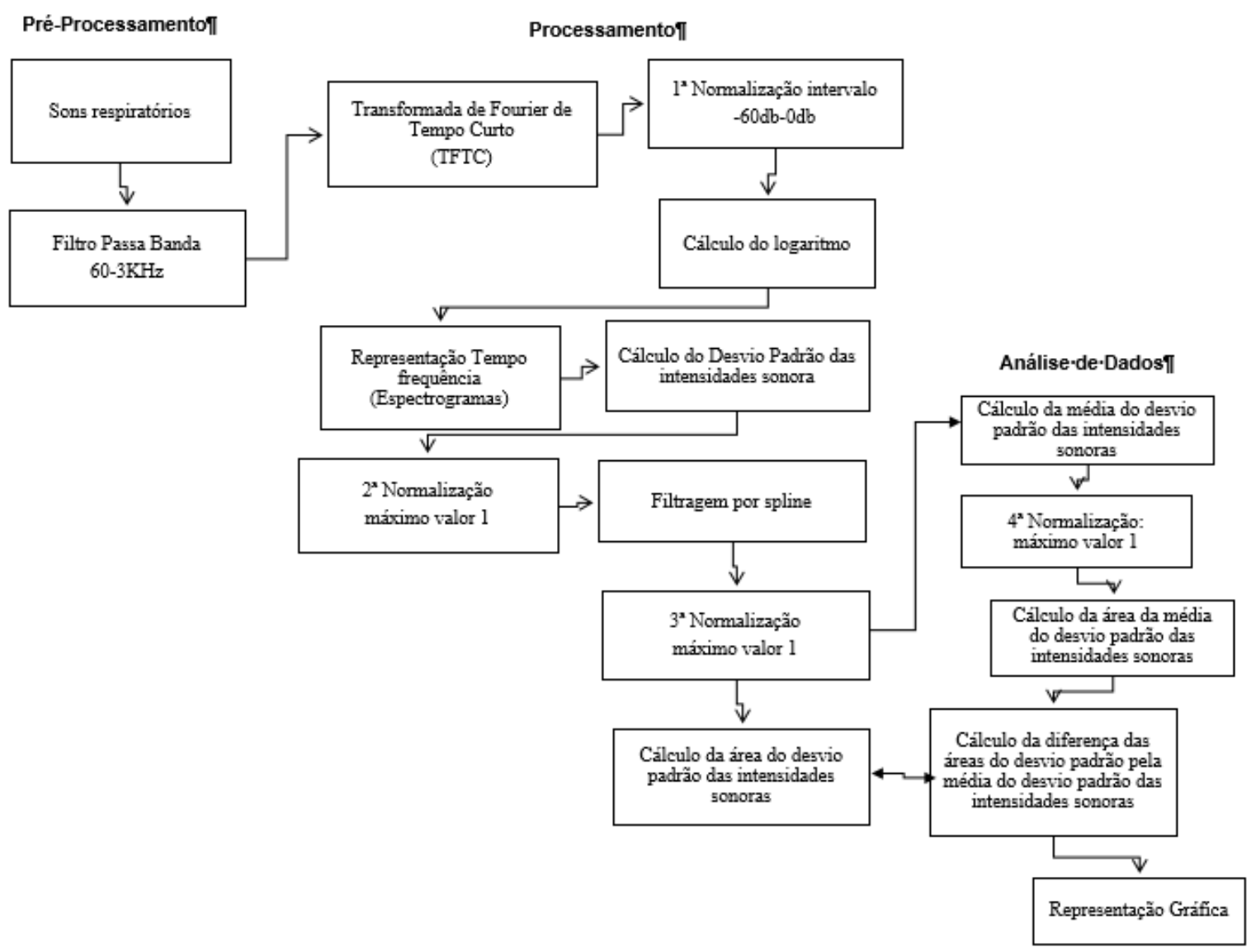

Fonte: Autor

Pré-processamento: Após a aquisição e armazenamento em arquivo wave (.wav), os sons respiratórios foram pré-processados, usando um filtro passa banda, de Resposta Infinita ao Impulso (RII) do tipo Butterworth de $6^{\mathrm{a}}$ ordem, com frequência de corte de $60 \mathrm{~Hz}$ a $3 \mathrm{kHz}$, como solução para redução de dimensionamento e de ruídos provenientes do coração e dos músculos, e evitar aliasing.

Processamento: Na caracterização dos sinais foi utilizada a Transformada de Fourier de Tempo Curto (TFTC) com janela de Hamming de 512 amostras, com sobreposição de 50\%. Os dados da matriz de TFTC foram normalizados, pelo cálculo da média entre os valores mínimos e máximos conforme equação (3.1), e posteriormente convertidos para escala logarítmica, 
equação (3.2), para que todos os espectrogramas gerados tivessem potências compreendidas entre -60 a 0db (decibéis).

$$
s=(s-\min (\mathrm{s}(:))) /(\max (\mathrm{s}(:))-\min (\mathrm{s}(:)))
$$

onde: s denota todos os valores de um espectrograma.

$$
s=20^{*} \log 10\left(s+1 e^{-3}\right)
$$

A variância das intensidades sonoras, foram obtidas pelo cálculo do desvio padrão, em cada frequência discreta da matriz da TFTC. Os dados do vetor resultante da variância foram normalizados para que tivessem valor máximo igual a 1, equação (3.1). Uma vez normalizados, os dados foram aproximados utilizando o método de interpolação, de tal forma que preservasse a área da banda de frequências e suavizasse as curvas. Após a filtragem utilizando o método de interpolação, a equação (3.1) foi novamente aplicada ao vetor das variâncias de cada arquivo, de tal forma que os dados tivessem valores máximos iguais a 1. Posteriormente, o método de interpolação foi aplicado também ao vetor de frequências para que ambos os vetores, variância e frequência, tivessem a mesma dimensão para que fosse possível gerar o gráfico em função da frequência.

Análise de dados: Com os resultados obtidos da fase de processamento foi calculado a área do gráfico do desvio padrão das intensidades sonoras para cada arquivo dos pacientes. Para que os gráficos das áreas do desvio padrão de cada paciente fossem comparados a área do gráfico do desvio padrão dentre todos os indivíduos saudáveis, foram realizados os seguintes passos nos arquivos dos individuos saudáveis: cálculo da média do desvio padrão entre todos os indivíduos saudáveis (tabela 5), cálculo da normalização equação (3.1) (tabela 6), cálculo da área da média do desvio padrão dentre todos os indivíduos saudáveis. Para ilustrar essas diferenças foram gerados gráficos comparativos entre as áreas. 
Tabela 5. Resultados da média de desvio padrão, dados de indivíduos saudáveis

$\begin{array}{llll}0,872307152401129 & 0,892076575490449 & 0,919177826111224 & 0,967819083273727 \\ 0,988087914522433 & 1 & 0,999918490060353 & 0,976851332142613 \\ 0,955212718302800 & 0,929913108368863 & 0,907998563726438 & 0,880296513070129 \\ 0,860564301267137 & 0,824298794614181 & 0,777777892386368 & 0,733650242570178 \\ 0,693258682622716 & 0,665152350946120 & 0,629762647780678 & 0,597754307810878 \\ 0,553565507202736 & 0,519955530396961 & 0,488924767404366 & 0,457852924223662 \\ 0,441797099179302 & 0,430486506799906 & 0,415934206849279 & 0,406300478987488 \\ 0,392533121843894 & 0,380883593463456 & 0,370249880215524 & 0,347060856642845 \\ 0,328800272925950 & 0,313834667191534 & 0,297627093164391 & 0,289939153740682 \\ 0,276959970891030 & 0,266746633483484 & 0,260611506509741 & 0,257642926881693 \\ 0,248440237160347 & 0,245594316728042 & 0,248671290716826 & 0,252059591353437 \\ 0,250395838799147 & 0,250932519628835 & 0,255194133490155 & 0,254136906883091 \\ 0,245628762483828 & 0,237066475349604 & 0,218082645171657 & 0,195043951793529 \\ 0,170530832660184 & 0,137882185918095 & 0,109407520763619 & 0,0890810034125668 \\ 0,0689828817181442 & 0,0521079709658535 & 0,0437112161442464 & 0,0342428824056871 \\ 0,0194803228160281 & 0,0115029556219177 & 0,01204405944868845 & \\ 0,00615634761649188 & 0,00203031125218697 & 0 & \end{array}$

Fonte: Autor

Tabela 6. Resultados de desvio padrão normalizado, dados de indivíduos saudáveis

$\begin{array}{llll}0,832386262085272 & 0,851177146350833 & 0,876936950345422 & 0,923170582441939 \\ 0,942436155365935 & 0,953758621305337 & 0,953681145911367 & 0,931755756748045 \\ 0,911188202171768 & 0,887140861989682 & 0,866311034520880 & 0,839980168645353 \\ 0,821224653797077 & 0,786754202369702 & 0,742535972745965 & 0,700592535304170 \\ 0,662200260281826 & 0,635485124322713 & 0,601847126219792 & 0,571423121979112 \\ 0,529421560562272 & 0,497475196651090 & 0,467980381681960 & 0,438446519895083 \\ 0,423185419516303 & 0,412434674215546 & 0,398602678059943 & 0,389445796522281 \\ 0,376359890395476 & 0,365286985609324 & 0,355179615553442 & 0,333138392791560 \\ 0,315781663983872 & 0,301556819685236 & 0,286151481532799 & 0,278844076592408 \\ 0,266507332030493 & 0,256799530223469 & 0,250968077257074 & 0,248146435170113 \\ 0,239399256423197 & 0,236694202197243 & 0,239618873385176 & 0,242839461301769 \\ 0,241258060491389 & 0,241768176912726 & 0,245818851152979 & 0,244813954716394 \\ 0,236726942971088 & 0,228588468425788 & 0,210544292114765 & 0,188645958564909 \\ 0,165346179783228 & 0,134313562413162 & 0,107248324596109 & 0,0879279208928827 \\ 0,0688246078114254 & 0,0527849644943031 & 0,0448038288108670 & 0,0358041547857257 \\ 0,0217723063367641 & 0,0141897996034544 & 0,0147041200941682 & \\ 0,00910783581577270 & 0,00518602831300154 & 0,00325621257733025 & \end{array}$

Fonte: Autor

Inicialmente, investigou-se a hipótese de que área do gráfico do desvio padrão versus frequência poderia estimar a gravidade da DPOC, entretanto, no decorrer deste estudo, notou-se que algumas das diferenças entre as áreas apresentaram valores negativos. As fichas desses pacientes foram 
reanalisadas por médico pneumologista, e foi identificado que estes se enquadravam no fenótipo de predominância de bronquite crônica. 


\section{CAPÍTULO 4}

\section{RESULTADOS}

Neste capítulo, apresentam-se os resultados da análise e os gráficos gerados em cada etapa do método, para estimar a gravidade da DPOC. Também são apresentados os resultados da validação do método através de indicadores.

\subsection{Características Demográficas da População}

Na tabela 5 são apresentadas as informações demográficas dos participantes (pacientes e indivíduos saudáveis). Há predominância no gênero masculino para a DPOC, os dados confirmam que o maior risco para a doença é o tabagismo. Pacientes fumantes são em sua maioria DPOC muito grave, 9 pacientes dentre os 10 fumantes. Pacientes ex-fumantes confirmaram mais de 10 anos de uso do cigarro. Não foi significativo o número de pacientes com baixo peso, apenas 2 casos para pacientes com DPOC muito grave e um caso para paciente com DPOC grave.

Tabela 7. Características Demográficas

\begin{tabular}{c|l|l}
\hline Características & $\begin{array}{l}\text { Pacientes DPOC } \\
(\mathbf{N = 5 1 )}\end{array}$ & $\begin{array}{l}\text { Indivíduos saudáveis } \\
(\mathbf{N}=\mathbf{7}) \%\end{array}$ \\
\hline $\begin{array}{l}\text { Gravidade de DPOC/ } \\
\text { Gênero }\end{array}$ & & \\
\hline A & $1(\mathrm{M}) 3(\mathrm{~F})=4$ & \\
\hline $\mathrm{B}$ & $8(\mathrm{M}) 7(\mathrm{~F})=15$ & \\
\hline $\mathrm{C}$ & $7(\mathrm{M}) 6(\mathrm{~F})=13$ & \\
\hline $\mathrm{D}$ & $13(\mathrm{M}) 6(\mathrm{~F})=19$ & \\
\hline Gênero, n $(\boldsymbol{\%})$ & & \\
\hline Masculino & $29(56,7)$ & $3(60,0)$ \\
\hline Feminino & $22(43,2)$ & $4(40,0)$ \\
\hline Idade, média $\pm \mathbf{d p}$ & & \\
\hline Idade & $70,5 \pm 9,7$ & \\
\hline Tabagismo, n $(\boldsymbol{\%})$ & & \\
\hline Fumantes & $10(20,7)$ & 0 \\
\hline Ex-fumantes & $40(79,3)$ & 0 \\
\hline Nunca fumaram & 1 & $7(100)$ \\
\hline
\end{tabular}

Fonte: Autor 


\subsection{Pré-Processamento}

Filtro passa banda (RII) do tipo Butterworth de $6^{\mathrm{a}}$ ordem foi utilizado para delimitar a faixa de frequências de interesse, como forma de redução de dimensionamento, bem como evitar aliasing e atenuar frequências fora da faixa. Por se tratar de um filtro digital, pós digitalização dos sinais acústicos, optou-se por usar um filtro de $6^{a}$ ordem, uma ordem a mais do que recomendada pelo CORSA, para suavizar ainda mais a banda de transição. A resposta em frequência do filtro é apresentada na figura 4.1.

Figura 4.1 - Resposta do Filtro Passa Banda

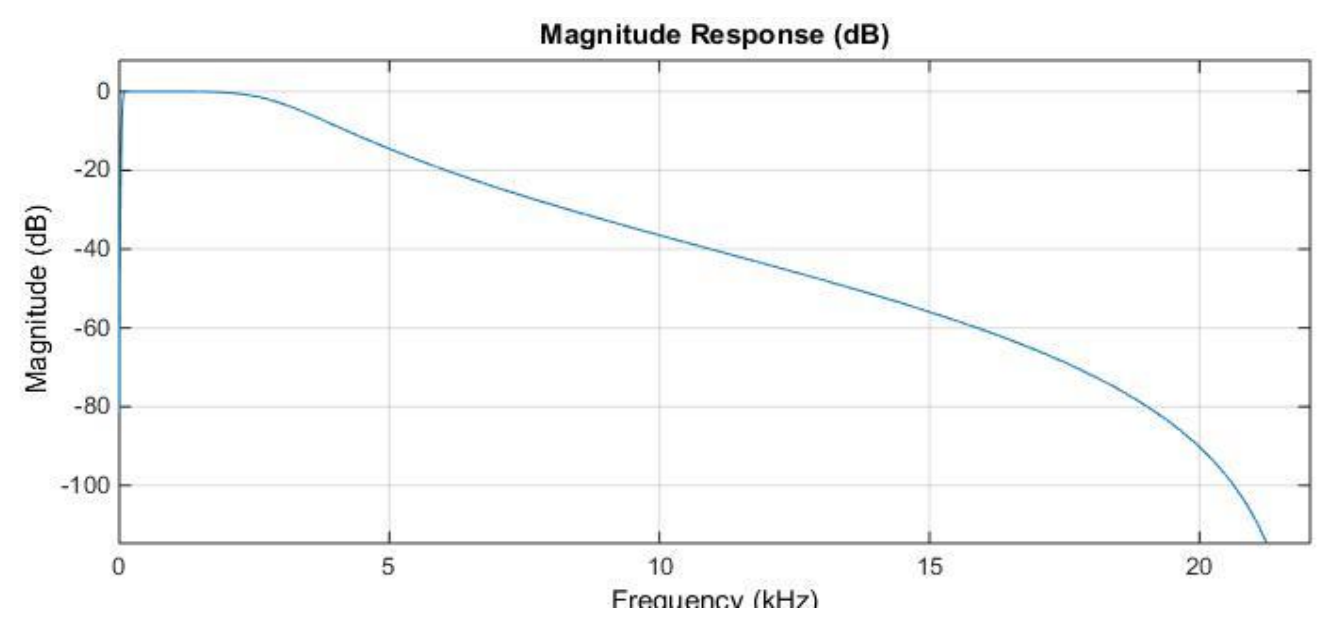

Fonte: Autor

\subsection{Resultados Processamento de Dados}

Com os dados acústicos filtrados, a TFTC foi processada, bem como o cálculo da normalização (equação 3.1) e do logaritmo (3.2), para então gerar os espectrogramas de representação no tempo-frequência de cada arquivo de dados gerado pela TFTC. Na figura 4.2, é apresentada o espectrograma, dados da TFTC, do som respiratório de um indivíduo saudável. Igualmente como apresentado na figura 2.2, o som respiratório broncovesicular, em pessoas saudáveis têm ciclos respiratórios bem definidos, as componentes inspiratórias mais intensas e a expiração levemente mais prolongada em relação a inspiração. Têm espectros com intensidades mais acentuadas abaixo de $500 \mathrm{~Hz}$, frequências acima de $500 \mathrm{~Hz}$ também são percebidas com menos intensidade, resultado da característica turbulenta do fluxo respiratório na região interescapulovertebrais, zona de brônquios de maior calibre (BOHADANA, 1989). 
Figura 4.2 - Indivíduo Saudável

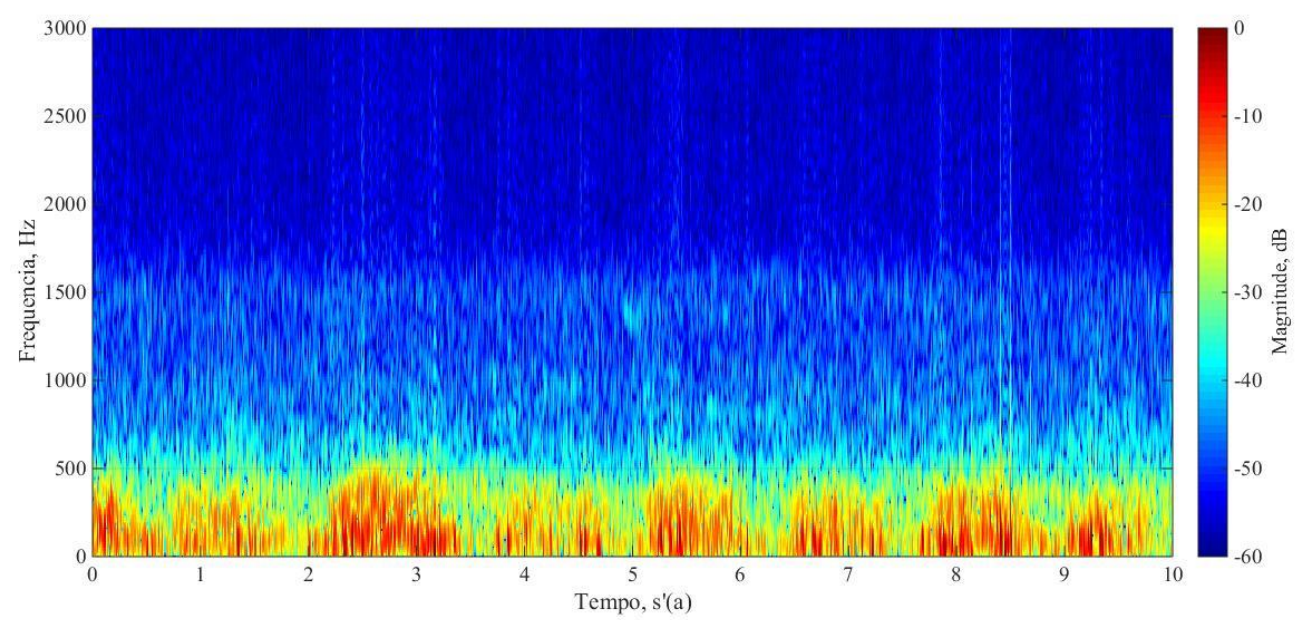

Fonte: Autor

Nas figuras 4.3, 4.4, 4.5 e 4.6, são apresentados exemplos de espectrogramas de pacientes com DPOC leve, moderado, grave e muito grave, respectivamente. Em comparação com indivíduos saudáveis, nota-se que a medida que a doença progride a intensidade sonora diminui, ficando prejudicada a identificação das fases do ciclo respiratório principalmente em pacientes muito graves. $\mathrm{Na}$ figura 4.6, a intensidade sonora é reduzida em 50\%, em relação a figura 4.3 , limitada em frequências abaixo de $300 \mathrm{~Hz}$. A presença de sibilos é comum em pacientes com DPOC, principalmente em casos de obstrução graves das vias áreas (FIZ, 2002), na figura 4.3 notam-se sibilos em 6,5 s presentes na inspiração.

Figura 4.3 - Espectrograma DPOC - Leve

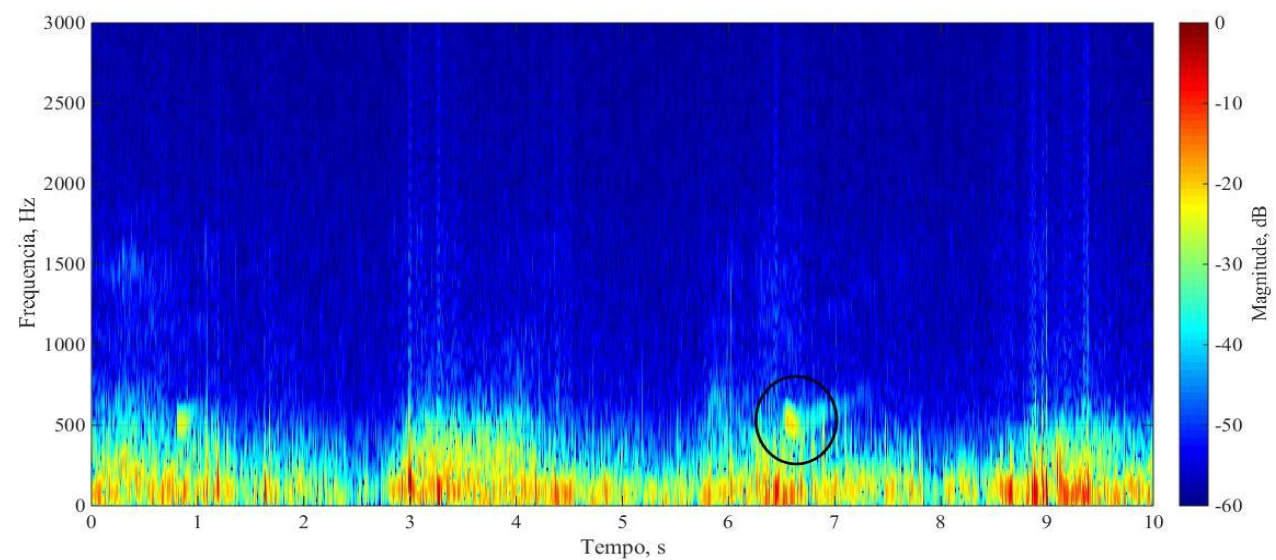

Fonte: Autor 
Figura 4.4- Espectrograma Paciente DPOC - Moderado

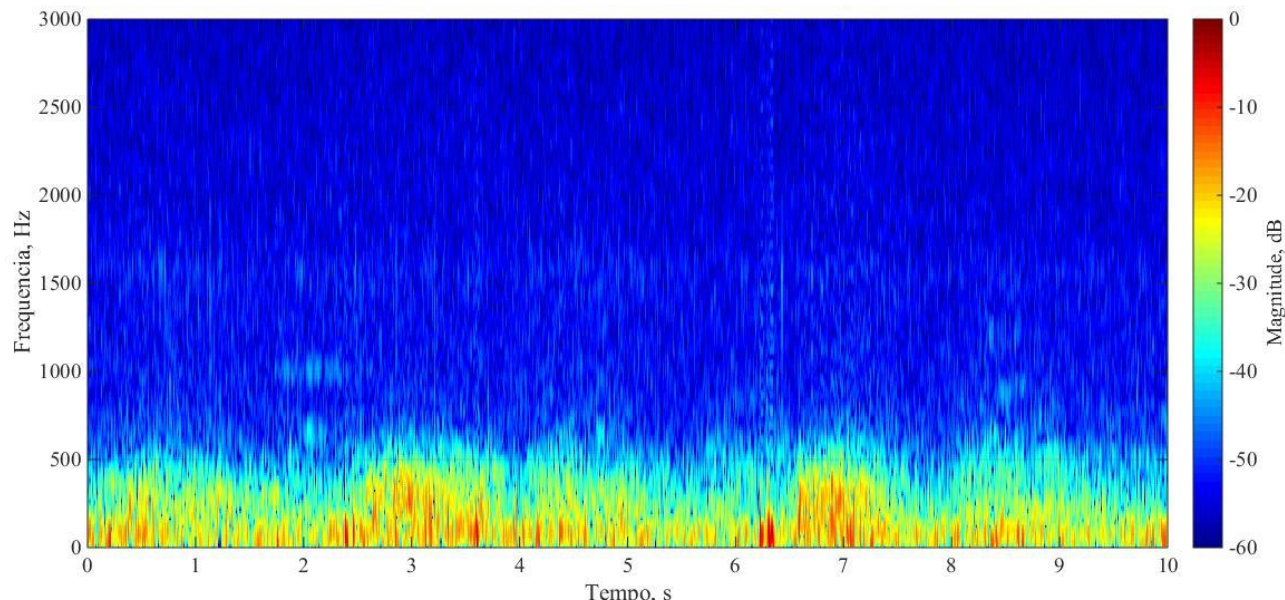

Fonte: Autor

Figura 4.5 - Espectrograma Paciente DPOC - Grave

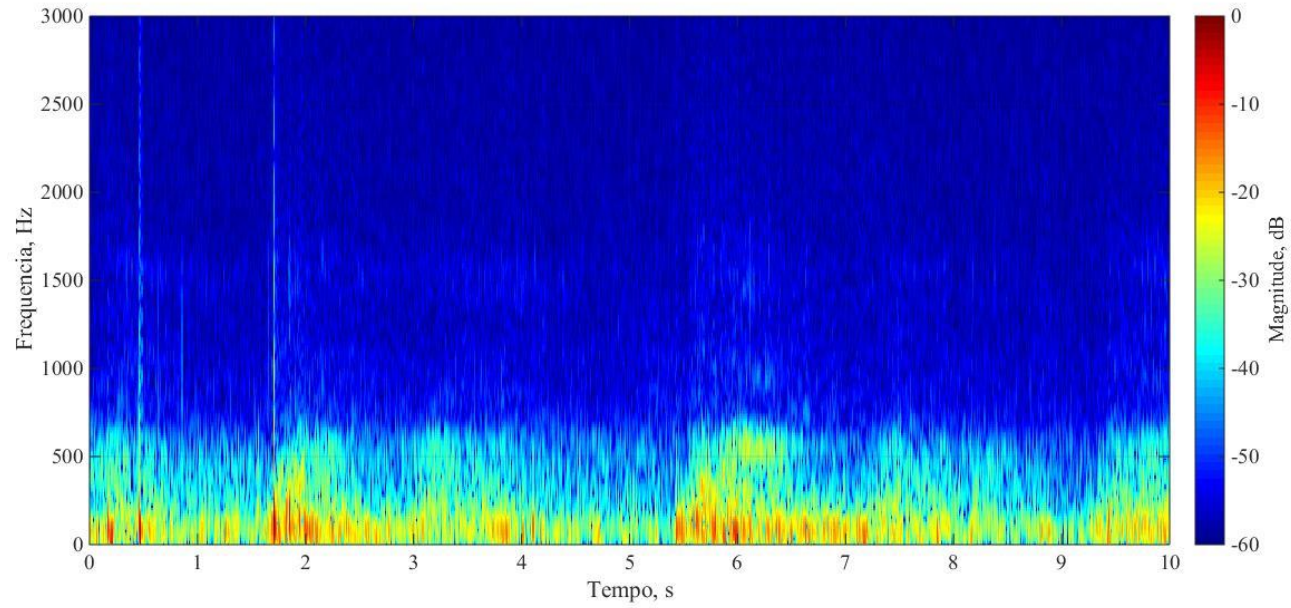

Fonte: Autor 1

Figura 4.6 - Espectrograma Paciente DPOC - Muito Grave

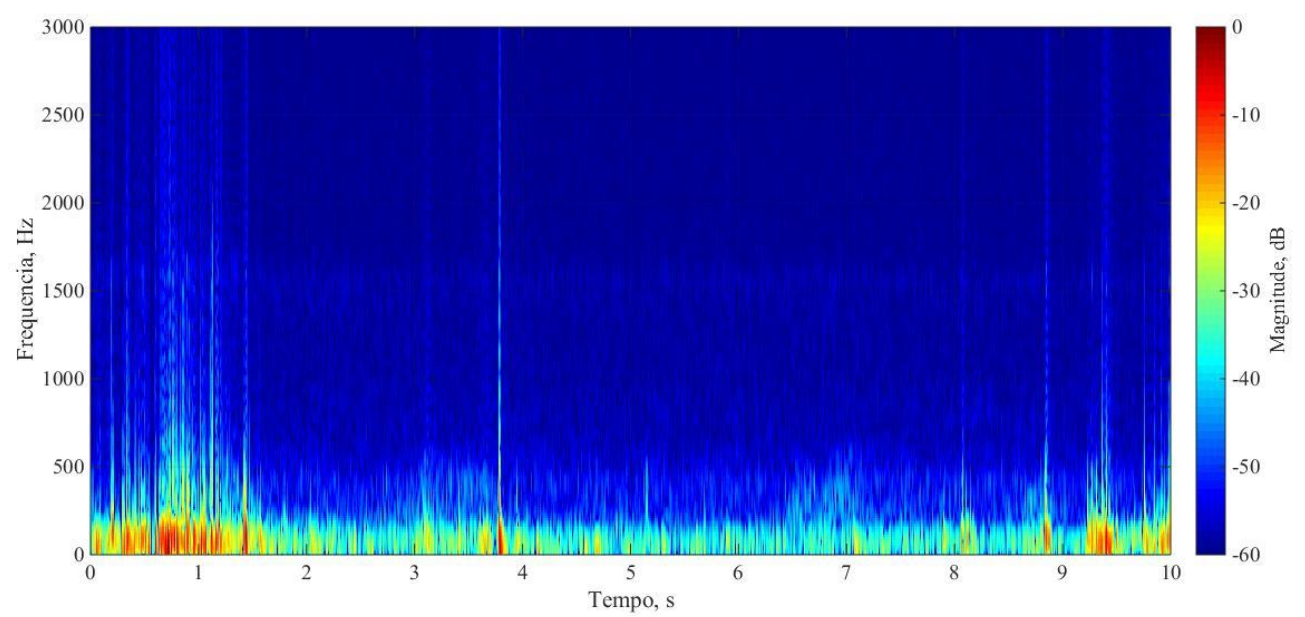

Fonte: Autor 
Considerando a estrutura de declaração dos argumentos do método de interpolação, apresentados na equação 4.1, em particular o argumento "xx", que foi definido pós remoção do offset, após o cálculo do desvio padrão e após a normalização dos dados (figura 4.7) xx=80:30:2049, sendo respectivamente; 80 a frequência inicial (eliminação de offset), 30 o número de subintervalos e 2049 a máxima frequência.

$$
\mathrm{yy}=\operatorname{spline}(\mathrm{x}, \mathrm{Y}, \mathrm{xx})
$$

onde: x é o vetor de frequências, Y os dados do desvio padrão normalizados, xx o intervalo de interesse.

Figura 4.7 - Gráfico da variância com offset

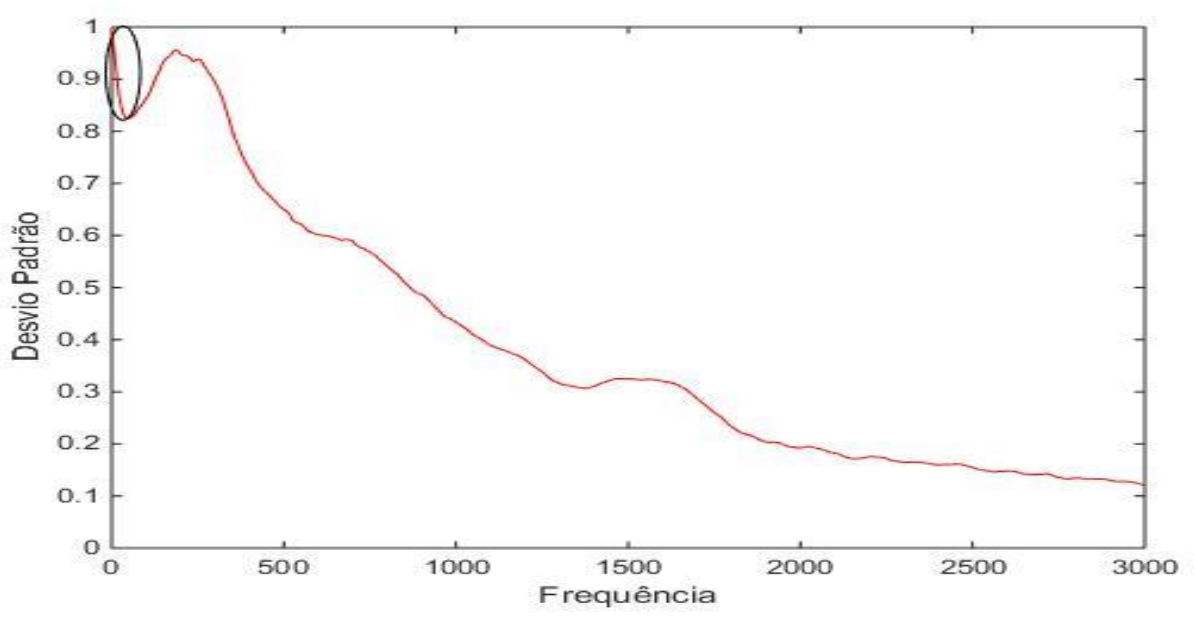

Fonte: Autor

Na figura 4.8 apresenta-se o resultado do gráfico obtido após a remoção do offset.

Figura 4.8 - Gráfico da variância sem offset

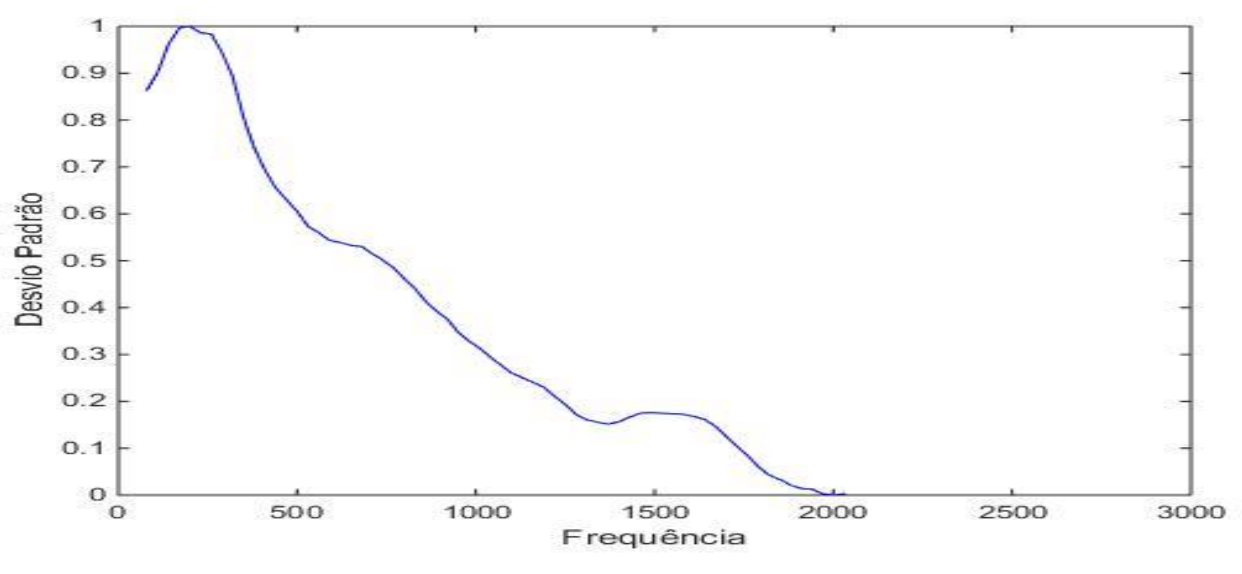

Fonte: Autor

Com os dados suavizados pelo método de interpolação e normalizados, foram calculadas as áreas para cada arquivo de dados e a média das áreas de cada grupo: indivíduos saudáveis (SD), pacientes DPOC Leve (LV), pacientes DPOC Moderado (MD), pacientes 
DPOC Grave (GR) e pacientes DPOC Muito Grave (MG). Esse procedimento é necessário para que as diferenças entre a média da área total de indivíduos saudáveis pela área de cada paciente fossem calculadas.

Na tabela 6 são apresentados os valores do cálculo das áreas das variâncias das intensidades sonoras de cada paciente por grupo de gravidade: DPOC leve (LV), DPOC moderado (MD), DPOC grave (GR), DPOC muito grave (MG).

Tabela 8 - Áreas das variâncias das intensidades sonora de pacientes por grupo de gravidade

\begin{tabular}{|l|c|c|c|c|c|c|c|c|c|c}
\hline GRUPOS & \multicolumn{10}{|c|}{ ÁREAS } \\
\hline LV (4) & 1 & 2 & 3 & 4 & & & & & & \\
\hline & 656,860 & 612,181 & 922,632 & 832,486 & & & & & & \\
\hline MD (15) & 1 & 2 & 3 & 4 & 5 & 6 & 7 & 8 & 9 & 10 \\
\hline & 492,138 & 738,274 & 820,108 & 642,886 & 711,580 & 734,893 & 703,311 & 735,597 & 703,037 & 570,369 \\
\hline & 11 & 12 & 13 & 14 & 15 & & & & & \\
\hline & 815,765 & 885,828 & 789,561 & 867,254 & 813,553 & & & & & \\
\hline GR (13) & 1 & 2 & 3 & 4 & 5 & 6 & 7 & 8 & 9 & 10 \\
\hline & 687,352 & 870,754 & 767,669 & 798,267 & 706,117 & 946,944 & 812,896 & 890,187 & 628,557 & 742,305 \\
\hline & 11 & 12 & 13 & & & & & & & \\
\hline & 814,402 & 897,430 & 760,505 & & & & & & & \\
\hline MG (19) & 1 & 2 & 3 & 4 & 5 & 6 & 7 & 8 & 9 & 10 \\
\hline & 561,420 & 647,509 & 582,878 & 666,765 & 601,862 & 498,906 & 746,973 & 429,531 & 768,681 & 688,328 \\
\hline & 11 & 12 & 13 & 14 & 15 & 16 & 17 & 18 & 19 & \\
\hline & 920,831 & 745,346 & 696,053 & 984,730 & 830,788 & 822,630 & 565,494 & 700,561 & 919,510 & \\
\hline
\end{tabular}

Fonte: Autor

Nas tabelas 7, 8 e 9, são apresentados os resultados dos testes realizados com as frequências de corte de $60-3 \mathrm{Khz}, 60-2 \mathrm{KHz}$ e $60-6 \mathrm{KHz}$ para o filtro passa banda. Constata-se que o filtro passa banda com frequência de corte de $60-3 \mathrm{Khz}$ obteve melhores resultados para o método. Nota-se que há alguns valores negativos, em vermelho, estes estão relacionados as áreas de pacientes que apresentaram valores superiores a área de individuos normais $(833,755)$. Constatou-se que estes valores negativos, ocorreram devido aos sons respiratórios de alguns pacientes apresentarem sons respiratórios anormais sobrepostos aos sons respiratórios normais. Os sons respiratórios anormais quando extraídos sobre o tórax tem intensidade elevada. Sibilos tem frequência dominante em 400hz e podem atingir a 1,6Khz (SOVIJARVI, 2000). 
Tabela 10 - Diferenças entre áreas de indivíduo normais e DPOC - filtro com frequência de corte 60-2Kz

\begin{tabular}{|c|c|c|c|c|c|c|c|c|c|c|}
\hline Gravidade DPOC ( $\left.\mathrm{N}^{\circ} 51\right)$ & \multicolumn{10}{|c|}{ Teste $60-2 \mathrm{KHz}$} \\
\hline \multirow[t]{2}{*}{ Leve (4) } & 1 & 2 & 3 & 4 & & & & & & \\
\hline & 177,012 & 209,389 & $-79,130$ & $-11,712$ & & & & & & \\
\hline \multirow[t]{4}{*}{ Moderado (15) } & 1 & 2 & 3 & 4 & 5 & 6 & 7 & 8 & 9 & 10 \\
\hline & 356,964 & 77,834 & 28,127 & 152,861 & 130,793 & 113,270 & 146,080 & 80,177 & 143,557 & 252,194 \\
\hline & 11 & 12 & 13 & 14 & 15 & & & & & \\
\hline & 21,366 & $-241,536$ & 55,077 & $-245,916$ & 12,498 & & & & & \\
\hline \multirow[t]{4}{*}{ Grave (13) } & 1 & 2 & 3 & 4 & 5 & 6 & 7 & 8 & 9 & 10 \\
\hline & 117,367 & $-46,275$ & 72,302 & 20,425 & 119,406 & $-124,206$ & 18,110 & $-45,917$ & 203,608 & 76,458 \\
\hline & 11 & 12 & 13 & & & & & & & \\
\hline & $-1,863$ & $-62,559$ & 73,335 & & & & & & & \\
\hline \multirow[t]{4}{*}{ Muito Grave (19) } & 1 & 2 & 3 & 4 & 5 & 6 & 7 & 8 & 9 & 10 \\
\hline & 276,781 & 185,973 & 263,064 & 180,629 & 239,895 & 325,815 & 74,348 & 417,160 & 38,533 & 158,300 \\
\hline & 11 & 12 & 13 & 14 & 15 & 16 & 17 & 18 & 19 & \\
\hline & $-84,854$ & 80,864 & 142,984 & $-152,848$ & $-2,703$ & 7,826 & 259,018 & 99,306 & $-91,520$ & \\
\hline
\end{tabular}

Fonte: Autor

Tabela 9 - Diferenças entre áreas de indivíduo normais e DPOC - filtro com frequência de corte 60-3Kz

\begin{tabular}{|c|c|c|c|c|c|c|c|c|c|c|}
\hline \multicolumn{11}{|c|}{ Gravidade DPOC ( $\mathrm{N}^{\circ}$ 51) } \\
\hline \multirow[t]{2}{*}{ Leve (4) } & 1 & 2 & 3 & 4 & & & & & & \\
\hline & 176,895 & 221,574 & $-88,877$ & 1,270 & & & & & & \\
\hline \multirow[t]{4}{*}{ Moderado (15) } & 1 & 2 & 3 & 4 & 5 & 6 & 7 & 8 & 9 & 10 \\
\hline & 341,617 & 95,481 & 13,647 & 190,869 & 122,175 & 98,863 & 130,444 & 98,158 & 130,718 & 263,386 \\
\hline & 11 & 12 & 13 & 14 & 15 & & & & & \\
\hline & 17,990 & $-52,0733$ & 44,194 & $-33,499$ & 20,202 & & & & & \\
\hline \multirow[t]{4}{*}{ Grave (13) } & 1 & 2 & 3 & 4 & 5 & 6 & 7 & 8 & 9 & 10 \\
\hline & 146,403 & $-36,998$ & 66,086 & 35,488 & 127,638 & $-113,188$ & 20,859 & $-56,431$ & 205,200 & 91,450 \\
\hline & 11 & 12 & 13 & & & & & & & \\
\hline & 19,353 & $-63,675$ & 73,250 & & & & & & & \\
\hline \multirow[t]{4}{*}{ Muito Grave (19) } & 1 & 2 & 3 & 4 & 5 & 6 & 7 & 8 & 9 & 10 \\
\hline & 272,335 & 186,246 & 250,877 & 166,990 & 231,893 & 334,850 & 86,782 & 404,225 & 65,074 & 145,427 \\
\hline & 11 & 12 & 13 & 14 & 15 & 16 & 17 & 18 & 19 & \\
\hline & $-87,076$ & 88,409 & 137,702 & $-150,974$ & 2,968 & 11,126 & 268,261 & 133,194 & $-85,755$ & \\
\hline
\end{tabular}

Fonte: Autor 
Tabela 11 - Diferenças entre áreas de indivíduo normais e DPOC - filtro com frequência de corte 60-6Kz

\begin{tabular}{|c|c|c|c|c|c|c|c|c|c|c|}
\hline \multirow{2}{*}{$\begin{array}{l}\text { Gravidade DPOC }\left(\mathrm{N}^{\circ} 51\right) \\
\text { Leve (4) }\end{array}$} & \multicolumn{10}{|c|}{ Teste $60-6 \mathrm{KHz}$} \\
\hline & 1 & 2 & 3 & 4 & & & & & & \\
\hline & 177,530 & 222,458 & $-87,335$ & $-4,143$ & & & & & & \\
\hline \multirow[t]{4}{*}{ Moderado (15) } & 1 & 2 & 3 & 4 & 5 & 6 & 7 & 8 & 9 & 10 \\
\hline & 336,732 & 106,719 & 10,985 & 191,191 & 122,277 & 92,980 & 123,250 & 98,990 & 126,680 & 267,505 \\
\hline & 11 & 12 & 13 & 14 & 15 & & & & & \\
\hline & 15,871 & $-208,153$ & 44,296 & $-195,004$ & 24,158 & & & & & \\
\hline \multirow[t]{4}{*}{ Grave (13) } & 1 & 2 & 3 & 4 & 5 & 6 & 7 & 8 & 9 & 10 \\
\hline & 147,850 & $-31,795$ & 64,454 & 41,320 & 128,595 & $-110,840$ & 19,839 & $-56,992$ & 207,647 & 92,753 \\
\hline & 11 & 12 & 13 & & & & & & & \\
\hline & 24,685 & $-62,112$ & 72,219 & & & & & & & \\
\hline \multirow[t]{4}{*}{ Muito Grave (19) } & 1 & 2 & 3 & 4 & 5 & 6 & 7 & 8 & 9 & 10 \\
\hline & 268,675 & 185,370 & 244,141 & 159,607 & 231,060 & 335,272 & 89,131 & 402,019 & 69,513 & 141,743 \\
\hline & 11 & 12 & 13 & 14 & 15 & 16 & 17 & 18 & 19 & \\
\hline & $-85,584$ & 89,698 & 137,026 & $-154,552$ & 7,081 & 8,309 & 274,724 & 139,971 & $-85,073$ & \\
\hline
\end{tabular}

Fonte: Autor 2

Nas figuras 4.9, 4.10 e 4.11, são apresentados alguns resultados da tabela 7, para os grupos de gravidade DPOC leve, moderado, grave e muito grave. No eixo vertical a variância em decibéis $(\mathrm{dB})$, e no eixo horizontal as frequências em Hertz $(\mathrm{Hz})$.

Na tabela 10 são apresentados os índices obtidos do indicador verdadeiro positivo, correspondente ao número de acertos do tipo de gravidade. Os valores apresentados na tabela 10 foram obtidos através da relação do número de acertos pelo total do tamanho da amostra, equação 4.2. Os resultados apresentam que sem a detecção de sons respiratórios anormais, o método obteve $100 \%$ de acerto para os testes realizados. Entretanto se considerarmos os sons respiratórios anormais, estes índices caem para: 75\% para DPOC leve, 86,6 \% para DPOC moderado, 69,2\% para DPOC grave e $84,5 \%$ para DPOC muito grave.

$$
A=\frac{V P}{V P+F N} \times 100
$$

Onde: VP verdadeiro positivo (valores positivos) número de acertos para pacientes com DPOC e FN falso negativo (valores negativos) número de erros para pacientes com DPOC. 
Tabela 12 - Percentuais de Acerto Método da Densidade Espectral

\begin{tabular}{|c|c|c|c|c|}
\hline & \multicolumn{4}{|c|}{ Pacientes DPOC } \\
\hline & Leve (LV) & Moderado (MD) & Grave (GR) & Muito Grave (MG) \\
\hline Verdadeiros Positivos (sem sons respiratórios anormais) & $100 \%$ & $100 \%$ & $100 \%$ & $100 \%$ \\
\hline Verdadeiros Positivos (com bronquite crônica) & $75 \%$ & $86,60 \%$ & $69,20 \%$ & $84,50 \%$ \\
\hline
\end{tabular}

Fonte: Autor

Figura 4.4 - Gráfico1 Áreas Indivíduos Saudáveis e Gravidade DPOC

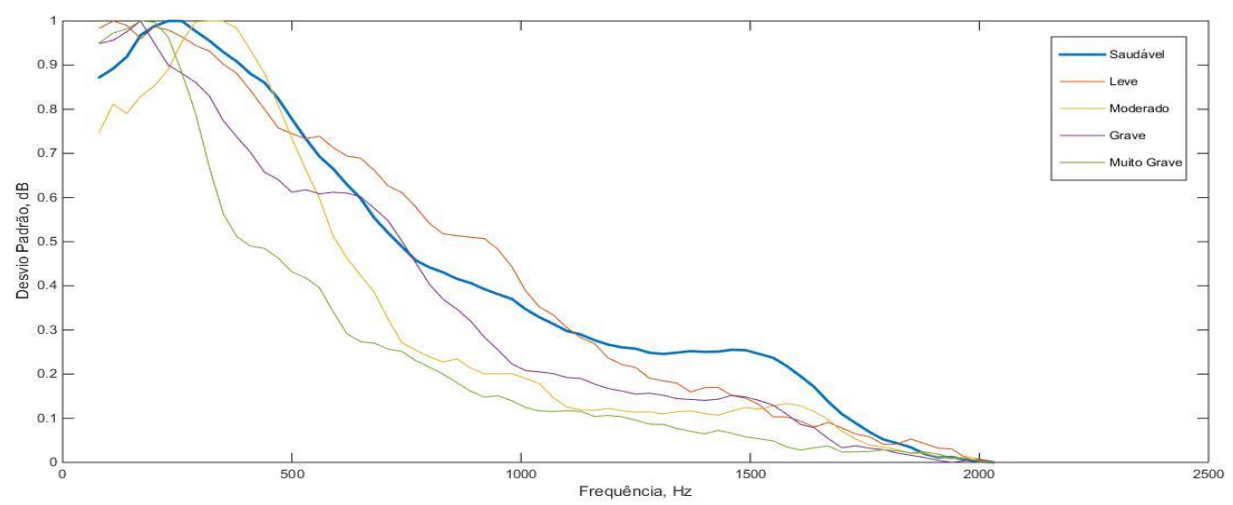

Fonte: Autor

Figura 4.5 - Gráfico2 Áreas Indivíduos Saudáveis e Gravidade DPOC

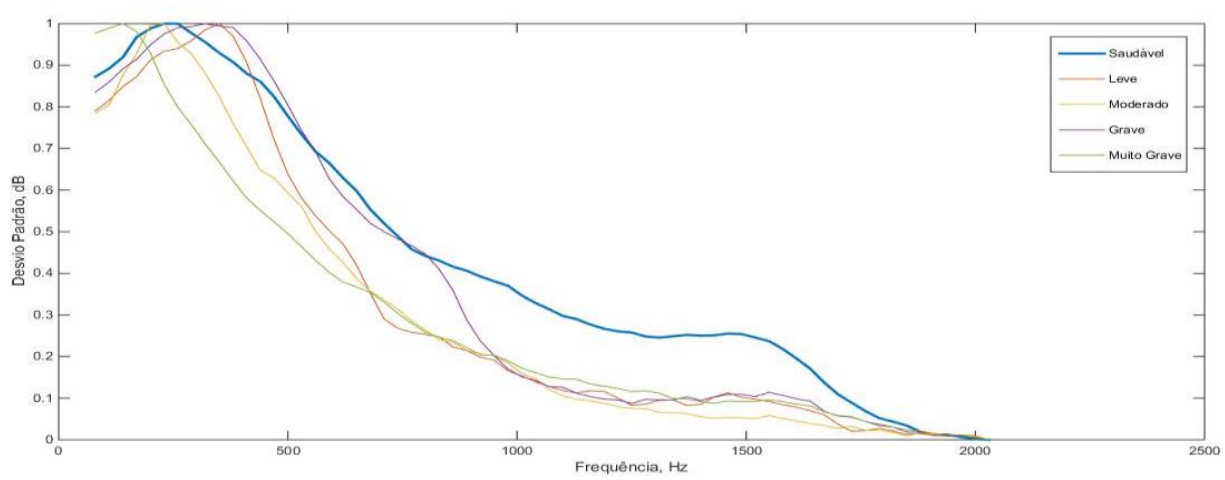

Fonte: Autor 
Figura 4.6 - Gráfico3 Áreas Indivíduos Saudáveis e Gravidade DPOC

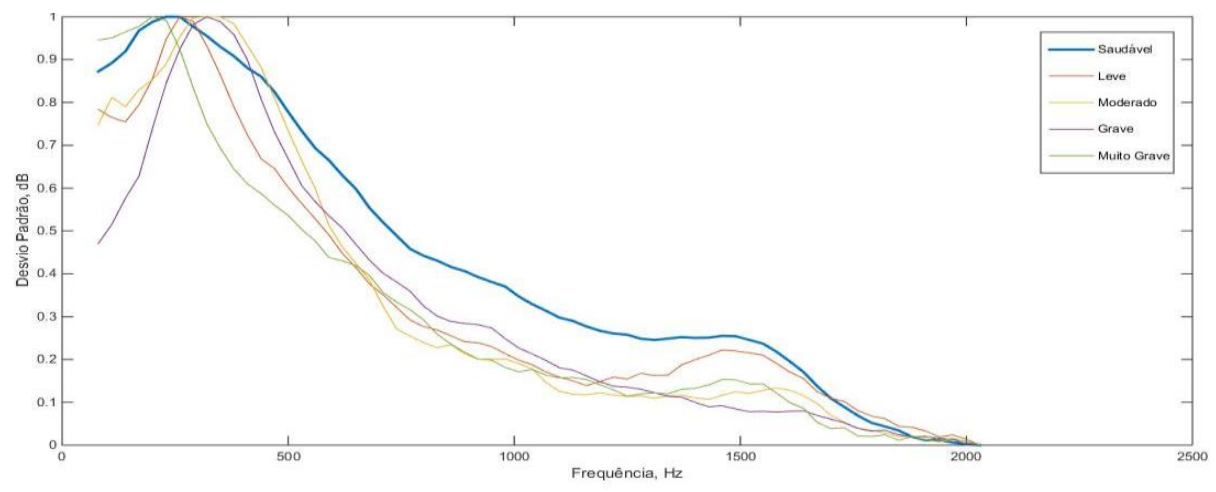

Fonte: Autor 


\section{CAPÍTULO 5}

\section{DISCUSSÃO}

Por se tratar de uma doença considerada a $4^{\mathrm{a}}$ causa de morte mundial, com propensão a ser tornar a $3^{\text {a }}$ causa de morte até 2020 (ALAT, 2014), o diagnóstico da DPOC é determinante para que o tratamento seja iniciado o quanto antes, para minimizar os efeitos na qualidade de vida, aliviar os sintomas e principalmente reduzir exacerbações e mortalidade (GOLD, 2017).

A intensidade e as modalidades de tratamento estão diretamente relacionadas com avaliação da gravidade da doença. Estudos apoiam que a análise acústica computadorizada de sons respiratórios, pode auxiliar no processo de diagnóstico na DPOC (JÁCOME, 2015), (POREVA, 2015). Desta forma buscou-se, neste estudo, determinar se a gravidade da DPOC pode estar associada área do gráfico da variância da intensidade sonora em função da frequência dos sons respiratórios em pacientes com DPOC, com finalidade de oferecer novas linhas de investigação no auxílio ao diagnóstico.

As características demográficas deste estudo confirmam que $98 \%$ da causa de DPOC é o tabagismo, dentre os 51 participantes da pesquisa, há apenas um caso de não fumante, os demais, são ex-fumantes e outros ainda permanecem fumando. Outra característica importante notada é que a quantidade de pacientes com gravidade leve é muito inferior à quantidade de pacientes de outras gravidades (moderado, grave e muito grave). Essa característica confirma os resultados da pesquisa realizada pelo Projeto Platino, publicada pela ALAT, que apresentou índice de $89 \%$ de subdiagnóstico. A justificativa é que na maioria dos casos os pacientes com DPOC inicial são assintomáticos, ou têm poucos sintomas e, portanto, não iniciam o tratamento precocemente às manifestações mais graves.

Os sons respiratórios de pacientes com DPOC podem apresentar sons respiratórios anormais, figura 4.3, pois estão relacionados com a obstrução do fluxo aéreo, que por sua vez estão associados à bronquite crônica, esses resultados são compatíveis com pesquisas similares (BOHADANA, 2014) (SOVIJARVI, 2000a).

O resultado das diferenças entre as áreas das variâncias das intensidades sonoras dos pacientes, tabela 6, pela média total das áreas das variâncias das intensidades sonoras de indivíduos saudáveis tabela 7, evidencia que é possível, porém com algumas limitações, 
determinar a gravidade da DPOC através do cálculo das diferenças das áreas das variâncias das intensidades sonoras. Observamos que na maioria dos casos, essas medidas tendem a serem maiores em indivíduos saudáveis do que em pacientes com DPOC. Desta forma credita-se que à medida que a DPOC se agrava a área da variância das intensidades sonora em função da frequência tende a ficar mais estreita, devido à concentração da energia sonora tender as baixas frequências. Na figura 5.1, é apresentado um comparativo entre as áreas, do som respiratório saudável, média das áreas calculada de todos os indivíduos saudáveis, com um paciente com DPOC muito grave, sem a presença de sons respiratórios anormais. Nota-se que a variação das intensidades sonoras do paciente em relação ao indivíduo saudável, se concentra perto de $250 \mathrm{~Hz}$ com declínio bem acentuado até próximo de $1 \mathrm{KHz}$. Em contrapartida a variação das intensidades sonoras do saudável se concentra entre 400 e $500 \mathrm{~Hz}$, com declínio suave até $1,5 \mathrm{KHz}$ (ondulação). Esta diferença de área pode estar associada a retenção de ar nos pulmões, portanto menor fluxo aéreo.

Figura 5.1 - Comparativo Saudável X DPOC Muito Grave

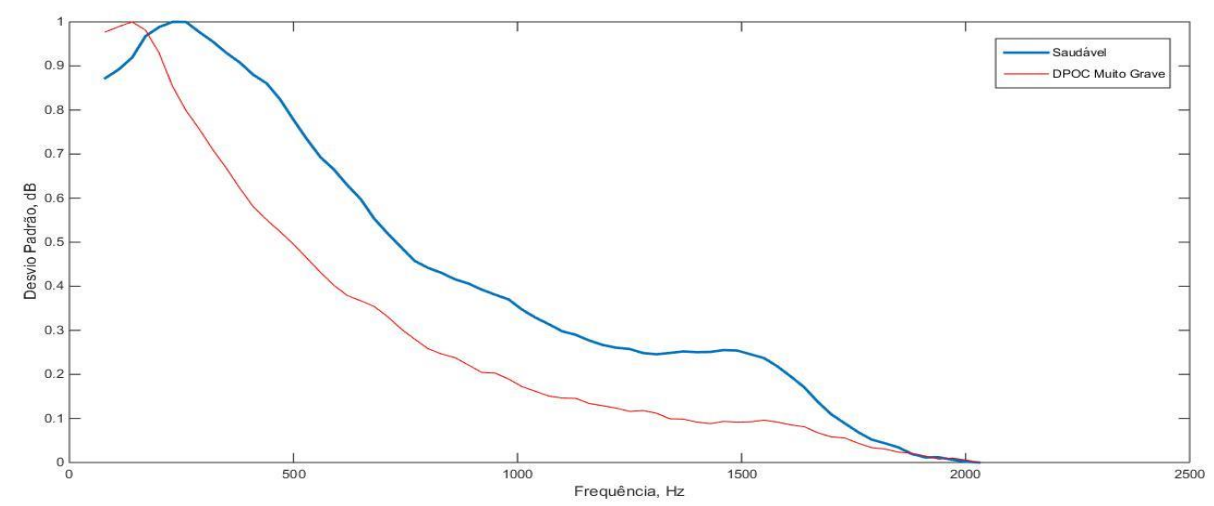

Fonte: Autor

Constata-se que a gravidade da DPOC está correlacionada com a área das variâncias das intensidades sonora, no entanto, ao correlacionarmos os resultados dos indivíduos saudáveis e pacientes com DPOC, observou-se também que em alguns pacientes a diferença das áreas apresentaram valores negativos. Na tabela 7 nota-se que estes valores negativos, estão presentes em apenas um paciente dos 4 com DPOC leve, 2 pacientes dos 15 com DPOC moderado, 4 pacientes dos 13 DPOC grave e 3 pacientes dos 19 com DPOC muito grave. Na DPOC os sintomas estão relacionados à bronquite crônica e com o enfisema, que podem ocorrer separadamente ou em associação. Esses valores negativos podem estar relacionados à concomitância habitual de bronquite crônica e enfisema pulmonar. Para estes casos uma reavaliação da ficha dos pacientes foi realizada por um médico pneumologista e foram também analisados os áudios, que constatou a predominância de bronquite crônica na maioria dos casos. 
Ilustraremos a seguir alguns destes casos, em que o cálculo das diferenças entre as áreas apresentou valores negativos. Na figura 5.2, um comparativo entre som saudável e paciente com DPOC leve é apresentado. Nota-se no gráfico que as áreas das variâncias das intensidades sonoras se diferenciam significativamente entre $1 \mathrm{KHz}$ e $2 \mathrm{KHz}$. Este comportamento se justifica se observarmos o espectrograma da figura 5.3, representação do som respiratório analisado, há um prolongamento da intensidade sonora até próximo a $2 \mathrm{KHz}$, e nos instantes entre 3 e 4 s há um aumento da intensidade devido a presença de ruídos na respiração. Na figura 5.4 é apresentado um comparativo entre som saudável e dois sons de pacientes com DPOC moderado. Nota-se que as áreas das intensidades sonoras são próximas a área do som saudável $(-52,073$ e -33,499), e que pelo mesmo motivo do caso anterior ambos apresentam ondulação perto de 1,5KHz. No primeiro caso (linha vermelha), ondulações são notadas no início da curva, essas variações podem ser percebidas no espectrograma deste sinal na figura 5.5. Na faixa de frequências entre 0 a $250 \mathrm{~Hz}$ há uma variação na intensidade de $0 \mathrm{~dB}$ à $-30 \mathrm{~dB}$, e nas faixas acima das variações mais intensas o som se propaga até $2 \mathrm{KHz}$ onde está bem atenuado. Este comportamento justifica as fortes ondulações que ocorrem entre 0 e $250 \mathrm{KHz}$ e as tênues ondulações da curva até $1,5 \mathrm{KHz}$ onde está um pouco mais acentuada.

Figura 5.2 - Densidade Espectral Saudável X DPOC Leve

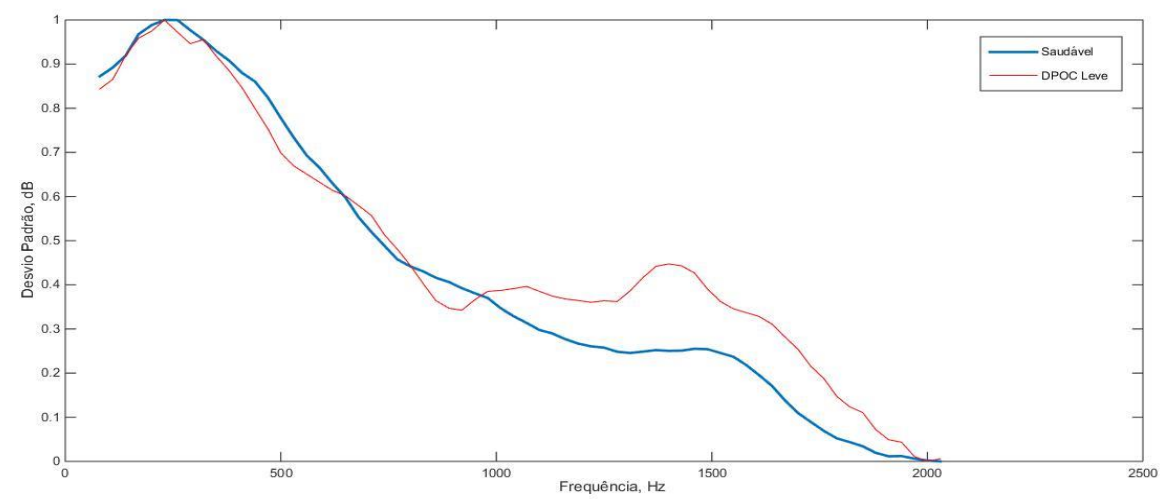

Fonte: Autor 
Figura 5.3 - Espectrograma DPOC Leve com ruídos respiratórios

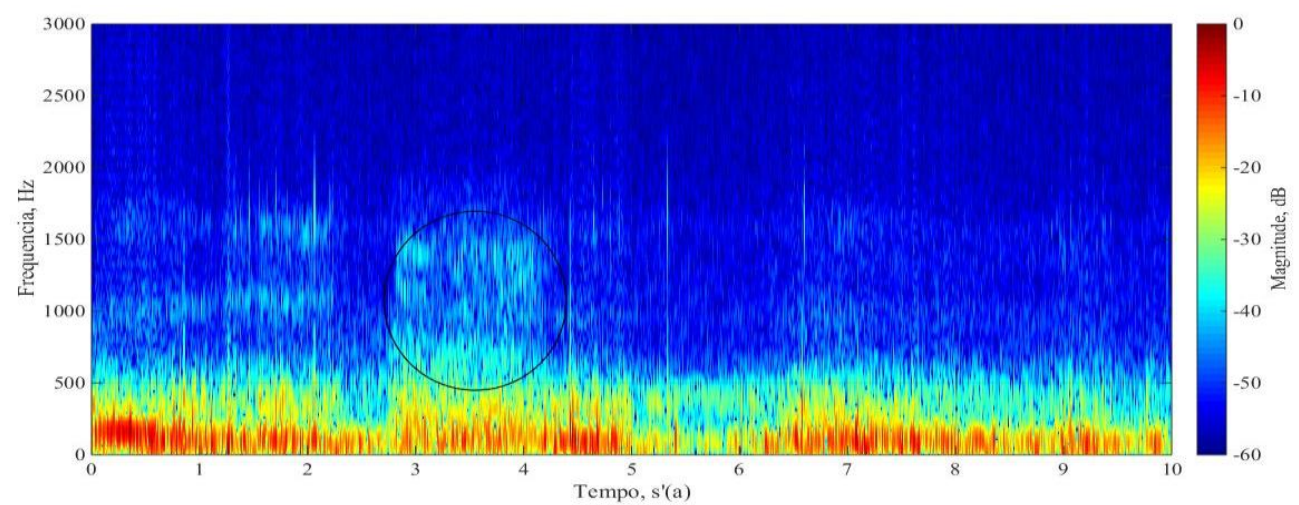

Fonte: Autor

Figura 5.3 - Densidade Espectral Saudável X DPOC Moderado

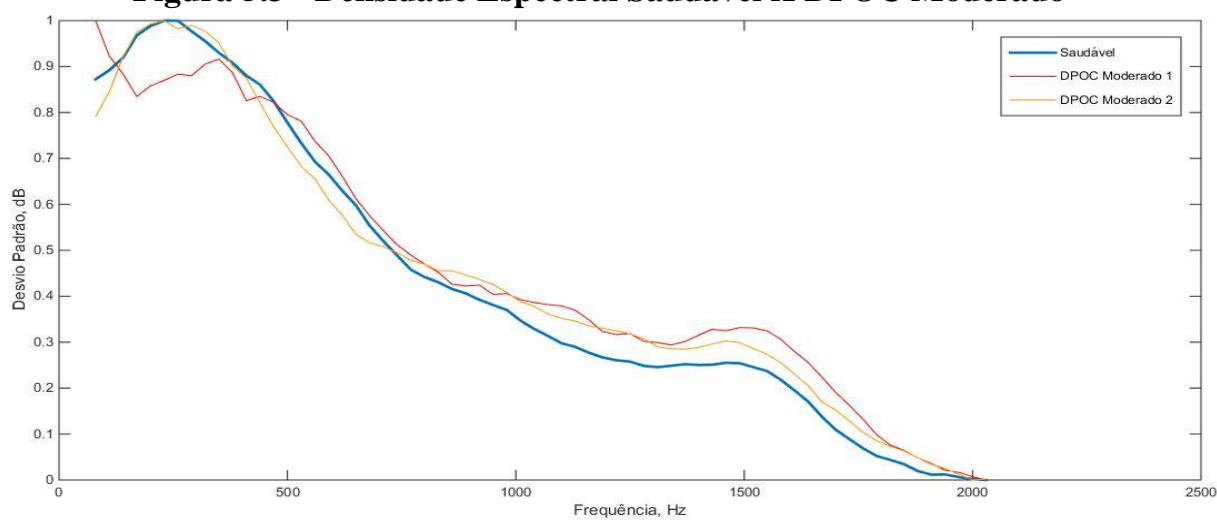

Fonte: Autor

Figura 5.5 - Espectrograma DPOC Moderado com ruído

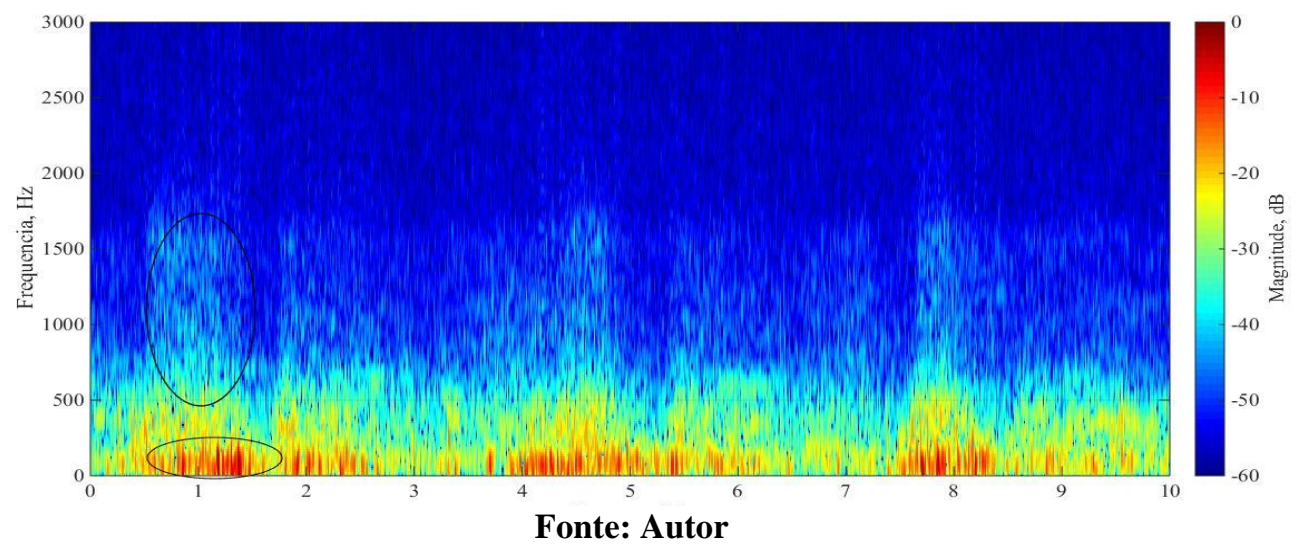


Na figura 5.6 é apresentado gráfico da variância das intensidades sonoras em um paciente com DPOC grave e na figura 5.7 o espectrograma deste sinal. Notam-se ondulações mais marcadas em toda a extensão da curva. Observa-se através do espectrograma (figura 5.7) que as discrepâncias das intensidades sonoras ocorrem em todas as faixas de frequências, diferentemente dos casos anteriores, em que as intensidades são mais homogêneas. Uma ondulação com pico em $1,5 \mathrm{~Hz}$ é percebida (figura 5.6) e justificável se analisarmos esta faixa de frequência pelo espectrograma onde as intensidades variam de $-60 \mathrm{~dB}$ a $-40 \mathrm{~dB}$.

Figura 5.4 - Densidade Espectral Saudável X DPOC Grave

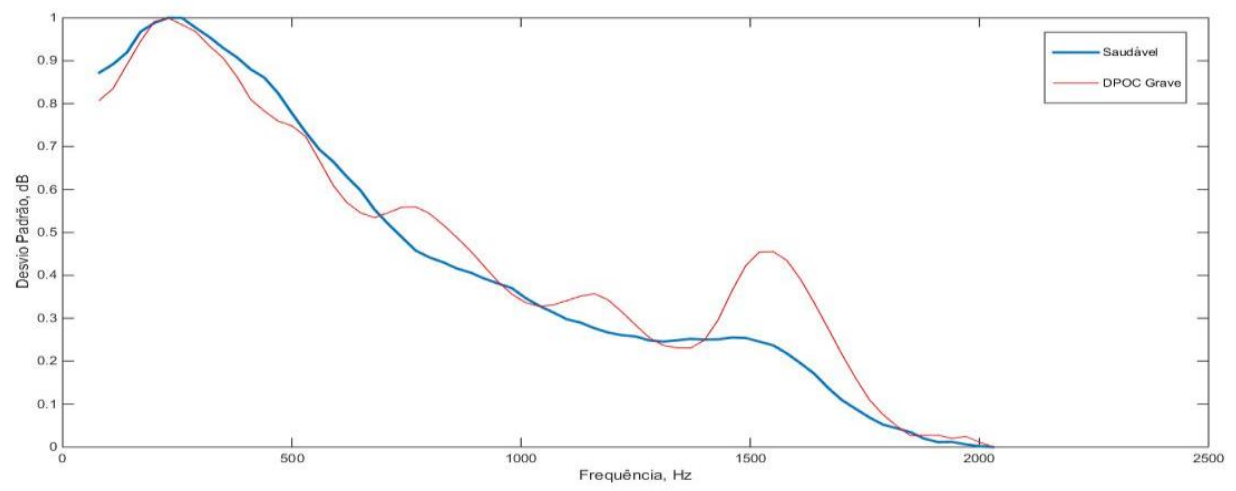

Fonte: Autor

Figura 5.5 - Espectrograma DPOC Grave com ruído

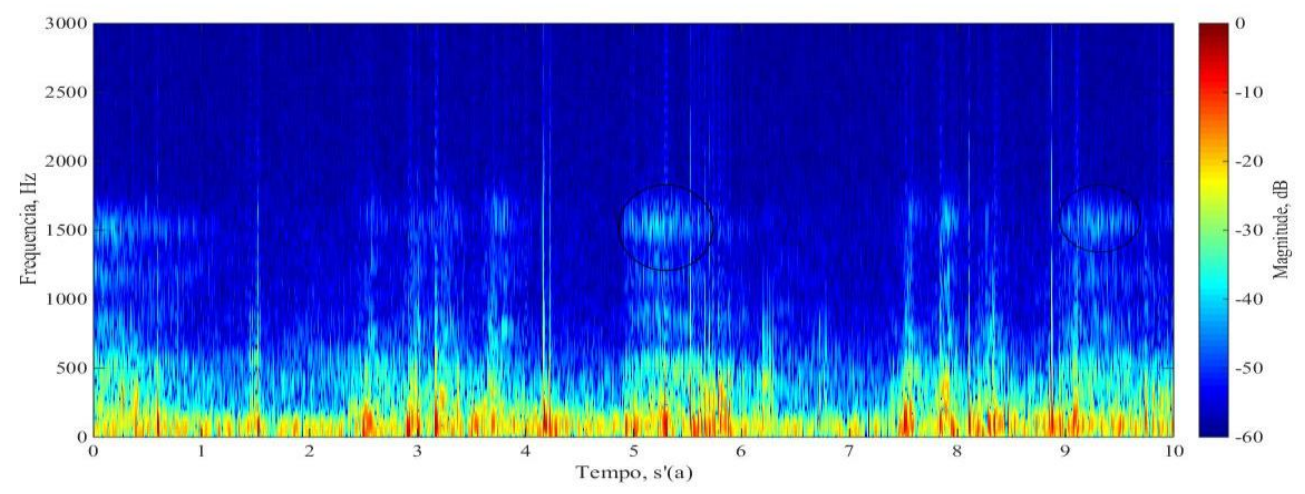

Fonte: Autor 
Na figura 5.8 é apresentado o gráfico da área da intensidade sonora de um paciente com DPOC muito grave comparado a indivíduo saudável. Analisarmos o espectrograma (figura 5.9) e comprando com a figura 5.8 nota-se uma intensidade alta quase que constante de $250 \mathrm{~Hz}$ à 300Hz.Observa-se também que o declínio da curva é menos acentuado em relação aos demais casos, isso porque as intensidades sonoras se mantêm por toda faixa temporal em todo o espectro de frequências de forma homogênea.

Figura 5.8 - Densidade Espectral Saudável X DPOC muito grave

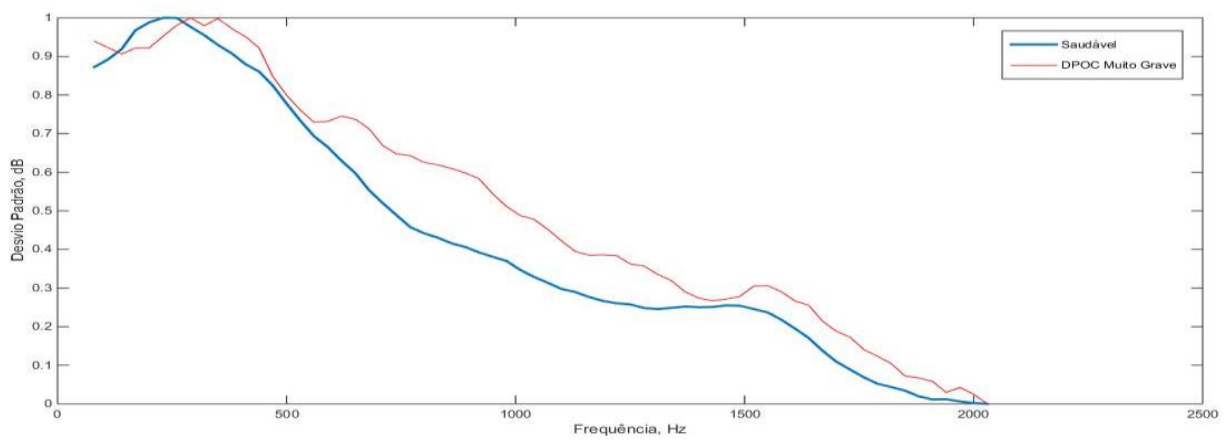

Fonte: Autor

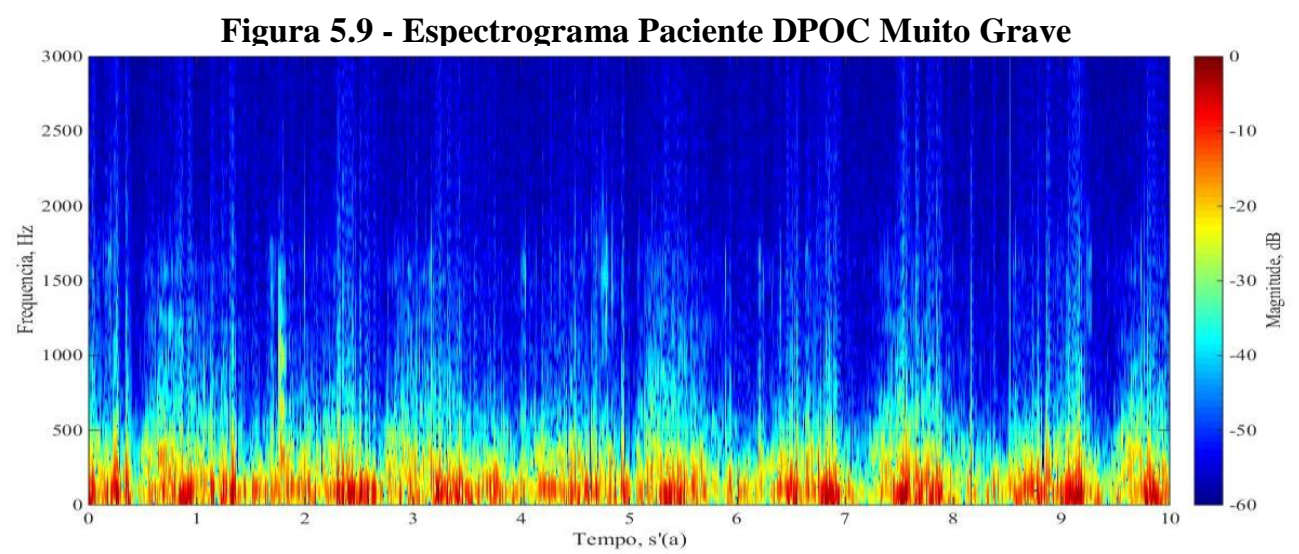

Fonte: Autor

A predominância da bronquite crônica em casos mais graves de obstrução desde que haja fluxo respiratório aumenta a área da variância das intensidades sonoras em função de suas frequências, devido à movimentação do resíduo sólido contido nos brônquios, responsável por gerar sons respiratórios anormais.

Considera-se que os indicadores de verdadeiros positivos de $75 \%$ para DPOC leve, 86,6 \% para DPOC Moderado, 69,2\% para DPOC grave e 84,5\% para DPOC muito grave, sejam 
resultados satisfatórios, considerando às limitações do tamanho da amostra e por se tratar de um estudo inicial com finalidade de oferecer novas linhas de investigação.

Julga-se que o método poderá ser mais eficiente, se outros fatores forem incluídos aos critérios de investigação. Pacientes ambulatoriais não são considerados pacientes estáveis, alguns estavam se recuperando de doenças como gripe, pneumonia e de exacerbações. Logo há de se considerar que a garantia do estado estável dos pacientes poderá oferecer resultados mais efetivos, posto que o método proposto tem como objetivo analisar a área da variância das intensidades dos sons respiratórios normais, para este estudo os sons respiratórios anormais são considerados artefatos incluídos na ausculta como os sons do coração e dos músculos. Outras considerações estão relacionadas à amostra dos pacientes saudáveis, uma amostra superior e a possibilidade de analise baseada no gênero também poderá trazer melhores resultados, uma vez que as intensidades sonoras em homens e mulheres adultos podem ser diferentes, devido a estrutura física entre os gêneros. A média da área da intensidade sonora calculada, para cada gênero de indivíduos saudáveis, deste estudo foi de 870,471 para mulheres e 760,654 para os homens, sendo que o cálculo utilizado na diferença obteve valor de 833,755. 


\section{CAPÍTULO 6}

\section{CONCLUSÃO}

Neste estudo foram apresentados os resultados da análise para determinar se a DPOC poderá ser estimada pelo cálculo da área da variância das intensidades sonoras dos sons respiratórios de pacientes diagnosticados com DPOC leve, moderado, grave e muito grave.

Neste contexto, para atender ao objetivo, um método foi proposto e testado baseado na combinação de técnicas de filtragem, TFTC interpolação e análise estatística, cálculo da média e desvio padrão.

Diante da aquisição de sons respiratórios, foi possível obter um banco de dados composto de 51 sons de pacientes com DPOC com as seguintes gravidades: 4 leves, 15 moderados, 13 graves e 19 muito graves. Os dados serão disponíbilzados pelo autor através de solicitação via contato eletrônico (meire.vidal@usp.br).

O critério quantitativo para determinar a gravidade da DPOC, proposto nesta pesquisa, foi a diferença entre a média das áreas das variâncias das intensidades sonoras de indivíduos saudáveis pela área das variâncias das intensidades sonoras de pacientes com DPOC.

Conclui-se que é possível estimar a gravidade de DPOC, quando não há presença de sons respiratórios anormais, através da área da variância das intensidades sonoras em função da frequência, isto é, área sob o gráfico da variação das intensidades sonora pela frequência, no intervalo de 60 a $3 \mathrm{KHz}$ com as variâncias normalizadas de tal de forma que seu valor máximo vale 1 . 


\section{CAPÍTULO 7}

\section{TRABALHOS FUTUROS}

Para trabalhos futuros propõe-se melhorar o método para que independente da presença de sons respiratórios anormais possa ser possível estimar a gravidade de DPOC, para tanto algumas metas e procedimentos serão adotados:

- Técnicas mais sofisticadas como transformada de wavelets, na caracterização dos sons.

- Melhorar a qualidade de áudio do banco de dados através de filtros projetados para remoção de ruídos ambientais.

- Testar o método com o som traqueal, o som traqueal tem intensidades mais altas do que os sons extraídos na área do tórax.

- Aumentar o número da amostra de indivíduos saudáveis e testar com uma amostra maior e por gênero. 


\section{REFERÊNCIAS}

ALAT, A. L.-A. D. T. https://www.alatorax.org/epoc. https: //www.alatorax.org, 2014. Disponivel em: <https://www.alatorax.org/epoc/guia-epoc-alat/guia-latinoamericanade-epoc-2014-basada-en-evidencia-latinepoc-2014>. Acesso em: 15 novembro 2016.

BOHADANA, A. . I. G. . \&. K. S. S. Fundamentals of lung auscultation. New England Journal of Medicine, v. 370, n. 8, p. 744-751, 2014.

BOHADANA, A. B. Acustica Pulomnar para o clínico. São Paulo: Savier, 1989.

CHARBONNEAU, G. E. A. Basic techniques for respiratory sound analysis.

European Respiratory Review, v. 10, n. 77, p. 625-635, 2000.

CHEETHAM, B. M. G. E. A. Digitization of data for respiratory sound recordings. European Respiratory Review, v. 10, n. 77, p. 621--624, 2000.

EARIS, J. E.; CHEETHAM, B. M. G. Current methods used for computerized respiratory sound analysis.. European Respiratory Review, v. 10, n. 77, p. 586-590, 2000.

FIZ, J. A. E. A. Detection of wheezing during maximal forced exhalation in patients with obstructed airways. Chest Journal, v. 122, n. 1, p. 186-191, 2002.

GLOBAL Initiative for Chronic Obstructive Lung Disease GOLD. www.goldcopd.org, 27 novembro 2016. Disponivel em: <http://goldcopd.org/gold-2017-global-strategydiagnosis-management-prevention-copd/>. Acesso em: 27 novembro 2016.

GOLD. Global Initiative for Chronic Obstructive Lung Disease GOLD.

www.goldcopd.org, 27 novembro 2017. Disponivel em:

<http://www.goldcopd.org/uploads/users/files/GOLD_Report_2015_Apr2.pdf>. Acesso em: 27 novembro 2016.

IÇER, S.; GENGEÇ, Ş. Classification and analysis of non-stationary characteristics of crackle and rhonchus lung adventitious sounds. Digital Signal Processing, v. 28, p. 18-27, 2014.

JÁCOME, C. E. M. A. Computerized respiratory sounds in patients with COPD: A systematic review. COPD: Journal of Chronic Obstructive Pulmonary Disease, v. 12, n. 1, p. 104--112, 2015.

JÁCOME, C.; MARQUES, A. Computerized Respiratory Sounds Are a Reliable Marker in Subjects With COPD. American Association for Respiratory Care, v. 60, n. 9, p. 1264--1275, maio 2015.

MENON, K. A. U.; DRISHYA, A.; NADARAJAN, D. Monitoring and Analysis of Lung sounds for the Diagnosis of Lung Abnormalities. IEEE -Wireless and Optical

Communications Networks, p. 1-4, 2014. 
MORILLO, D. S. E. A. Computerized analysis of respiratory sounds during COPD exacerbations. Computers in biology and medicine, v. 43, n. 7, p. 914-921, 2013.

MORILLO, D. S.; JIMÉNEZ, A. L.; MORENO, S. A. Computer-aided diagnosis of pneumonia in patients with chronic obstructive pulmonary disease. Journal of the American Medical Informatics Association, v. 20, n. 1, p. 111-117, 2013.

NALON, J. A. Introdução ao Processamento Digital de Sinais. $1^{\text {a }}$ edição. ed. Rio de Janeiro: LTC, 2009.

OPPENHEIM, A. V. Sinais e Sistemas. $2^{a}$ edição. ed. [S.I.]: Pearson, 2010.

POREVA, A. . K. Y. . M. A. . \&. M. A. Detection of COPD's diagnostic signs based on polyspectral lung sounds analysis of respiratory phases. Electronics and Nanotechnology (ELNANO), p. 351-355, 2015.

REICHERT, S. . G. R. . B. C. . \&. A. E. Analysis of Respiratory Sounds: State of the Art. Clinical Medicine Insights. Circulatory, Respiratory and Pulmonary Medicine, v. 2, p. 45-58, 2008.

ROSSI, M. E. A. Environmental and subject conditions and breathing manoeuvres for respiratory sound recording. European Respiratory Review, v. 10, n. 77, p. 611-615, 2000.

SOVIJARVI, A. R. A. E. A Definition of terms for applications of respiratory sounds. European Respiratory Review, v. 10, n. 77, p. 597--610, 2000.

SOVIJARVI, A. R. A. E. A. Characteristics of breath sounds and adventitious respiratory sounds. European Respiratory Review, v. 10, n. 77, p. 591-596, 2000.

TAPLIDOU, S. A.; HADJILEONTIADIS, L. J. Wheeze detection based on timefrequency analysis of breath sounds. Computers in biology and medicine, v. 37, n. 8, p. 1073-1083, 2007.

TISIOLOGIA, S. B. D. P. E. http://sbpt.org.br/consensos-diretrizes-nacionais/, 23 ago. 2016. Disponivel em:

<http://bkpsbpt.org.br/arquivos/COM_DPOC/Diretrizes_DPOC_2016_completa_FINA L.pdf>. Acesso em: 11 dez. 2016.

TISIOLOGIA, S. P. D. P. E. http://pneumologiapaulista.org.br/. http:

//pneumologiapaulista.org.br/, 2016. Disponivel em:

<http://pneumologiapaulista.org.br/wp-content/uploads/2016/11/PP31102016.pdf>.

Acesso em: 12 nov. 2016.

VANNUCCINI, L. E. A. Capturing and preprocessing of respiratory sounds.

European Respiratory Review, v. 10, n. 77, p. 616--620, 2000.

WEST, J. B. Fisiologia Respiratória: Princípios básicos. 8ª ed. [S.I.]: Artmed, 2010. Cap. 2, p. 33.

WHO, O. W. H. http://www.who.int/mediacentre/factsheets/fs310/en/index1.html, 2012. Disponivel em:

<http://www.who.int/mediacentre/factsheets/fs310/en/index1.html>. Acesso em: 28 nov. 2016. 
YAMASHITA, M.; MATSUNAGA, S.; MIYAHARA, S. Discrimination between healthy subjects and patients with pulmonary emphysema by detection of abnormal respiration. IEEE International Conference on Acoustics, Speech and Signal Processing (ICASSP)., p. 693-696, maio 2011. 


\section{APÊNDICE A - ESPECTROGRAMAS DOS SINAIS ACÚSTICOS}

Figura A.1 - Espectrograma - Indivíduos Saudáveis (1)

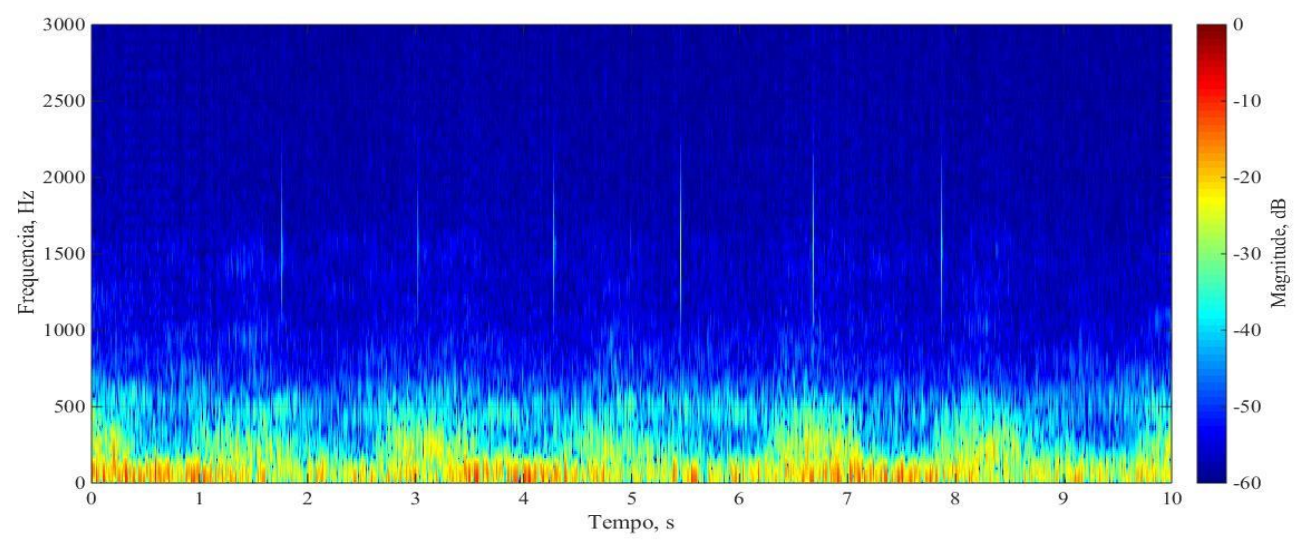

Fonte: Autor

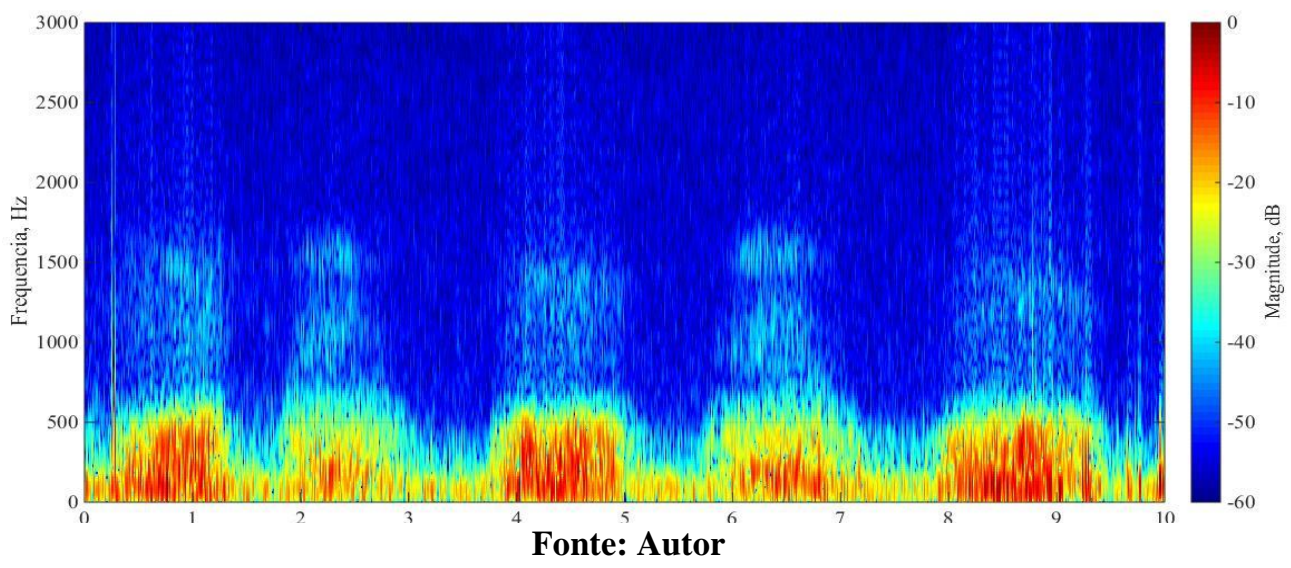

Figura A.3 - Espectrograma - Indivíduos Saudáveis (3)

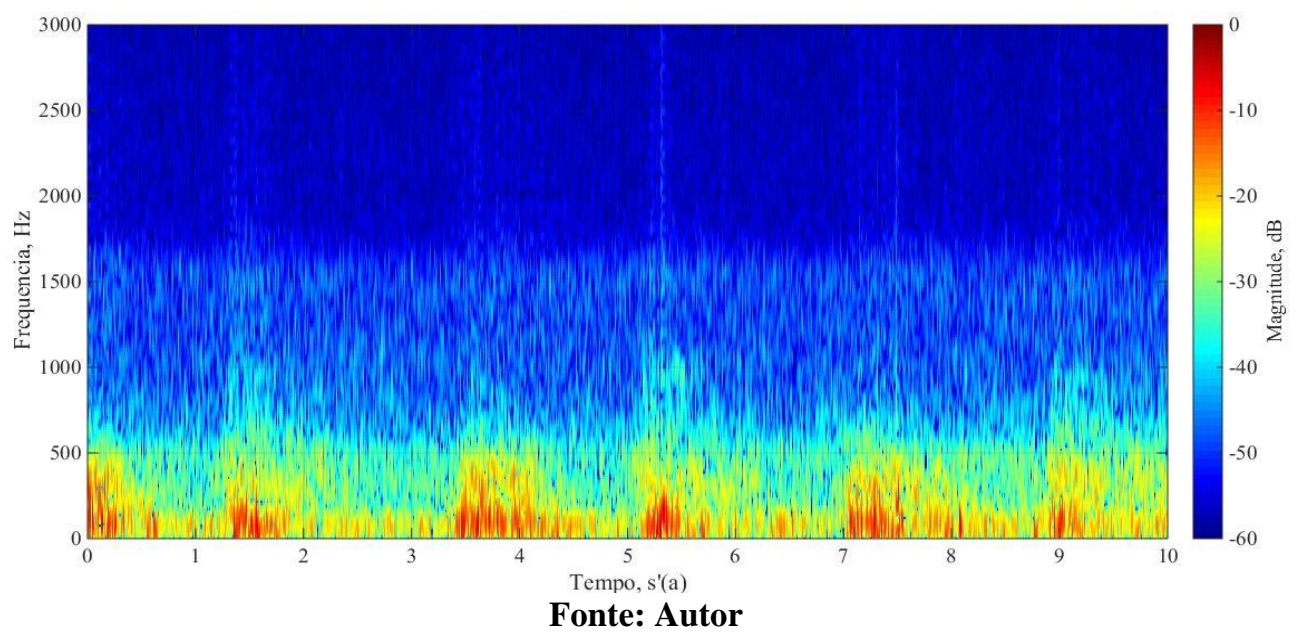


Figura A.4 - Espectrograma - Indivíduos Saudáveis (4)
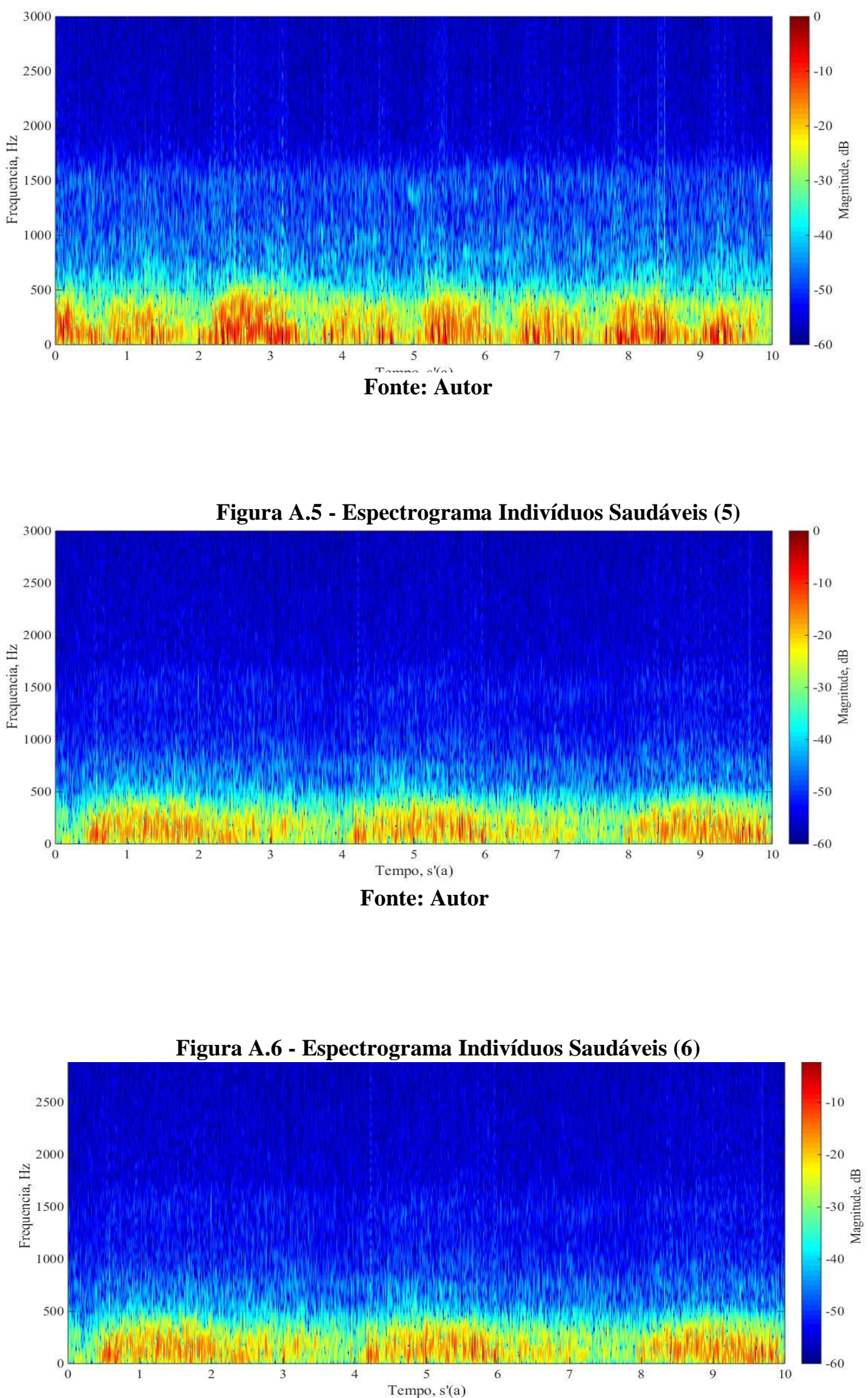

Fonte: Autor 
Figura A.7 - Espectrograma Indivíduos Saudáveis (7)

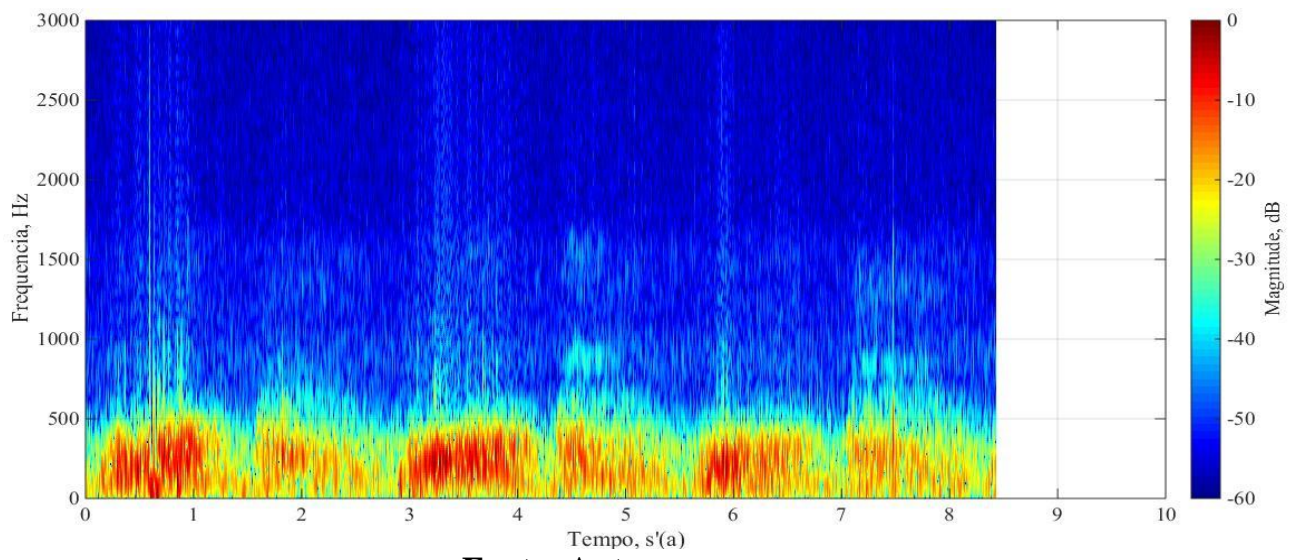

Fonte: Autor

Figura A.8 - Espectrograma - DPOC Leve (1)

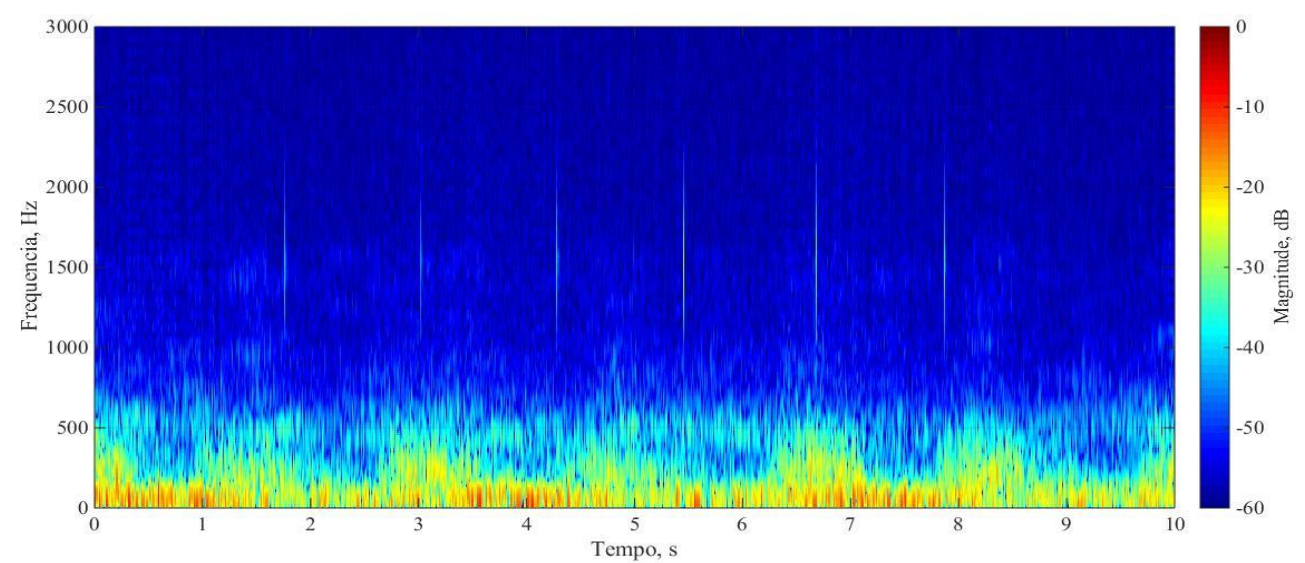

Fonte: Autor

Figura A.9 - Espectrograma - DPOC Leve (2)

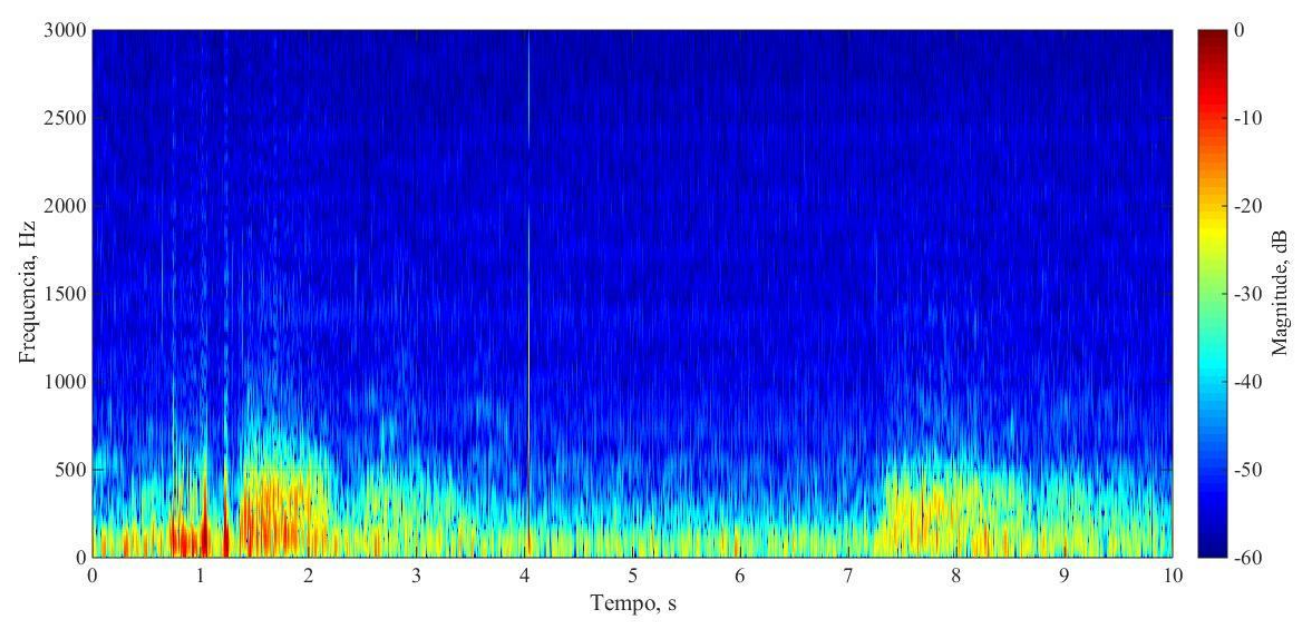

Fonte: Autor 
Figura A.10 - Espectrograma - DPOC Leve (3)

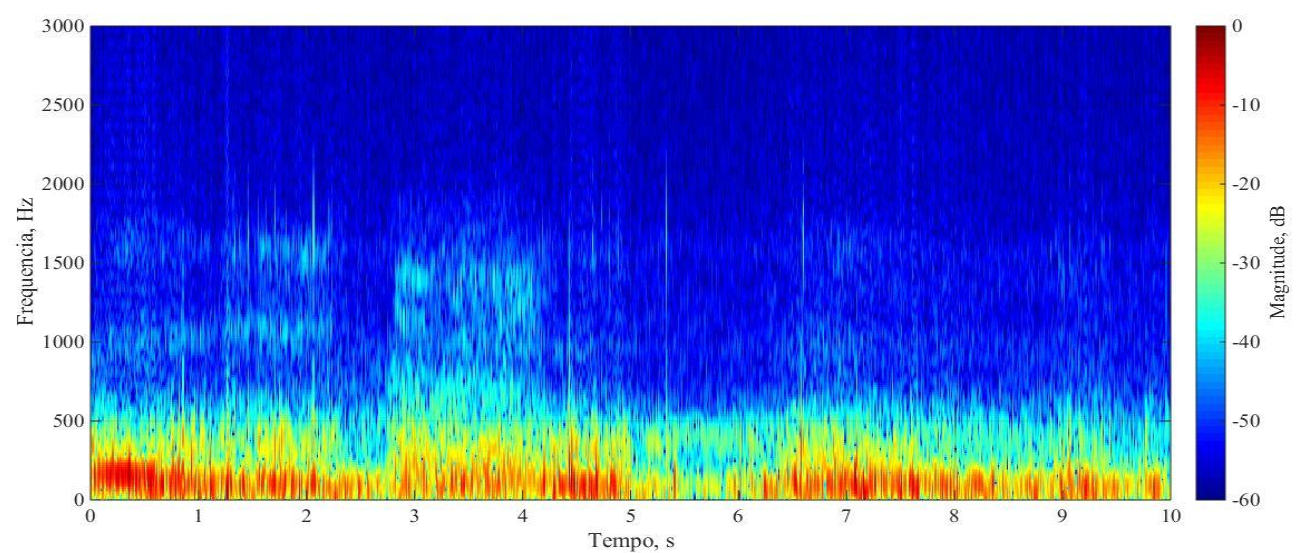

Fonte: Autor

Figura. A.11 - Espectrograma - DPOC Leve (4)

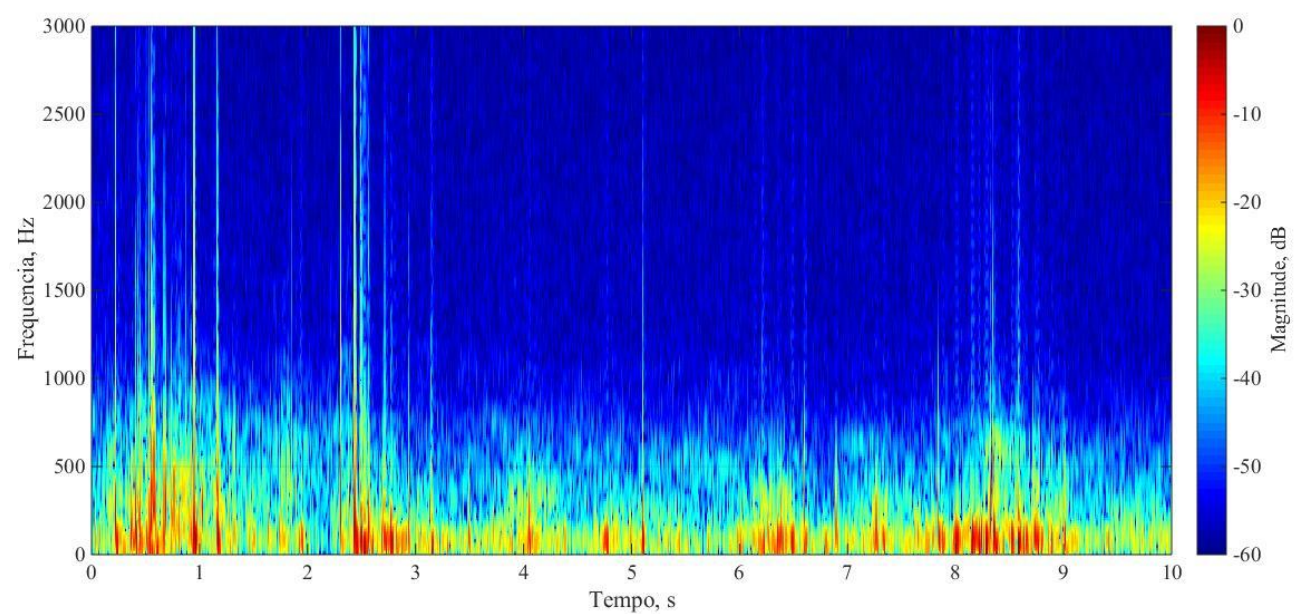

Fonte: Autor

Figura A.12 - Espectrograma - DPOC Moderado (1)

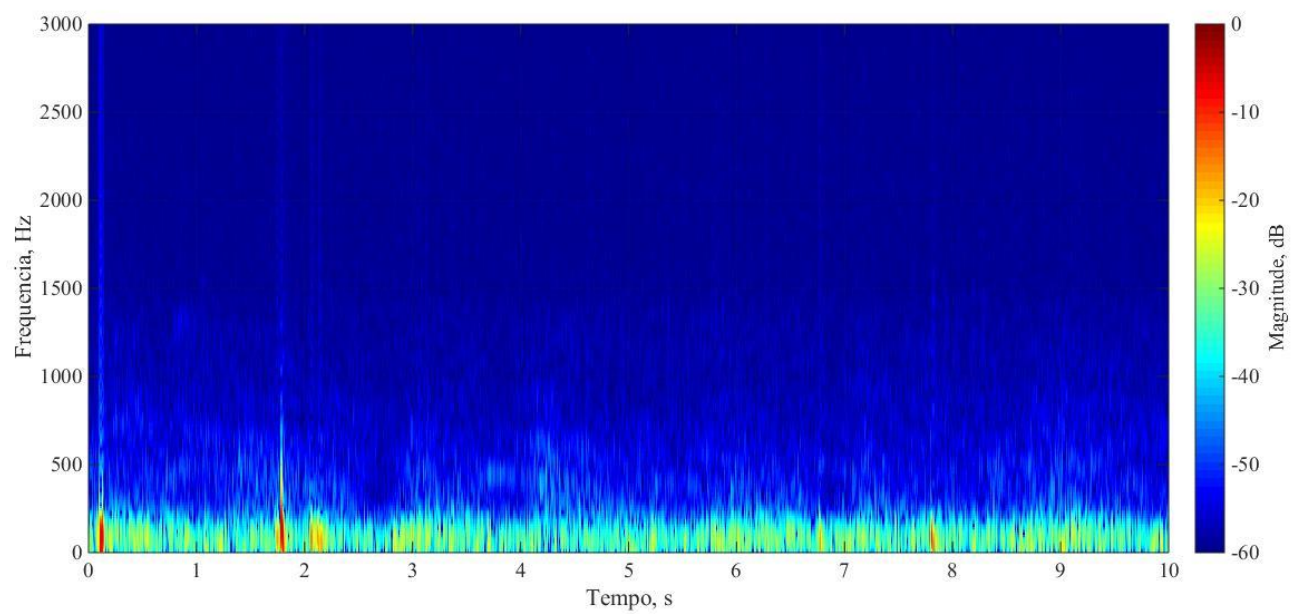

Fonte: Autor 
Figura A.13 - Espectrograma - DPOC Moderado (2)

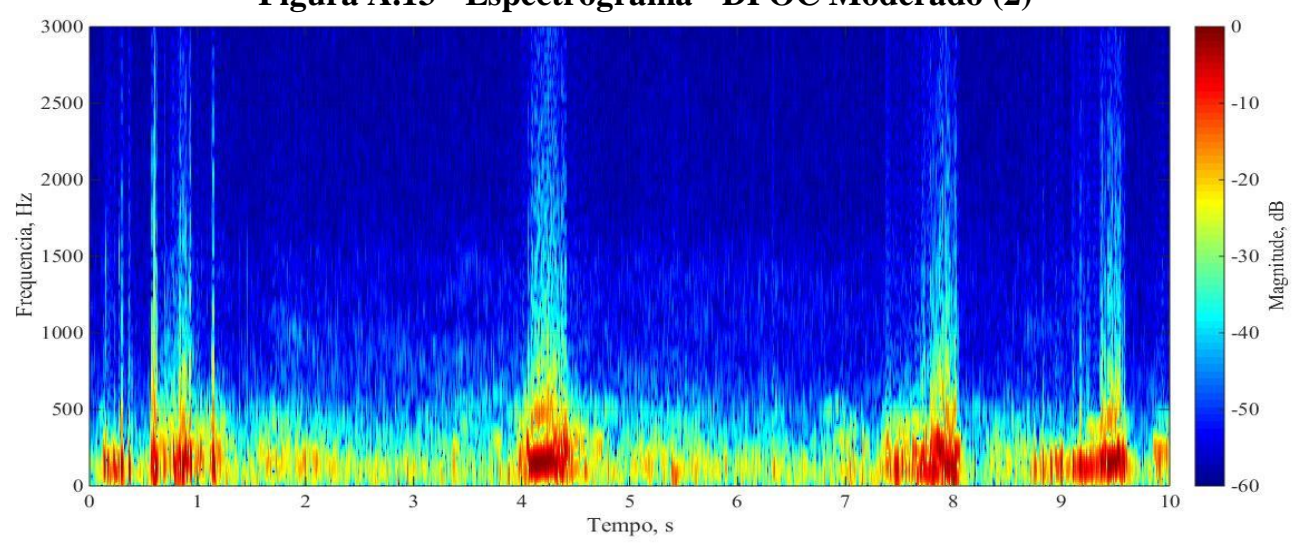

Fonte: Autor

Figura A.14 - Espectrograma - DPOC Moderado (3)

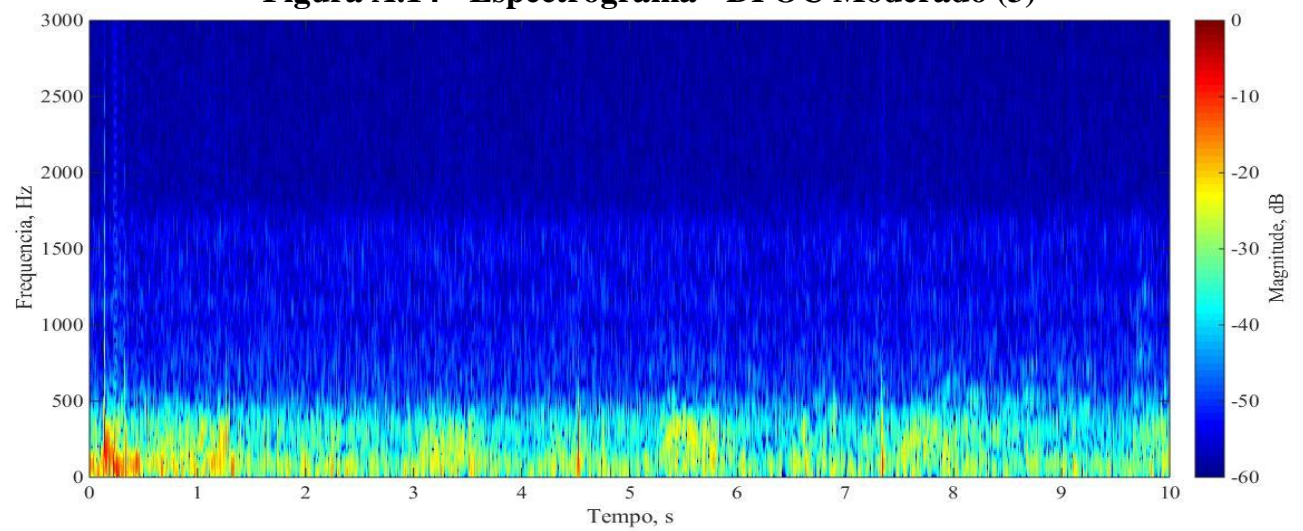

Fonte: Autor

Figura A.15 - Espectrograma - DPOC Moderado (4)

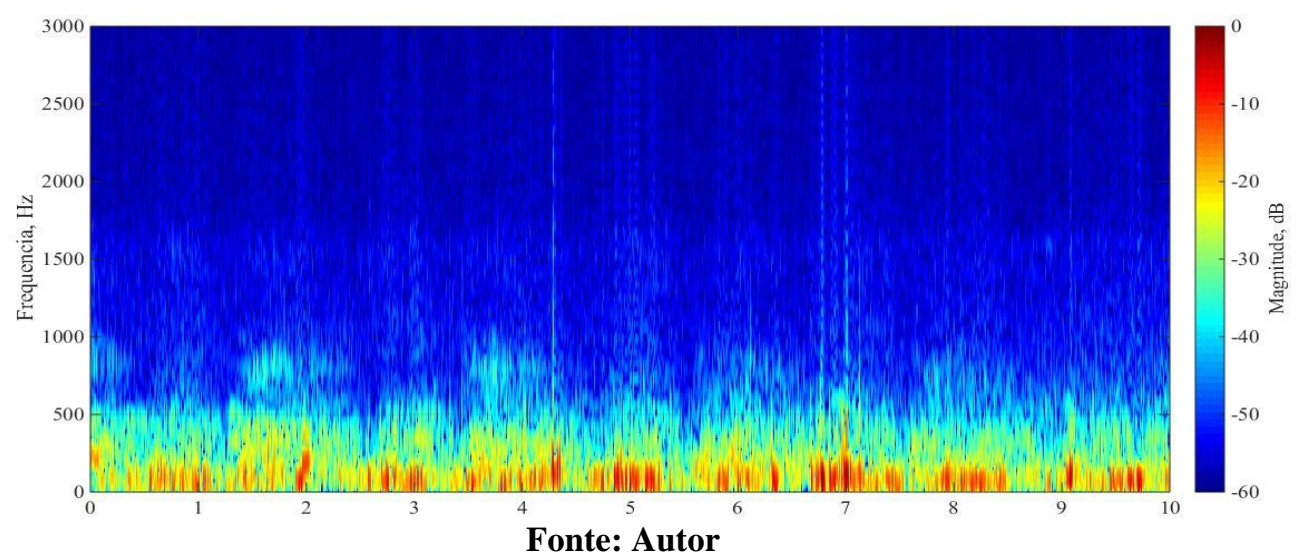


Figura A.16 - Espectrograma - DPOC Moderado (5)

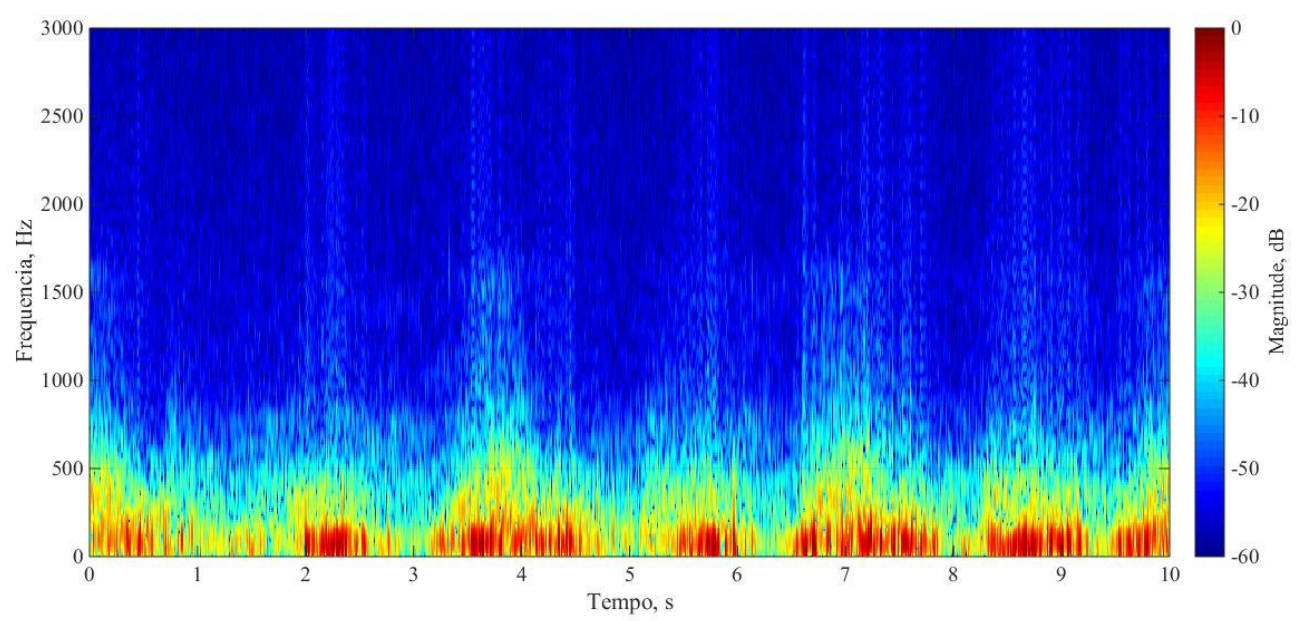

Fonte: Autor

Figura A.17 - Espectrograma - DPOC Moderado (6)

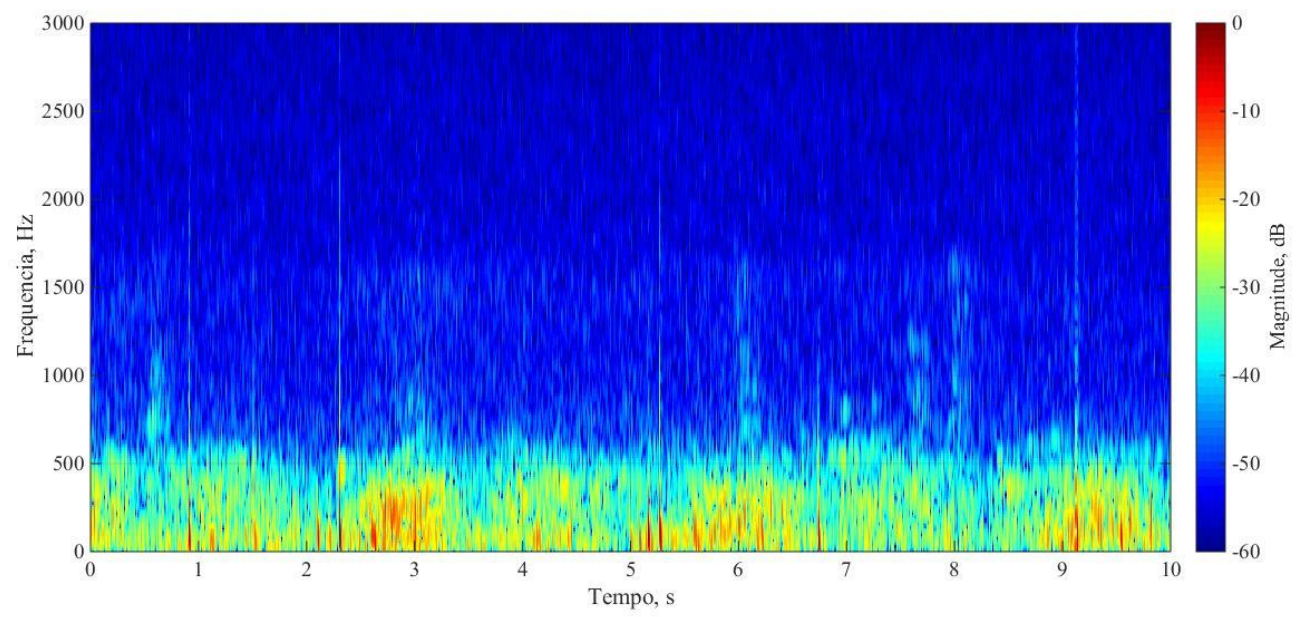

Fonte: Autor

Figura A.18 - Espectrograma - DPOC Moderado (7)

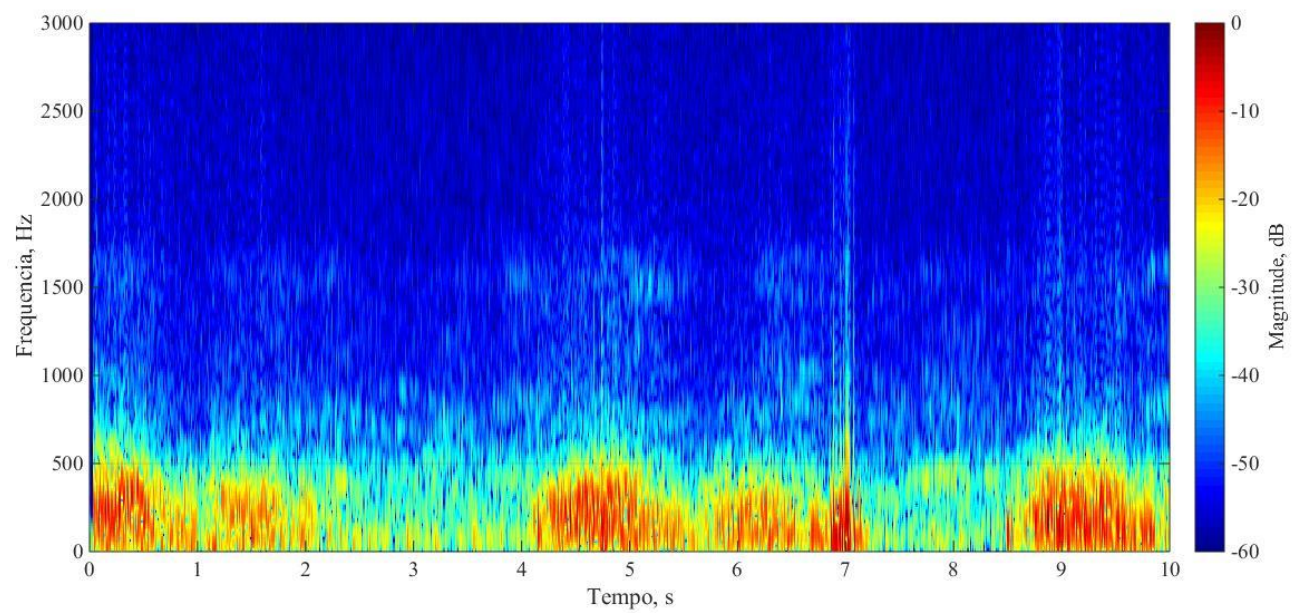

Fonte: Autor 
Figura A.19 - Espectrograma - DPOC Moderado (8)

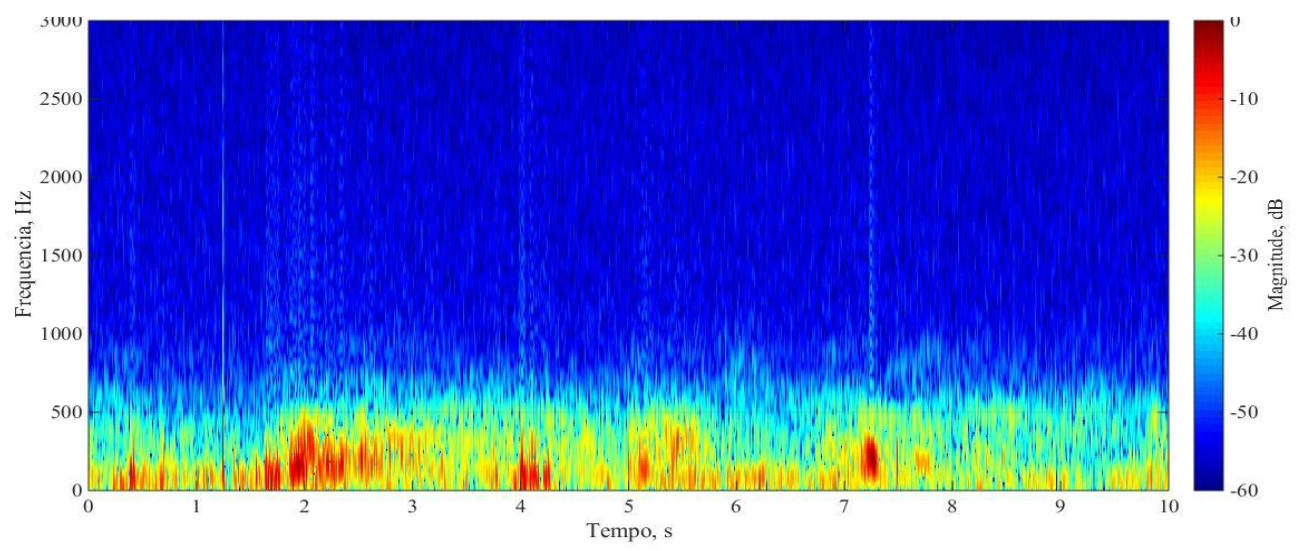

Fonte: Autor

Figura A.20 - Espectrograma - DPOC Moderado (9)

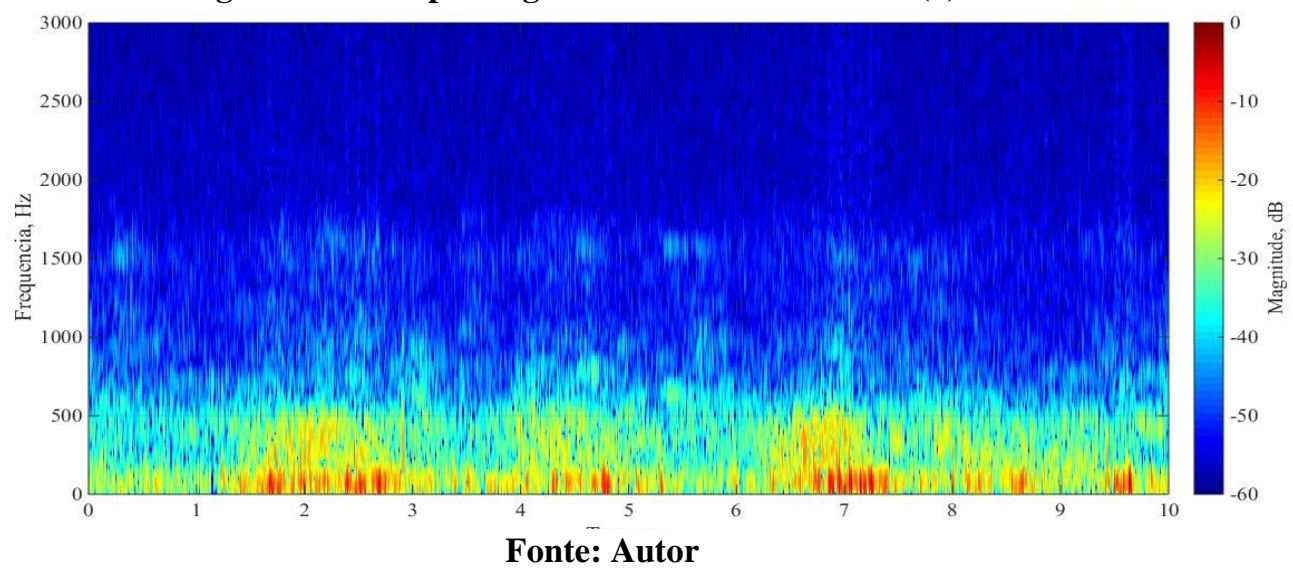

Figura A.21 - Espectrograma - DPOC Moderado (10)

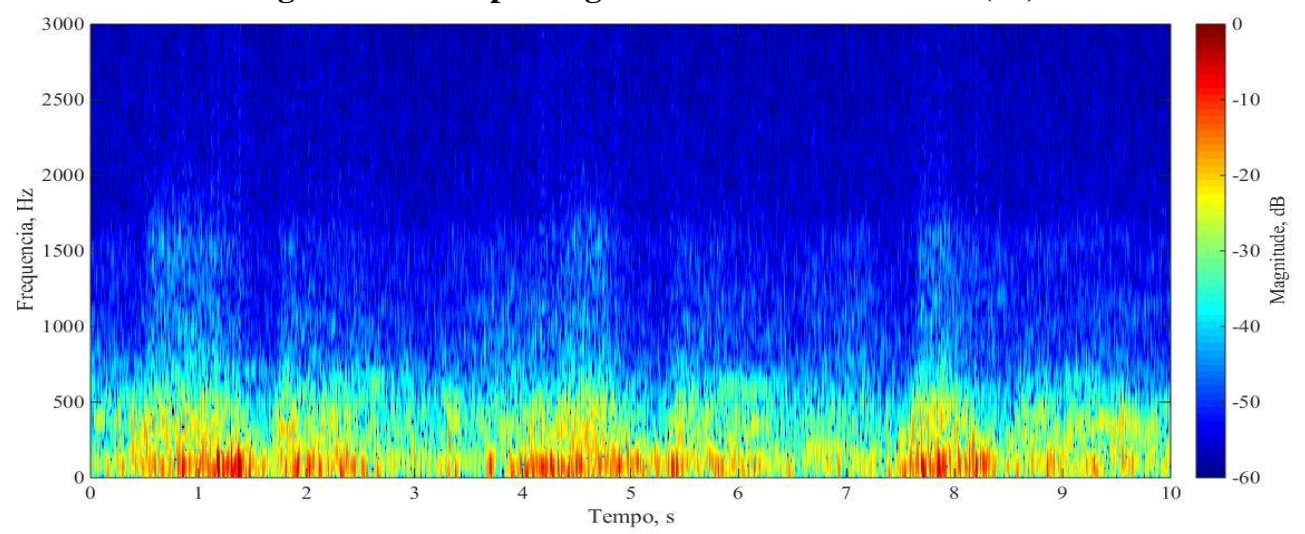

Fonte: Autor 


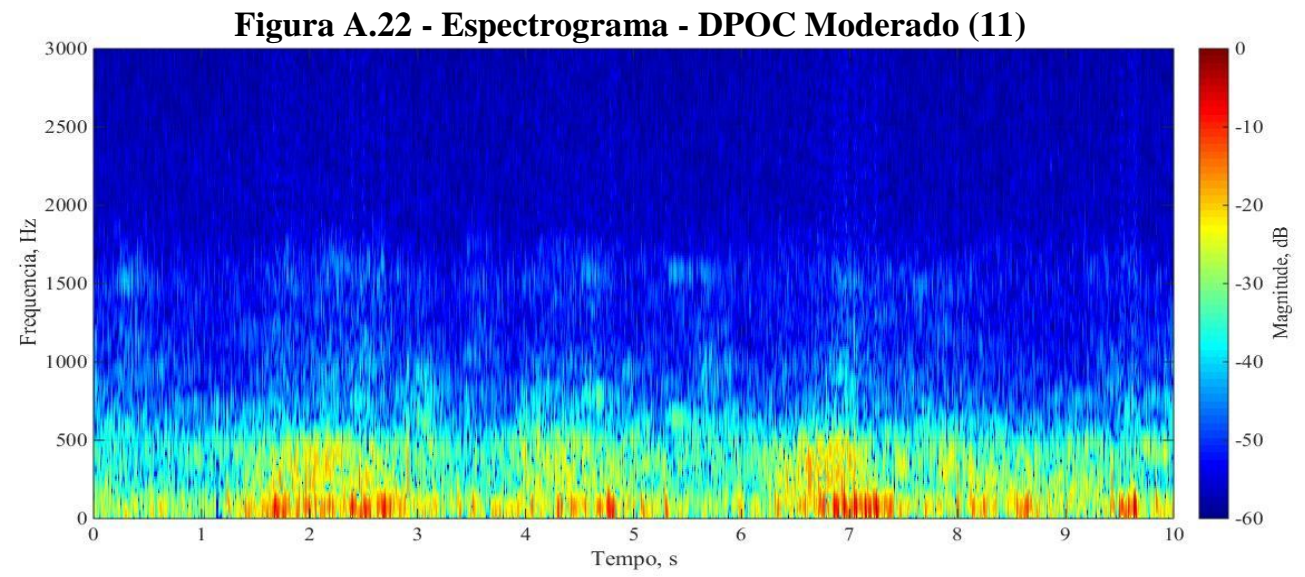

Fonte: Autor

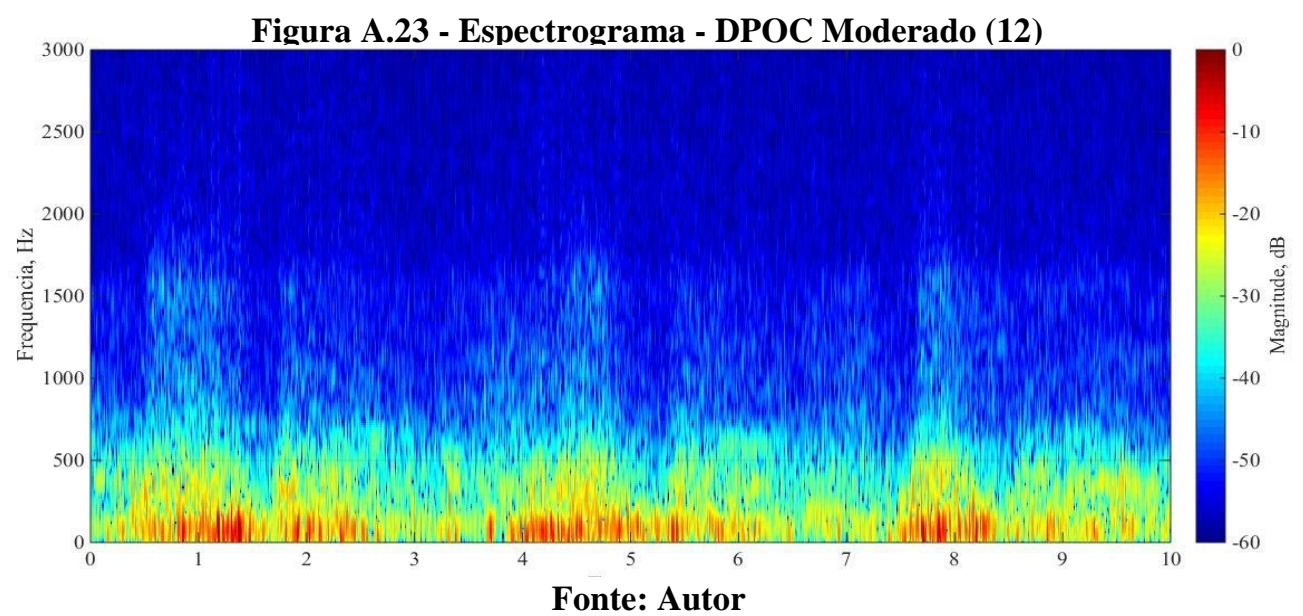

Figura A.24 - Espectrograma - DPOC Moderado (13)

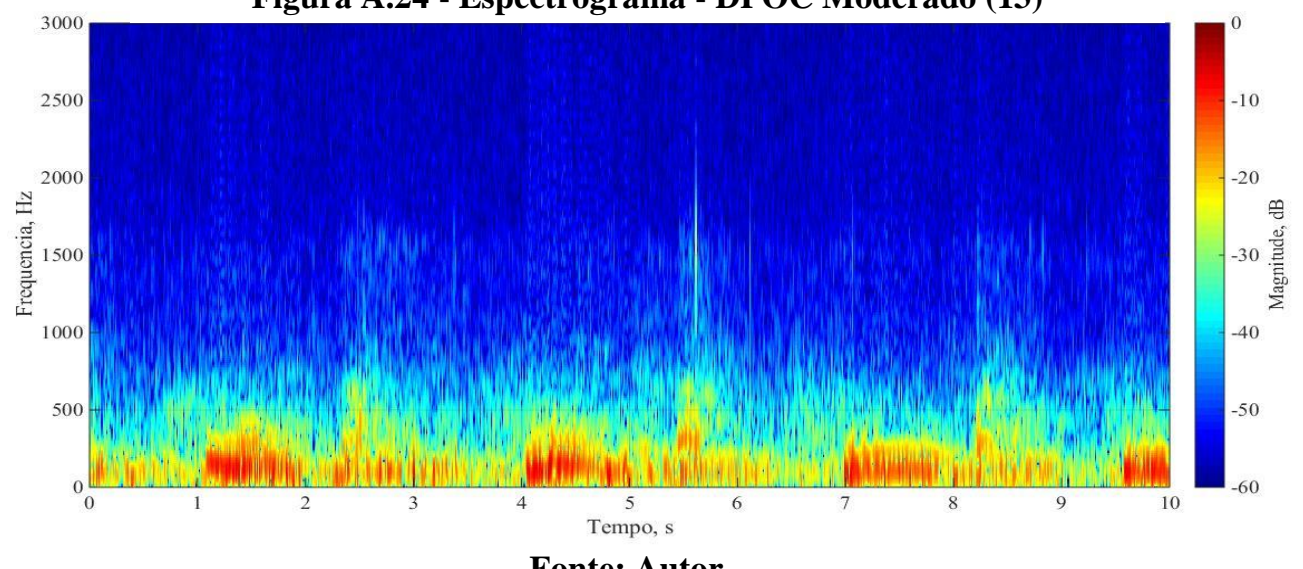

Fonte: Autor 
Figura A.25 - Espectrograma - DPOC Moderado (14)

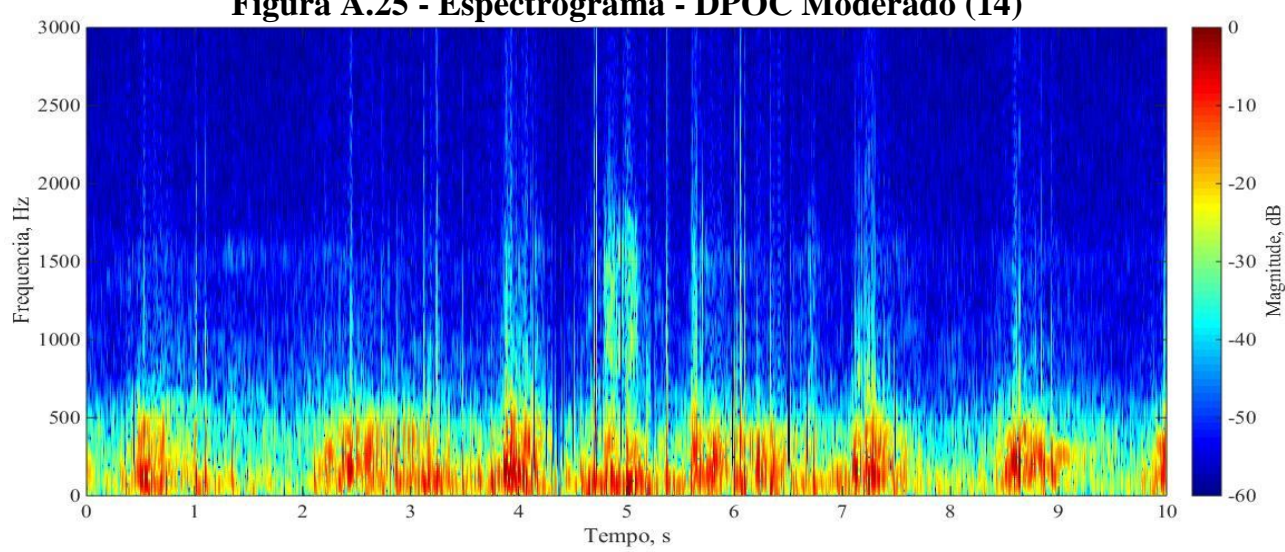

Fonte: Autor

Figura A.26 - Espectrograma - DPOC Moderado (15)

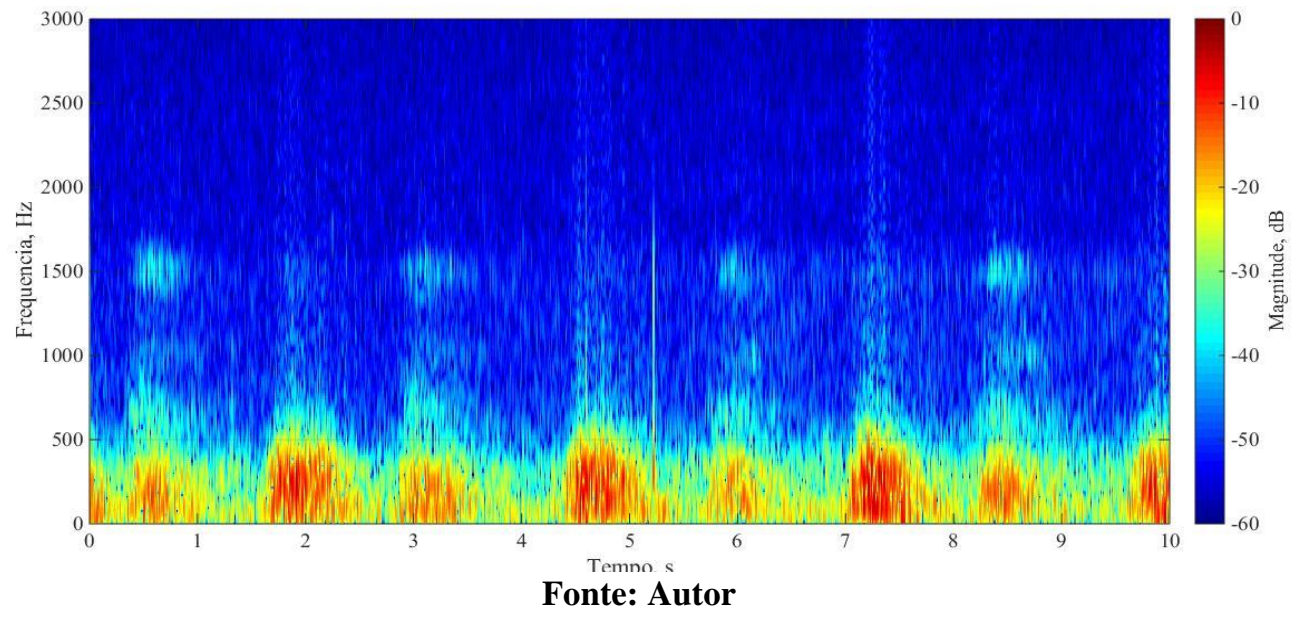

Figura A.27 - Espectrograma - DPOC Grave (1)

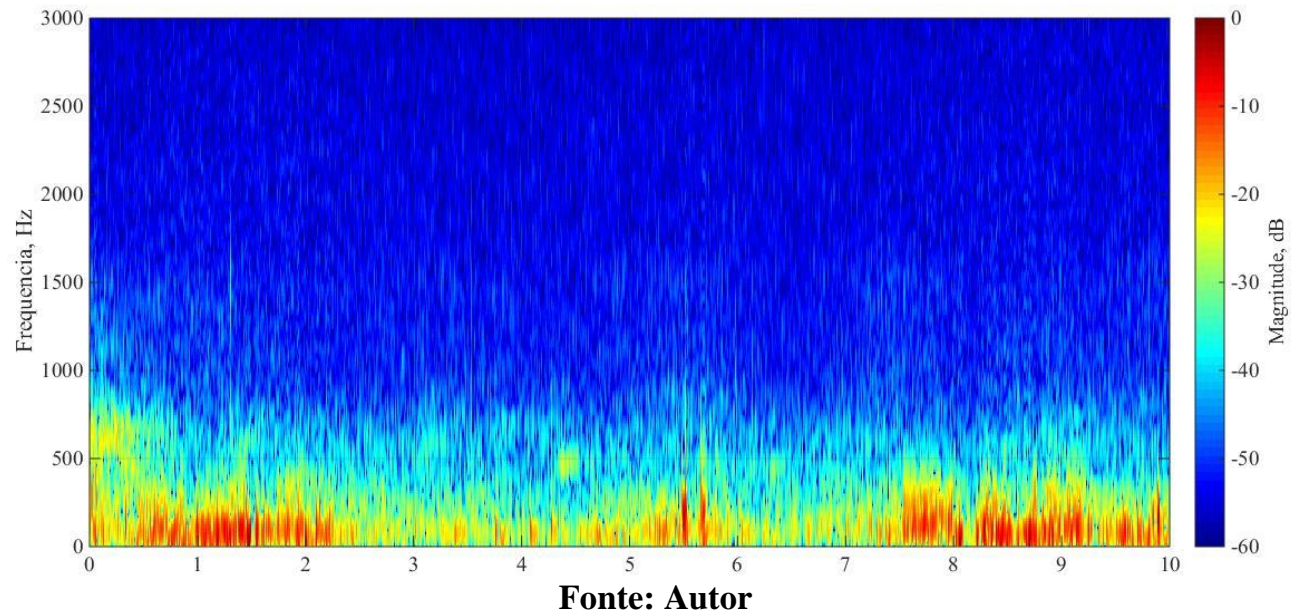


Figura A.28 - Espectrograma - DPOC Grave (2)

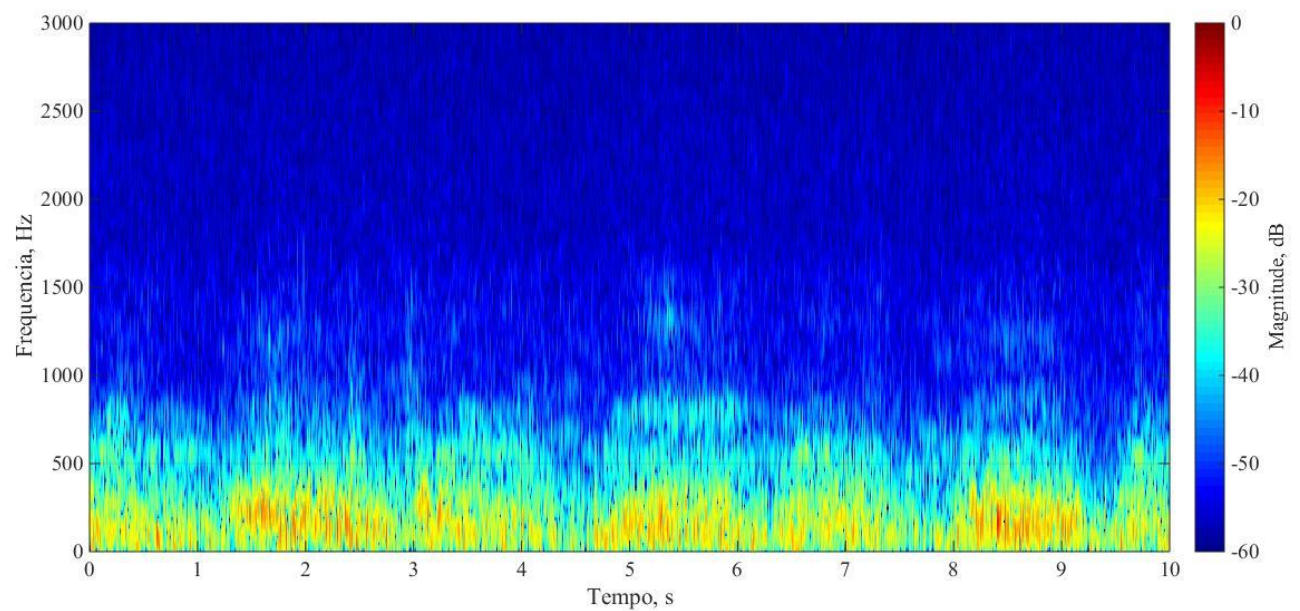

Fonte: Autor

Figura A.29 - Espectrograma - DPOC Grave (3)

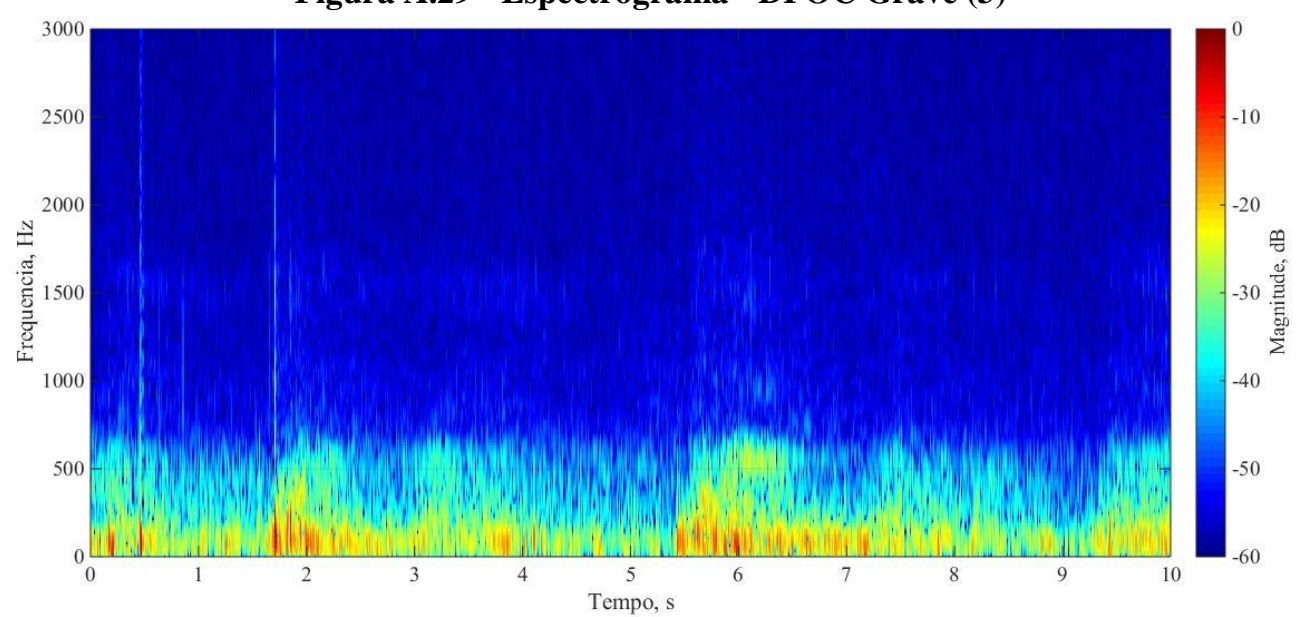

Fonte: Autor

Figura A.30 - Espectrograma - DPOC Grave (4)

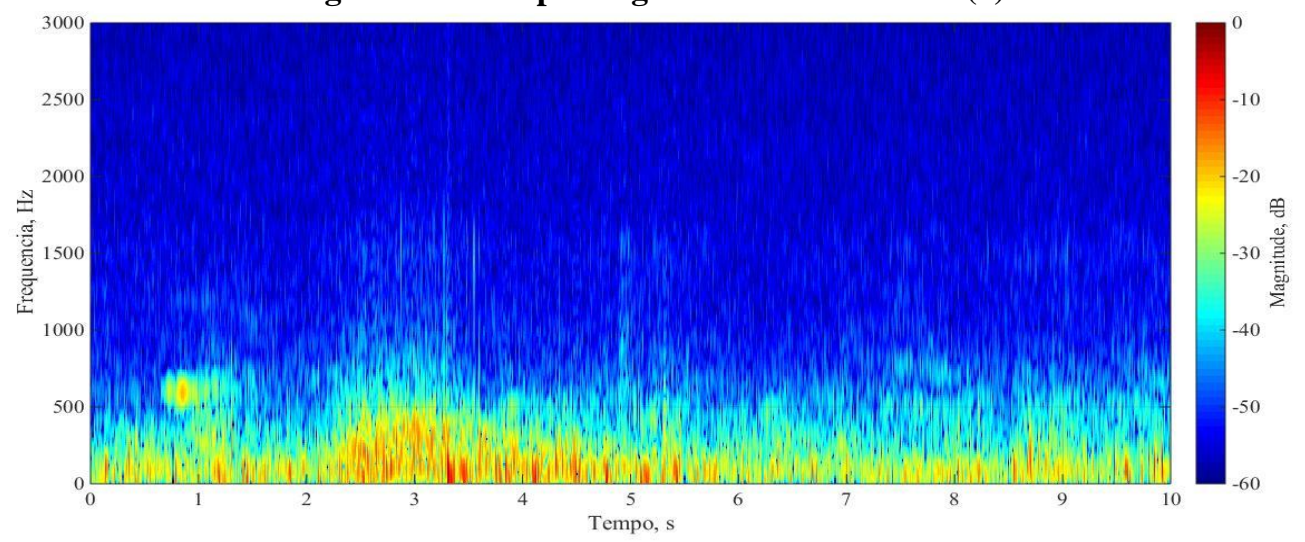

Fonte: Autor 
Figura A.31 - Espectrograma - DPOC Grave (5)

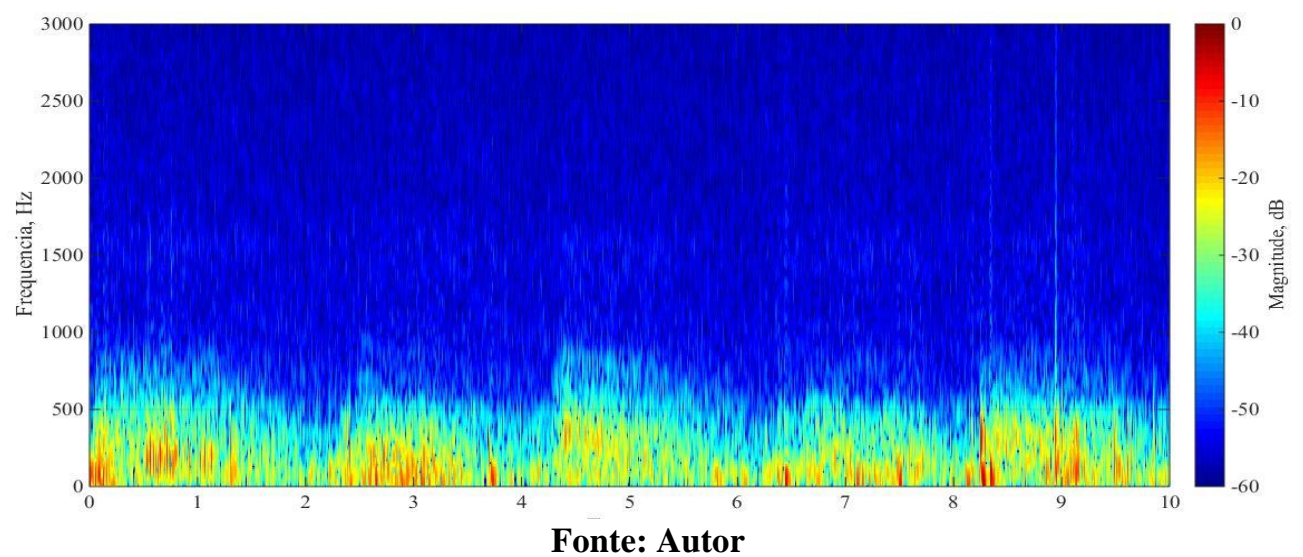

Figura A.32 - Espectrograma - DPOC Grave (6)

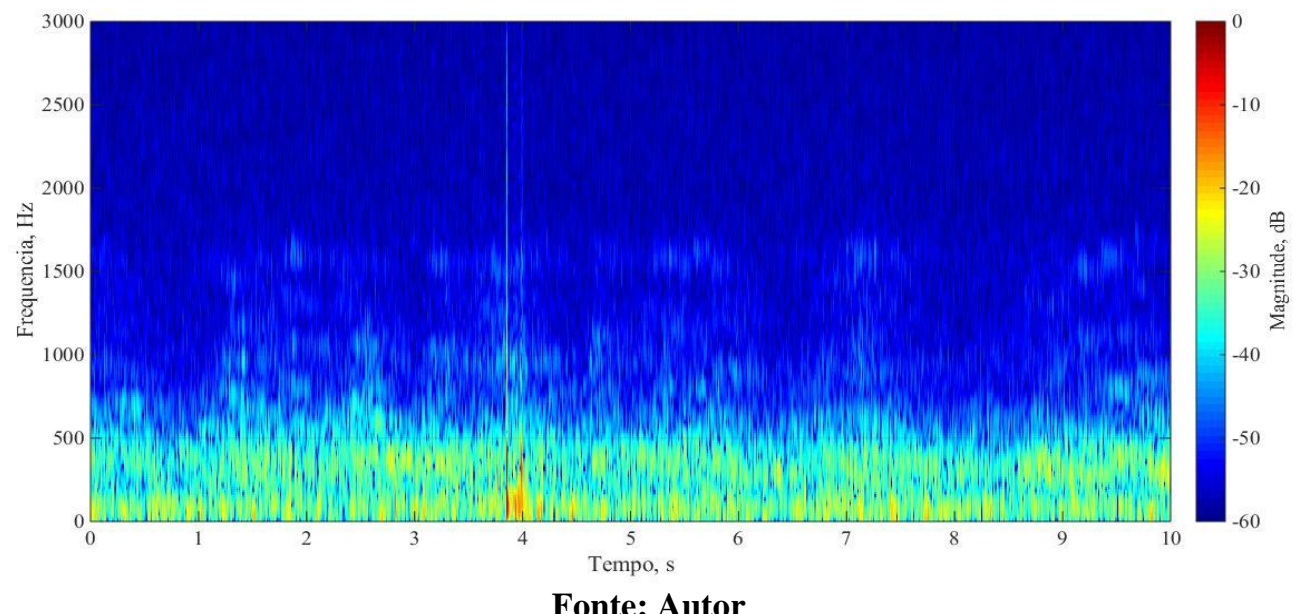

Figura A.33 - Espectrograma - DPOC Grave (7)



Fonte: Autor 
Figura A.34 - Espectrograma - DPOC Grave (8)

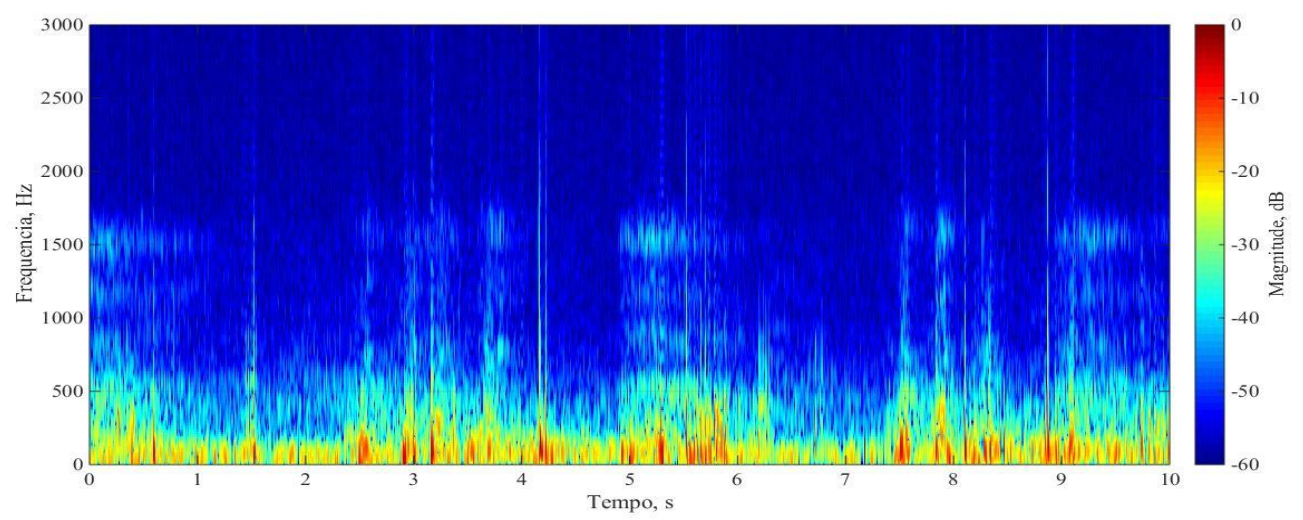

Fonte: Autor

Figura A.35 - Espectrograma - DPOC Grave (9)

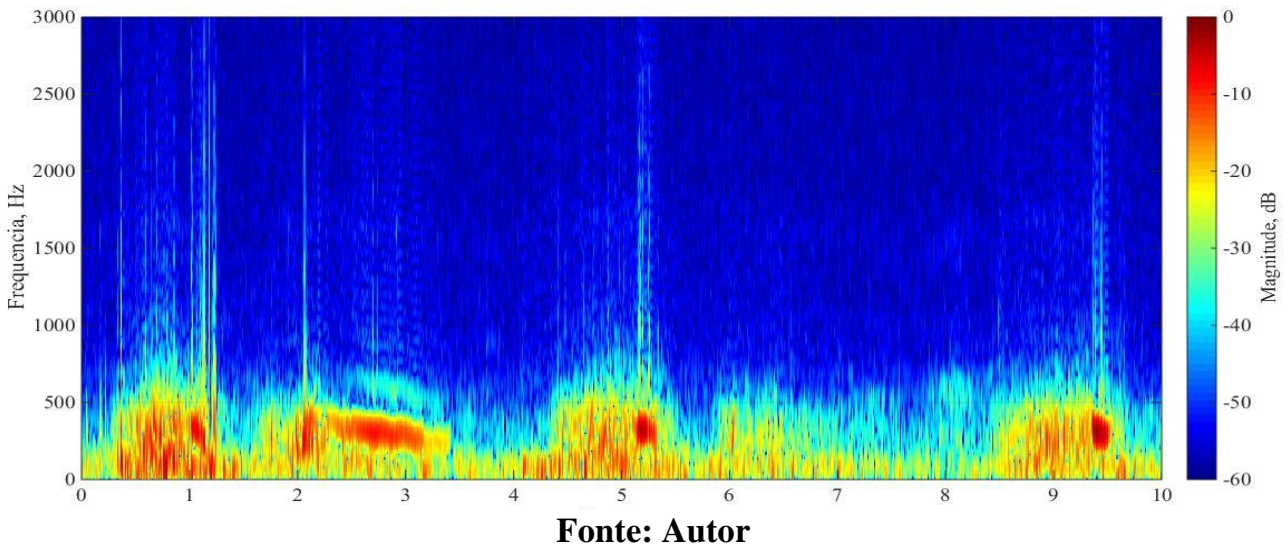

Figura A.36 - Espectrograma - DPOC Grave (10)

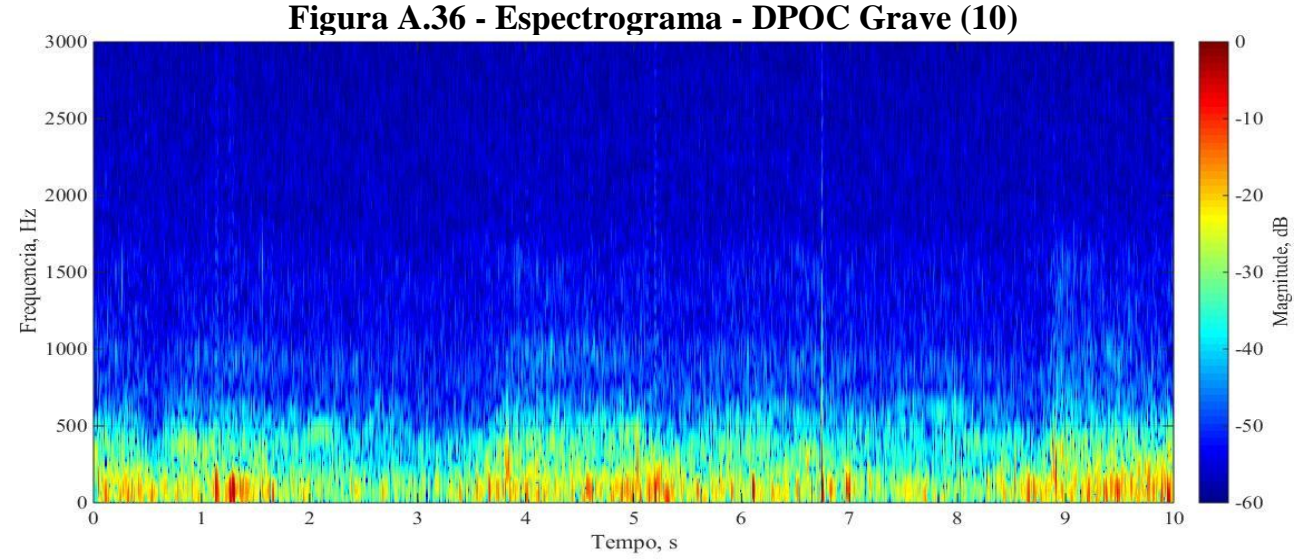

Fonte: Autor 
Figura A.37 - Espectrograma - DPOC Grave (11)

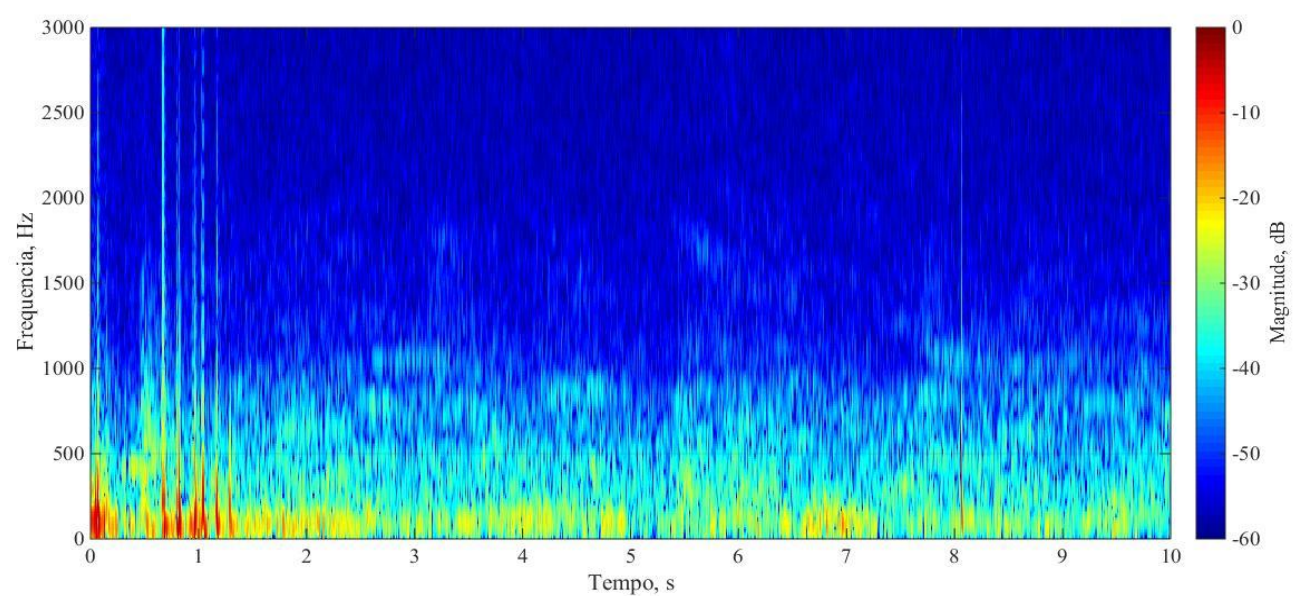

Fonte: Autor

Figura A.38 - Espectrograma - DPOC Grave (12)

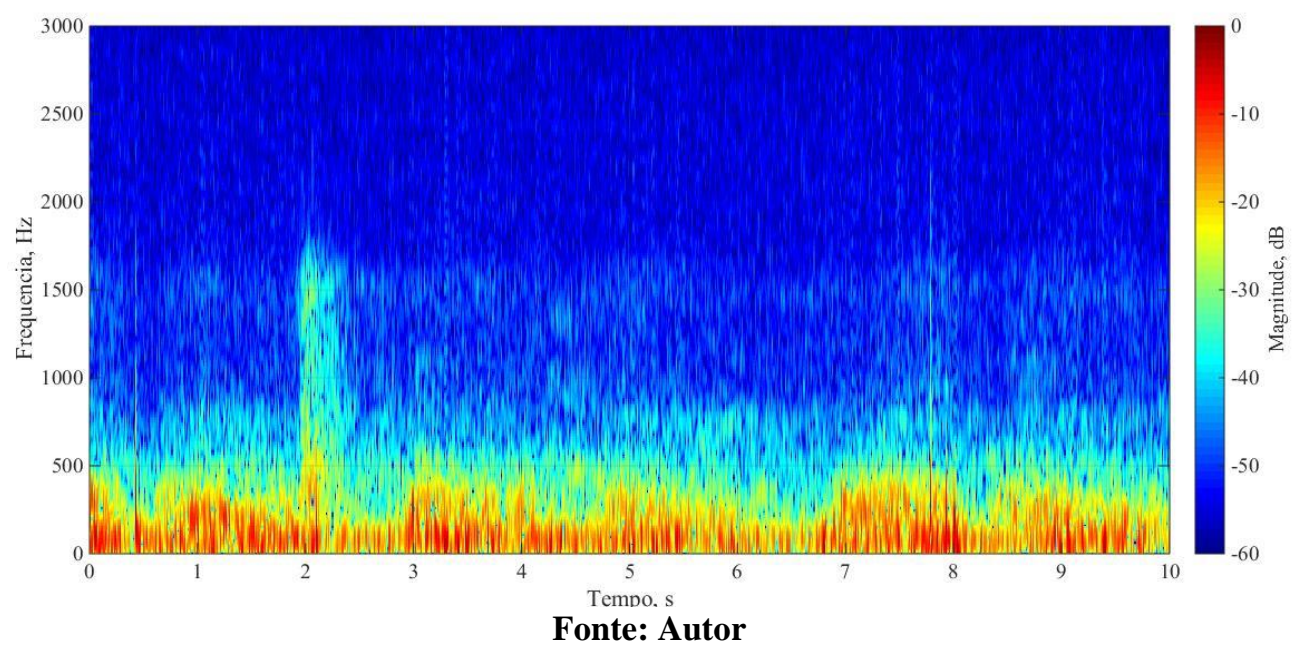

Figura A.39 - Espectrograma - DPOC Grave (13)

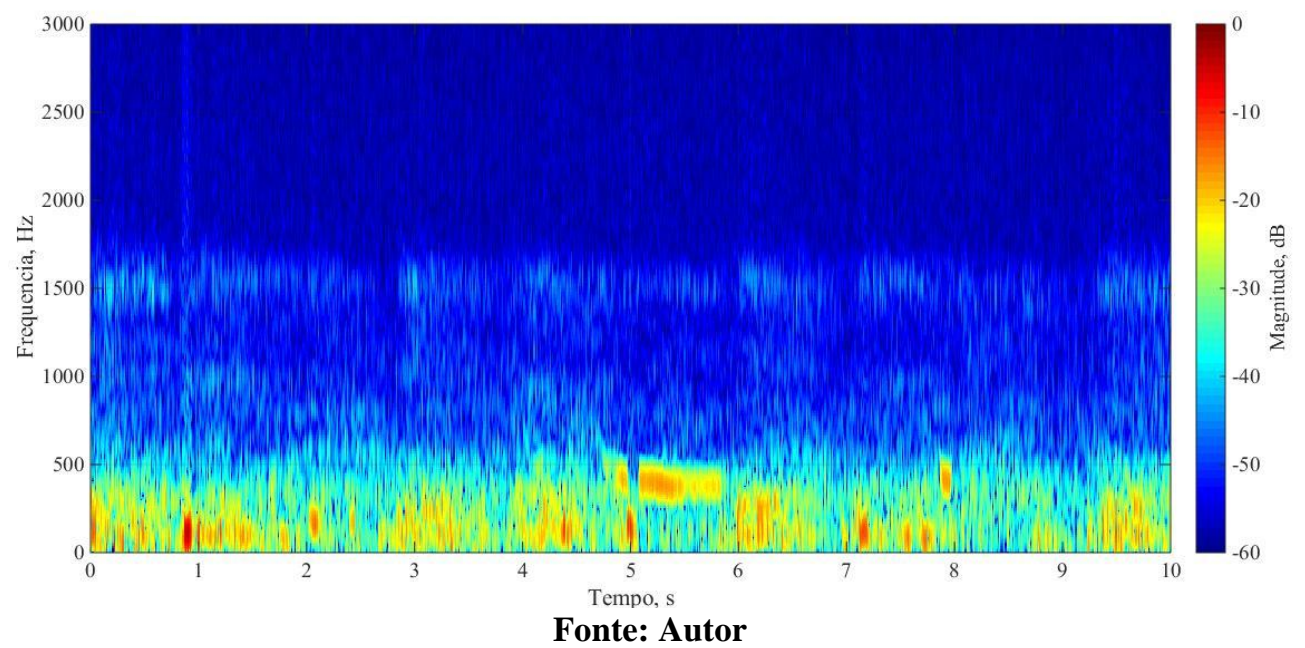


Figura A.40 - Espectrograma - DPOC Muito Grave (1)

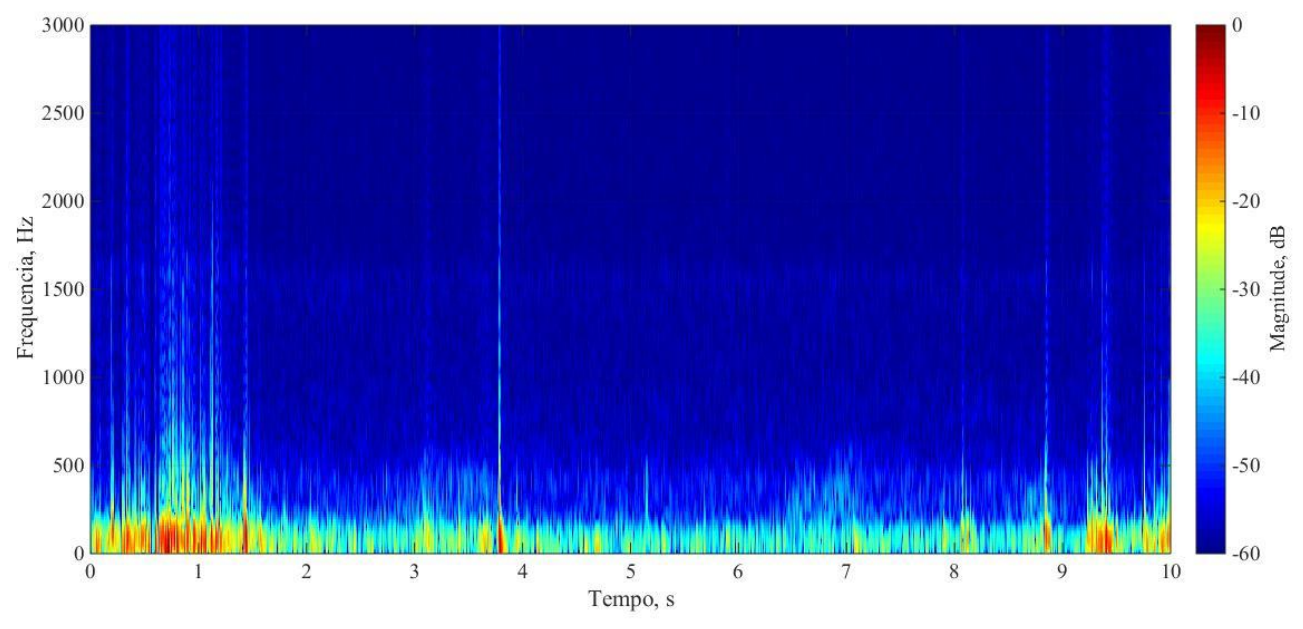

Fonte: Autor

Figura A.41 - Espectrograma - DPOC Muito Grave (2)

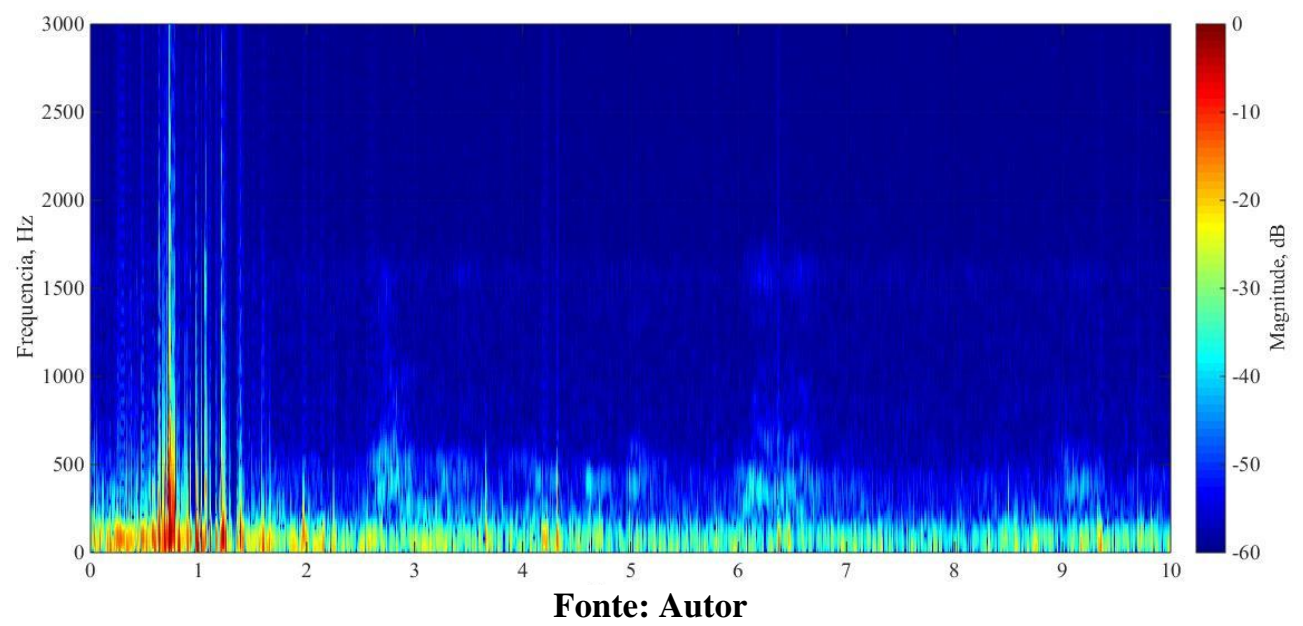

Figura A.42 - Espectrograma - DPOC Muito Grave (3)

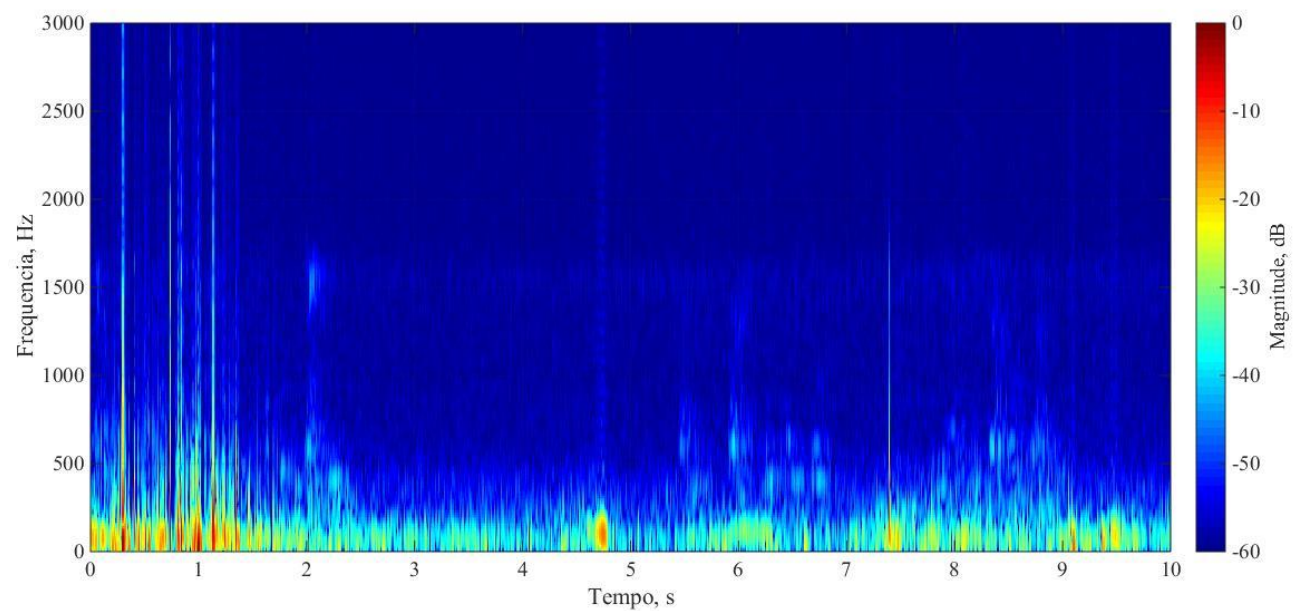

Fonte: Autor 
Figura A.43 - Espectrograma - DPOC Muito Grave (4)

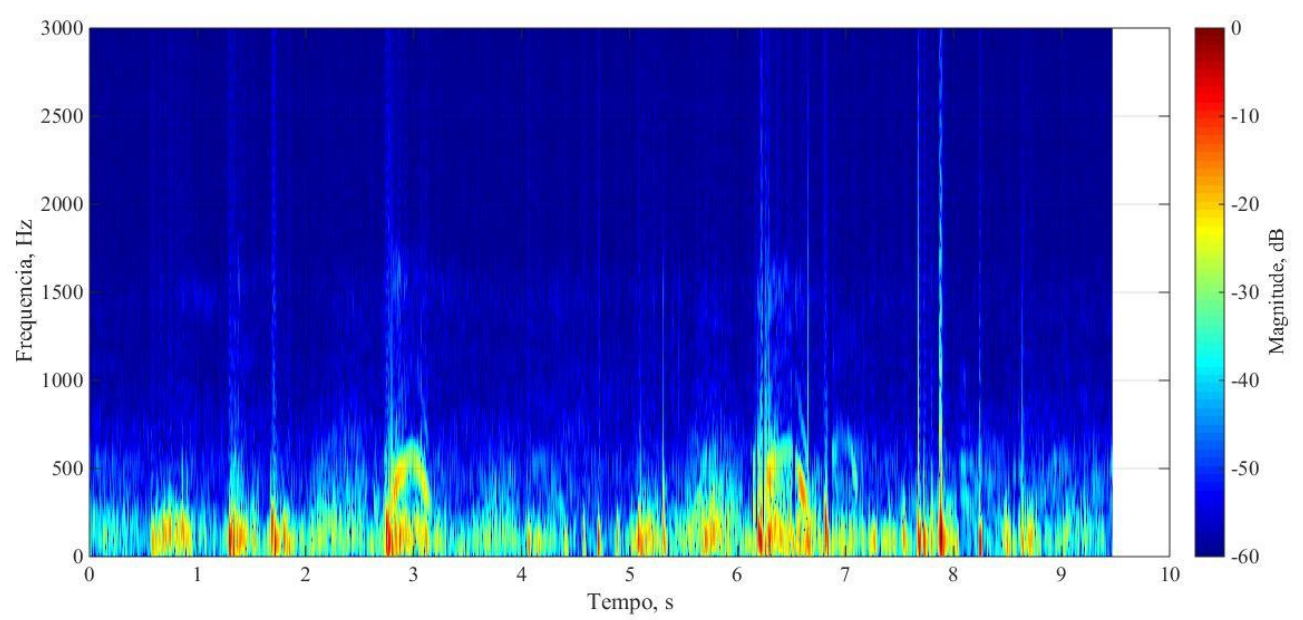

Fonte: Autor

Figura A.44 - Espectrograma - DPOC Muito Grave (5)

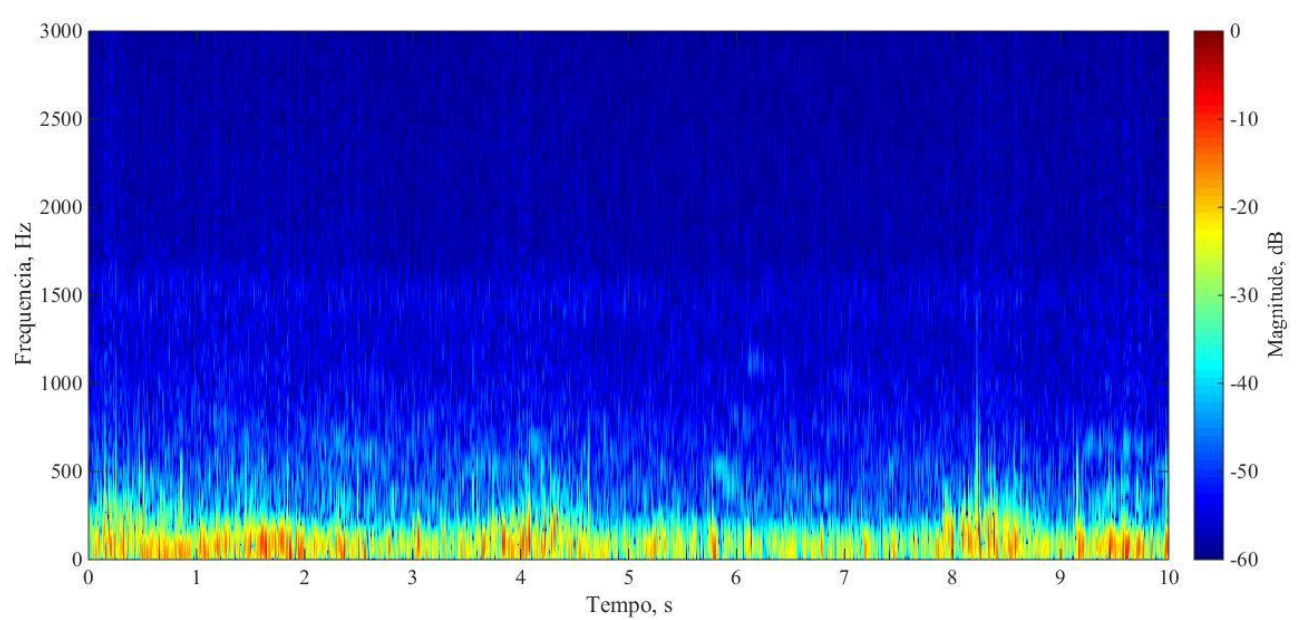

Fonte: Autor

Figura A.45 - Espectrograma - DPOC Muito Grave (6)

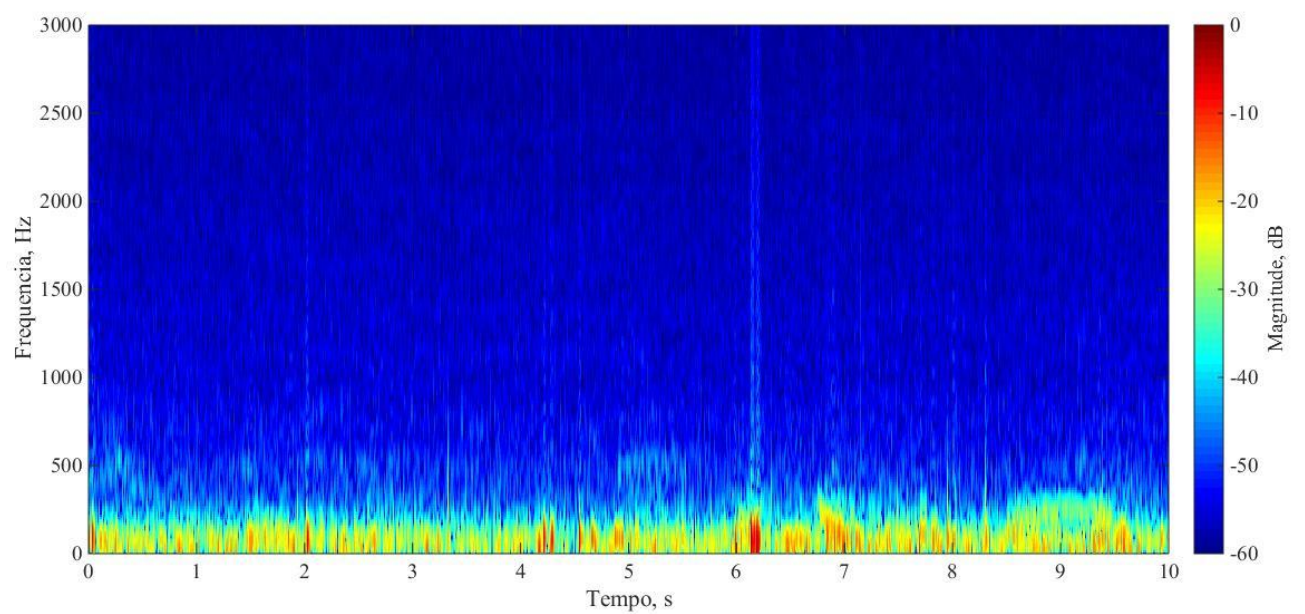

Fonte: Autor 
Figura A.46 - Espectrograma - DPOC Muito Grave (7)

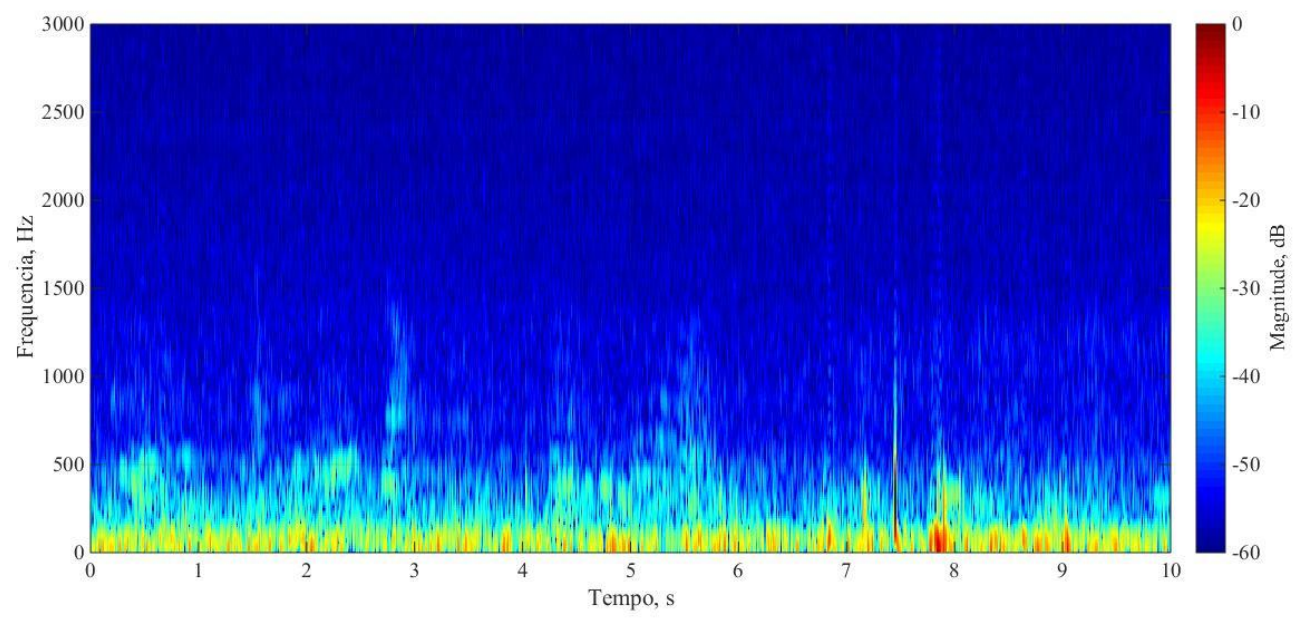

Fonte: Autor

Figura A.47 - Espectrograma - DPOC Muito Grave (8)

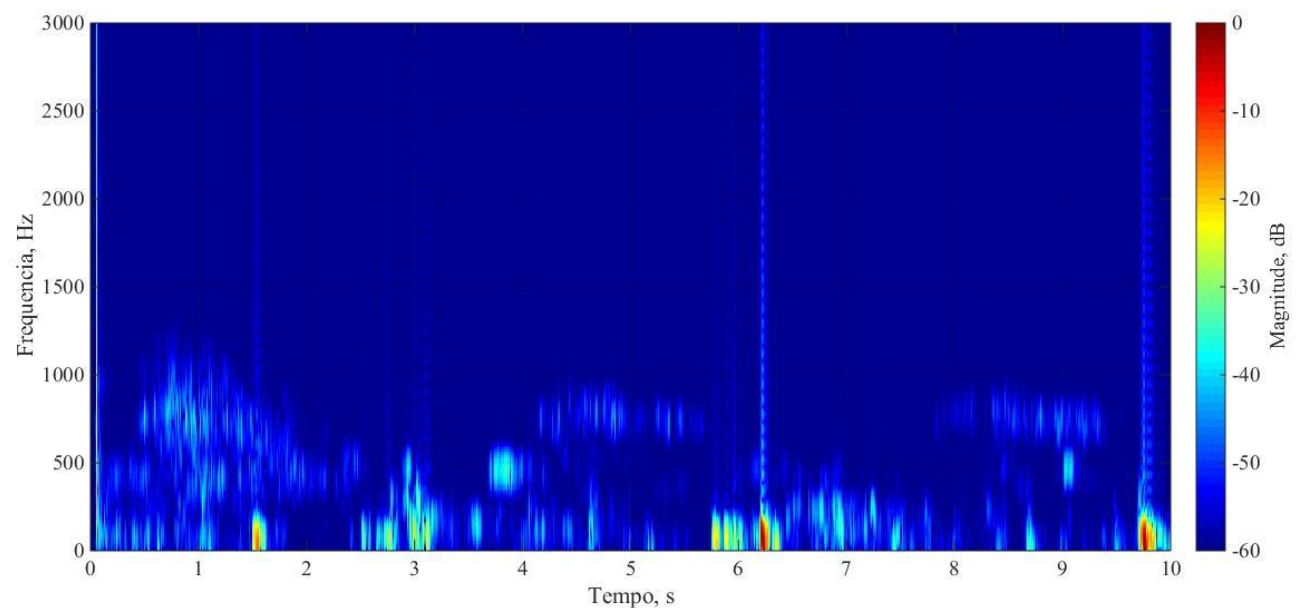

Fonte: Autor

Figura A.48 - Espectrograma - DPOC Muito Grave (9)

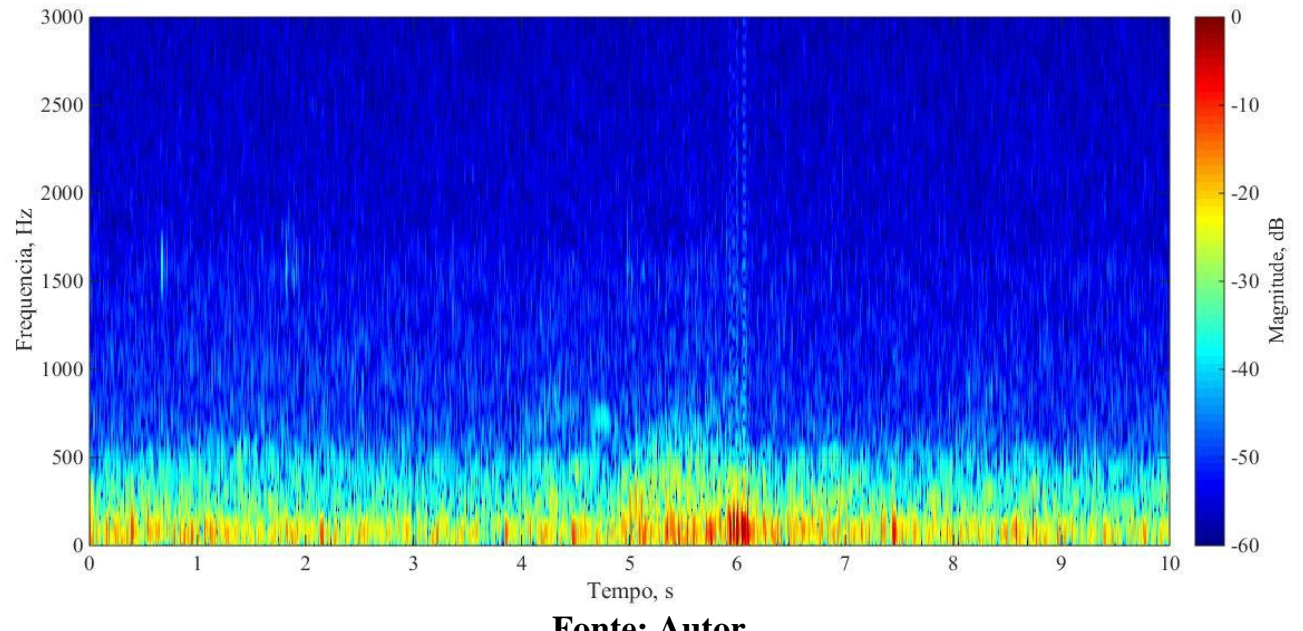

Fonte: Autor 
Figura A.49 - Espectrograma - DPOC Muito Grave (10)

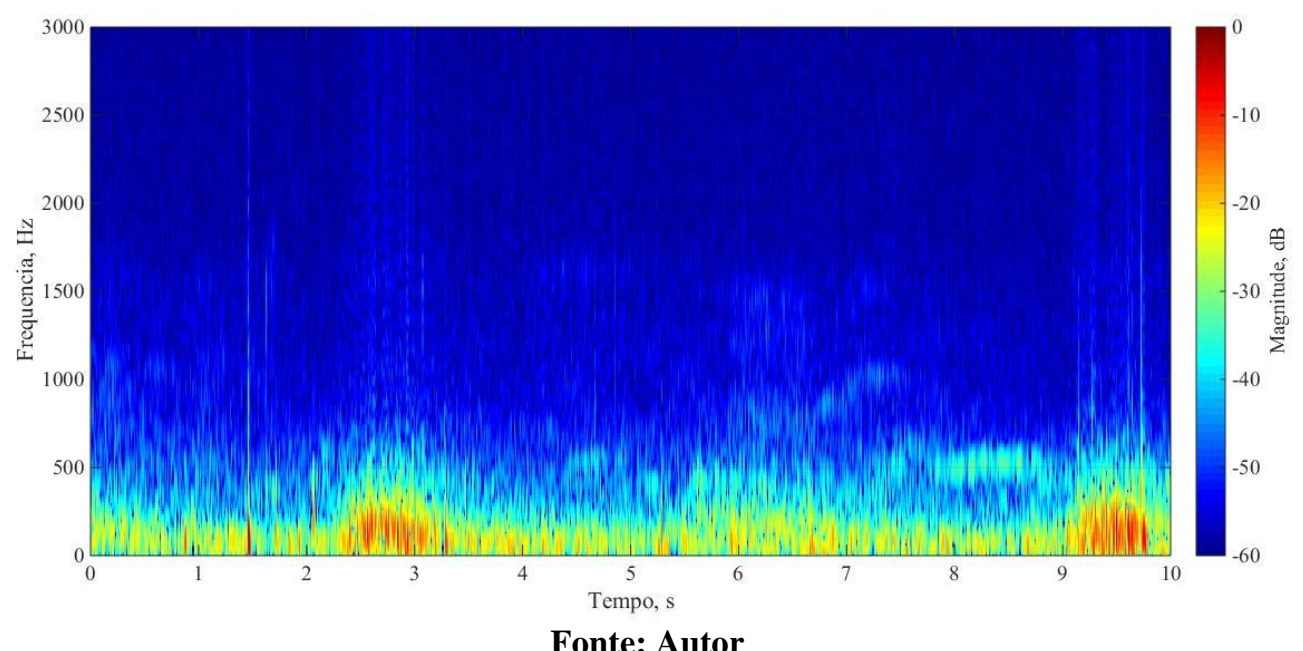

Figura A.50 - Espectrograma - DPOC Muito Grave (11)

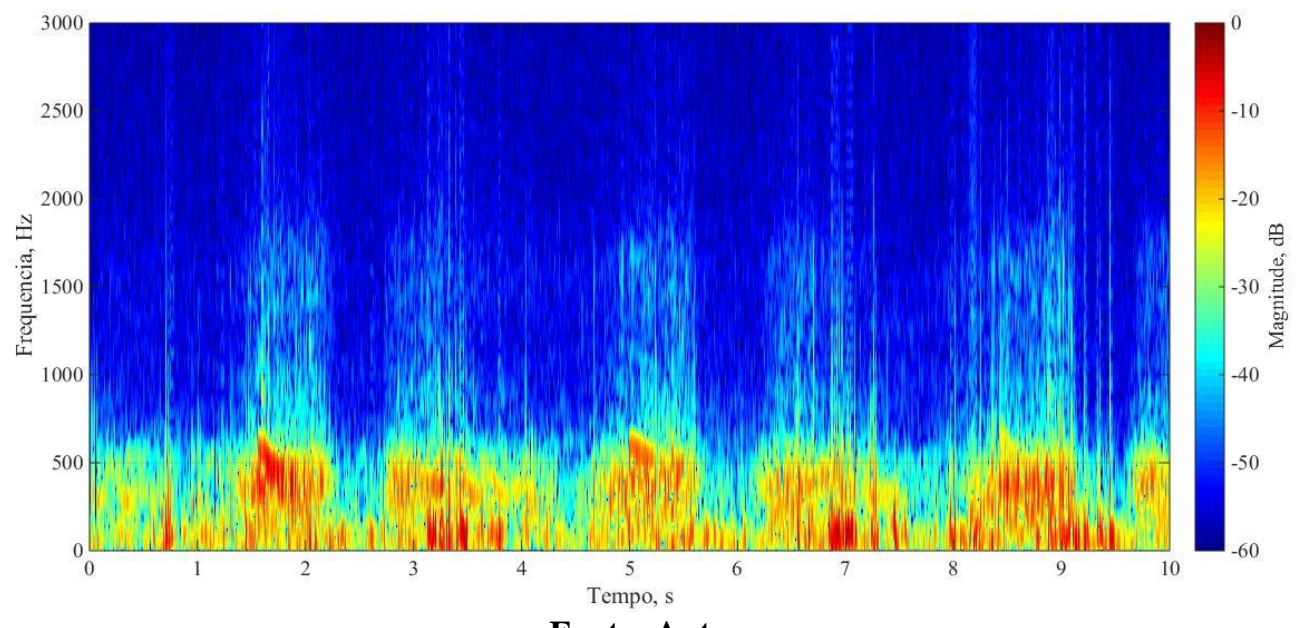

Fonte: Autor

Figura A.51 - Espectrograma - DPOC Muito Grave (12)

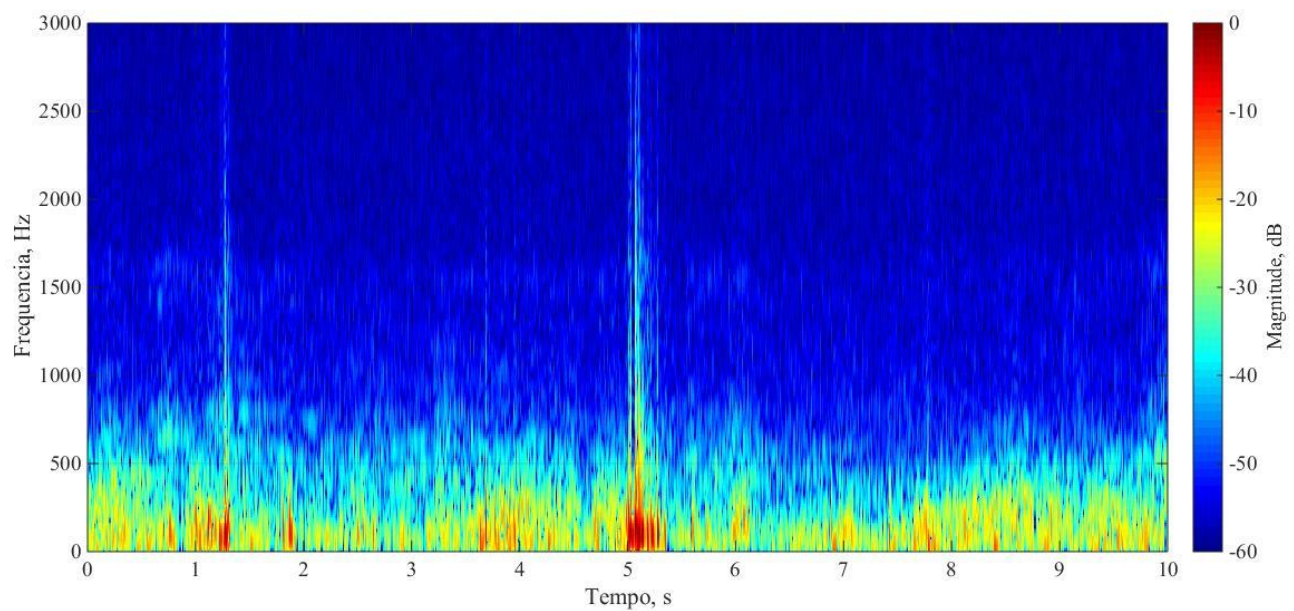

Fonte: Autor 
Figura A.52 - Espectrograma - DPOC Muito Grave (13)

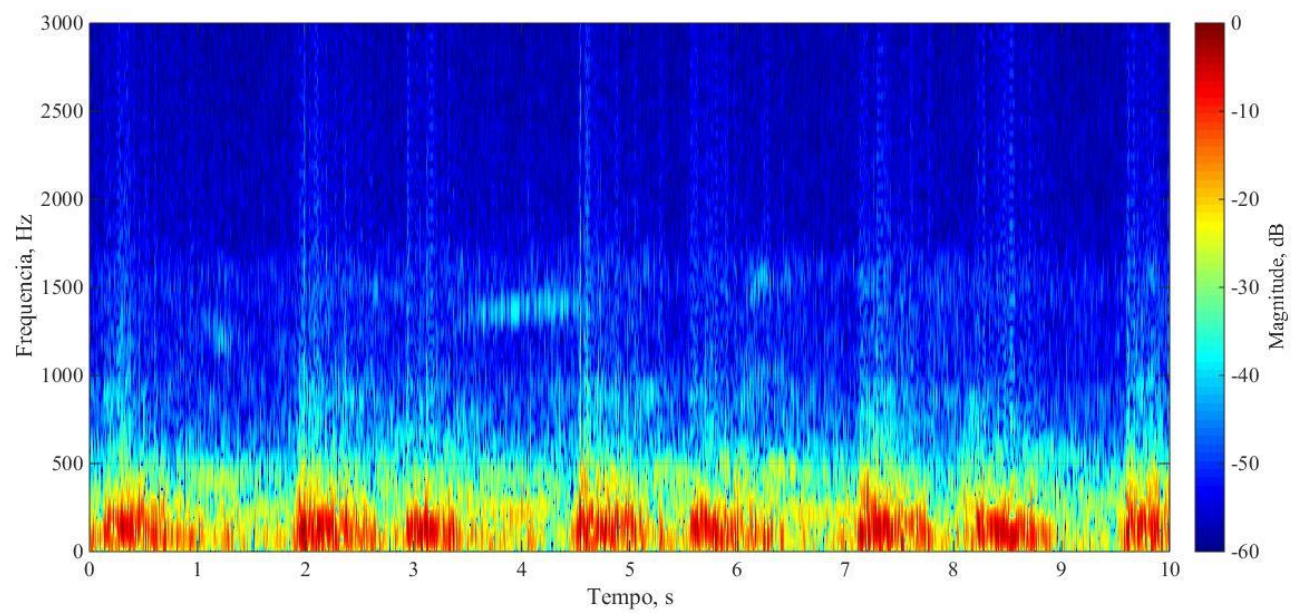

Fonte: Autor

Figura A.53 - Espectrograma - DPOC Muito Grave (14)

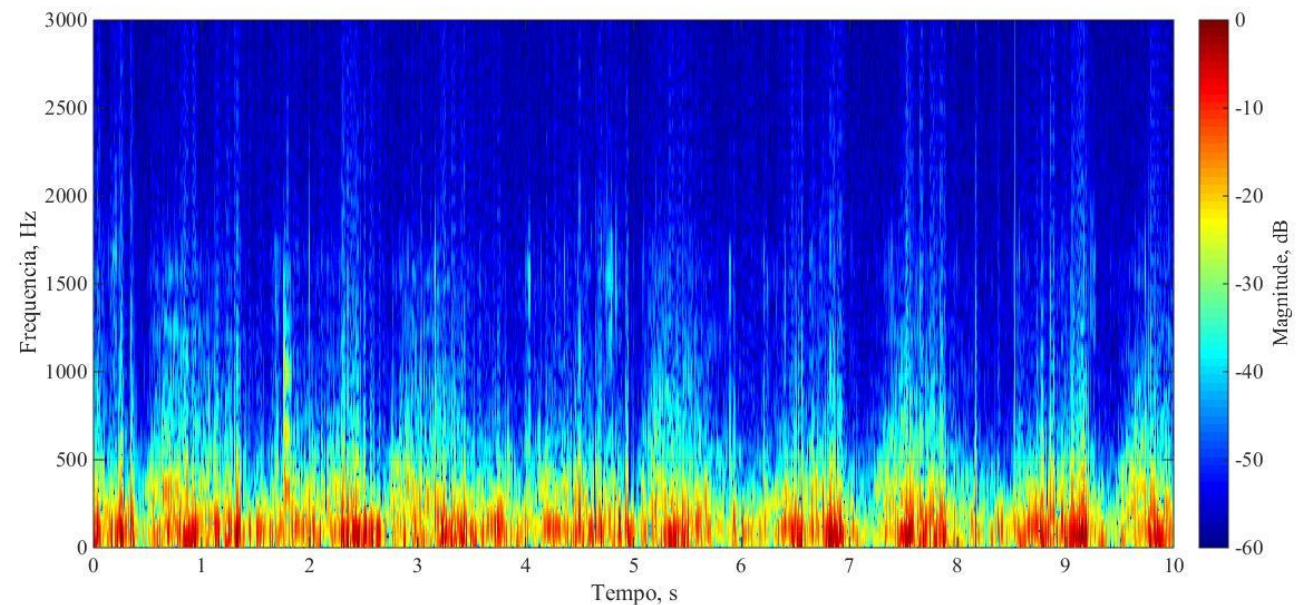

Fonte: Autor

Figura A.54 - Espectrograma - DPOC Muito Grave (15)

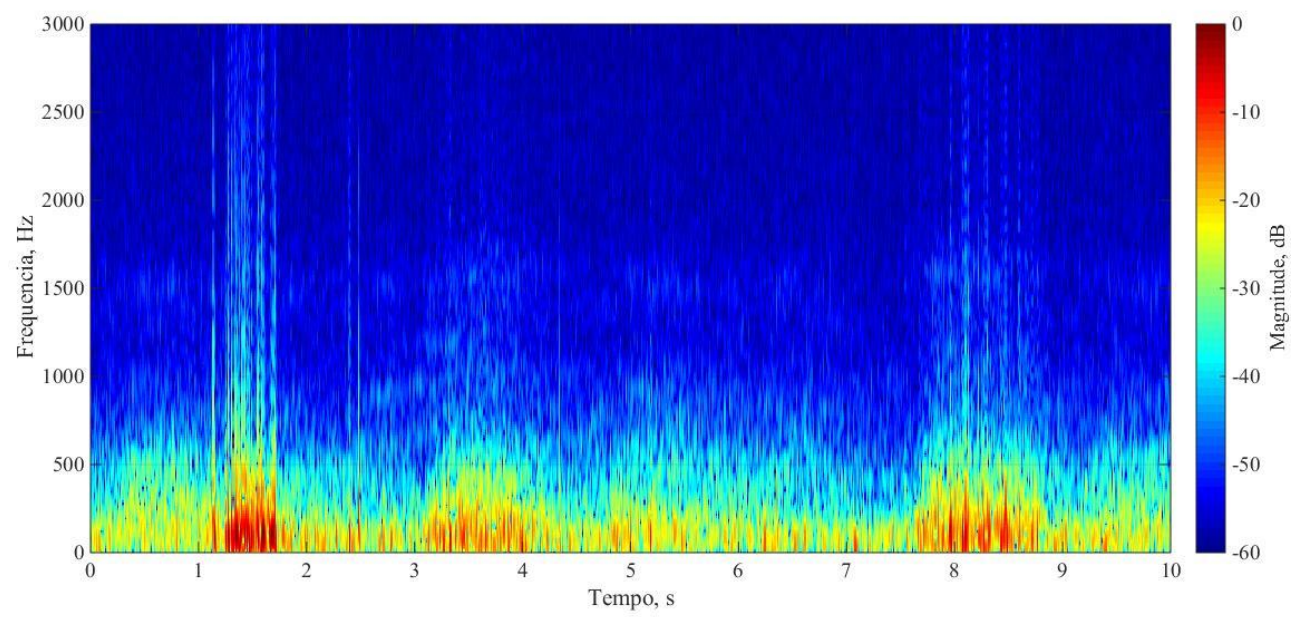

Fonte: Autor 
Figura A.55 - Espectrograma - DPOC Muito Grave (16)

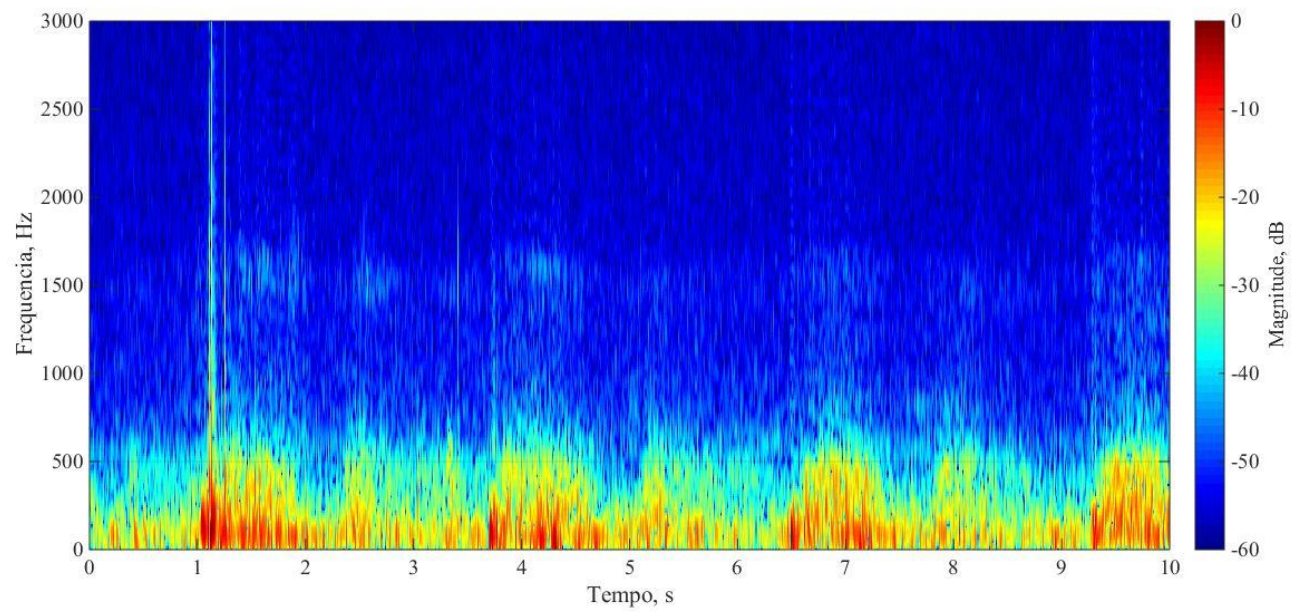

Fonte: Autor

Figura A.56 - Espectrograma - DPOC Muito Grave (17)

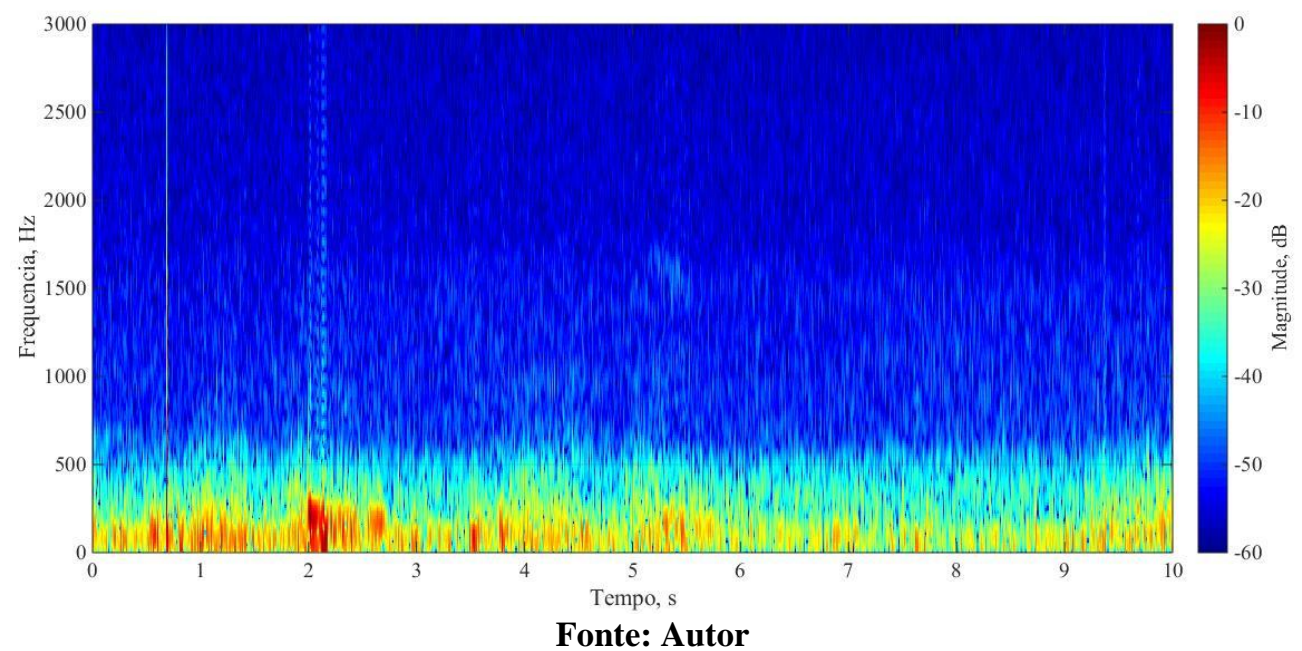

Figura A.57 - Espectrograma - DPOC Muito Grave (18)

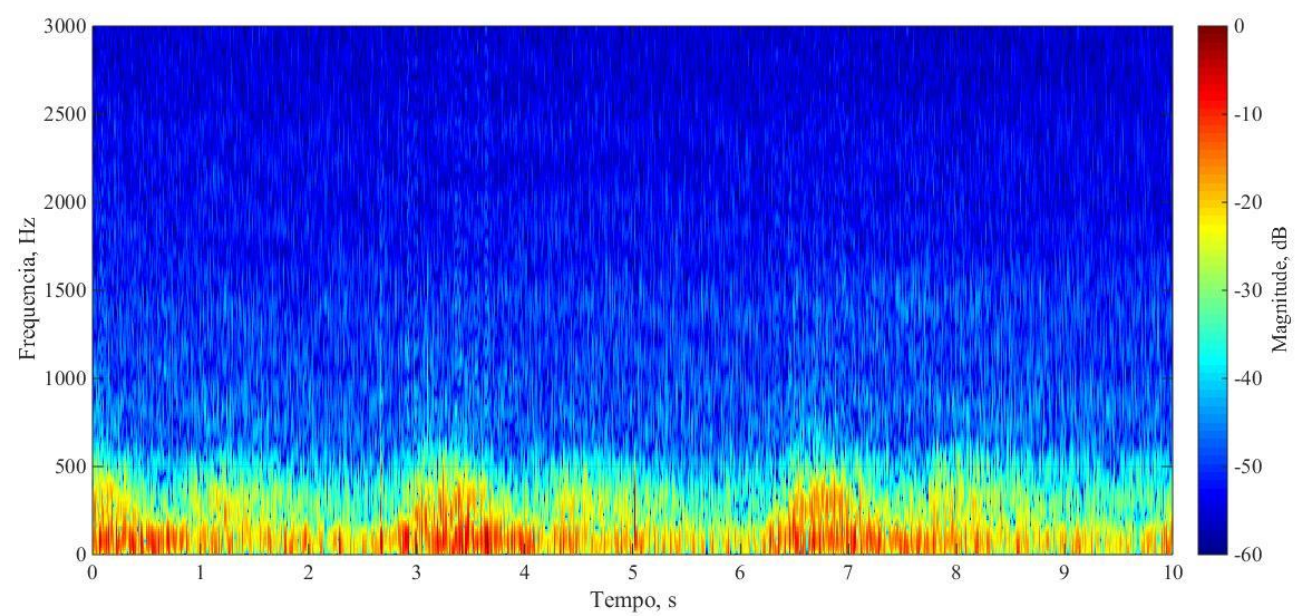

Fonte: Autor 
Figura A.58 - Espectrograma - DPOC Muito Grave (19)

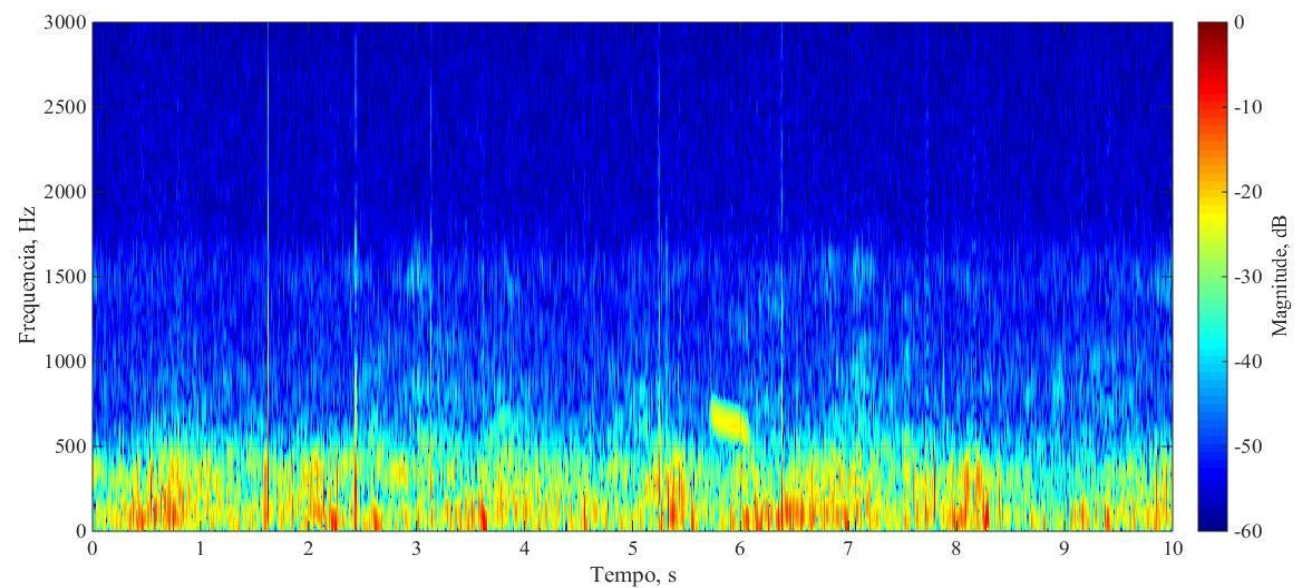

Fonte: Autor 